Supporting Information

\title{
Metal Binding and its Amelioration in Tetramates
}

Ruirui Zhang, $†$ Miroslav Genov, $\ddagger$ Alexander Pretsch, $\ddagger$ Dagmar Pretsch, $\ddagger$ and Mark G. Moloney ${ }^{*}$, ,\#

†The Department of Chemistry, Chemistry Research Laboratory, University of Oxford, 12 Mansfield Road, Oxford. OX1 3TA ‡Oxford Antibiotic Group, The Oxford Science Park, Magdalen Centre, Oxford OX4 4GA, UK.

\#Oxford Suzhou Centre for Advanced Research, Building A, 388 Ruo Shui Road, Suzhou Industrial Park, Jiangsu, 215123, P.R. China.

mark.moloney@chem.ox.ac.uk

Table of contents

1. Figure S1 S-2

2. Figure $\mathrm{S} 2 \quad \mathrm{~S}-3$

3. Figure $\mathrm{S} 3 \quad \mathrm{~S}-4$

4. Figure $S 4 \quad S-5$

5. Figure S5 S-6

6. NMR SPECTRA S-7 

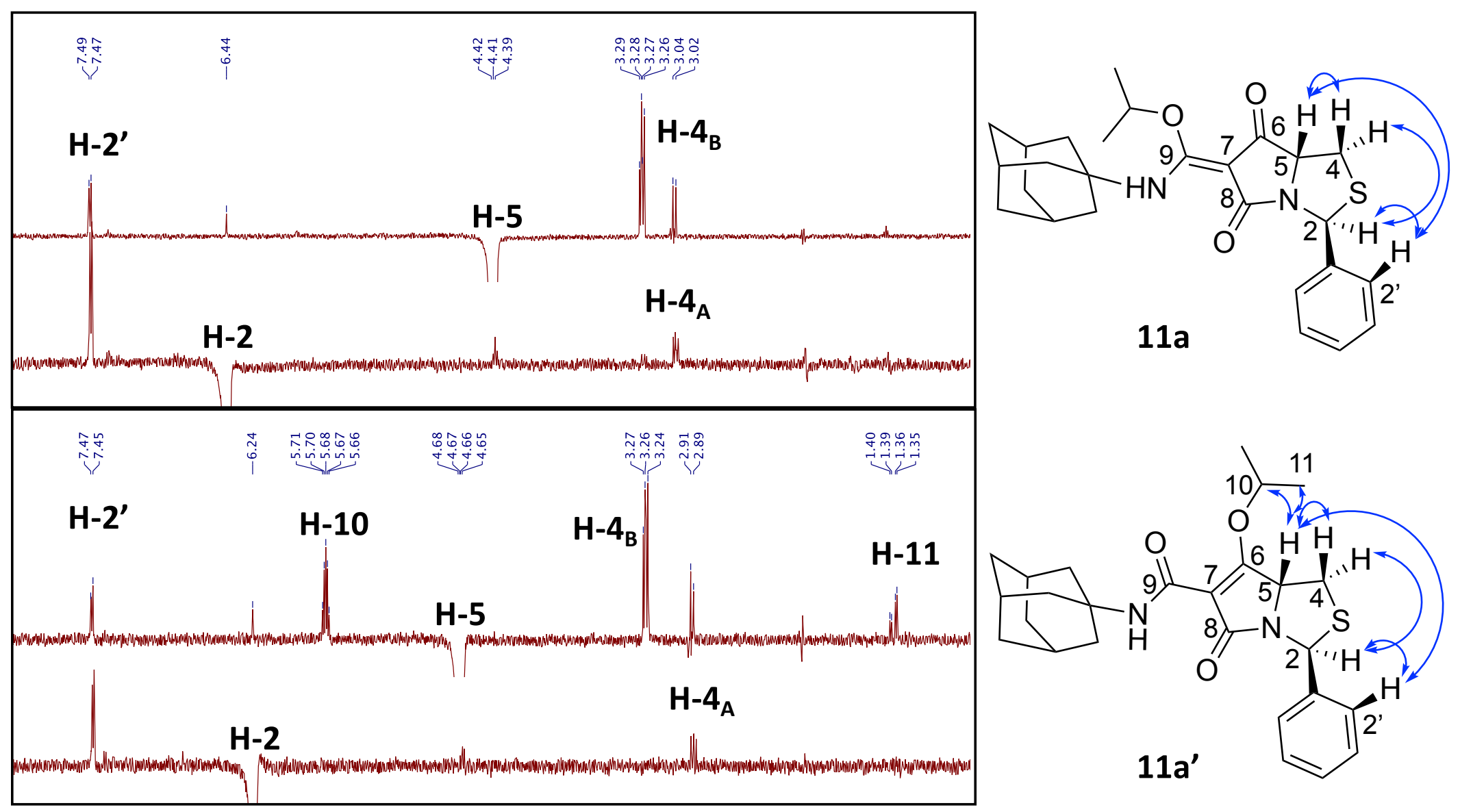

Figure S1: NOE spectra for 11a and 11a' 


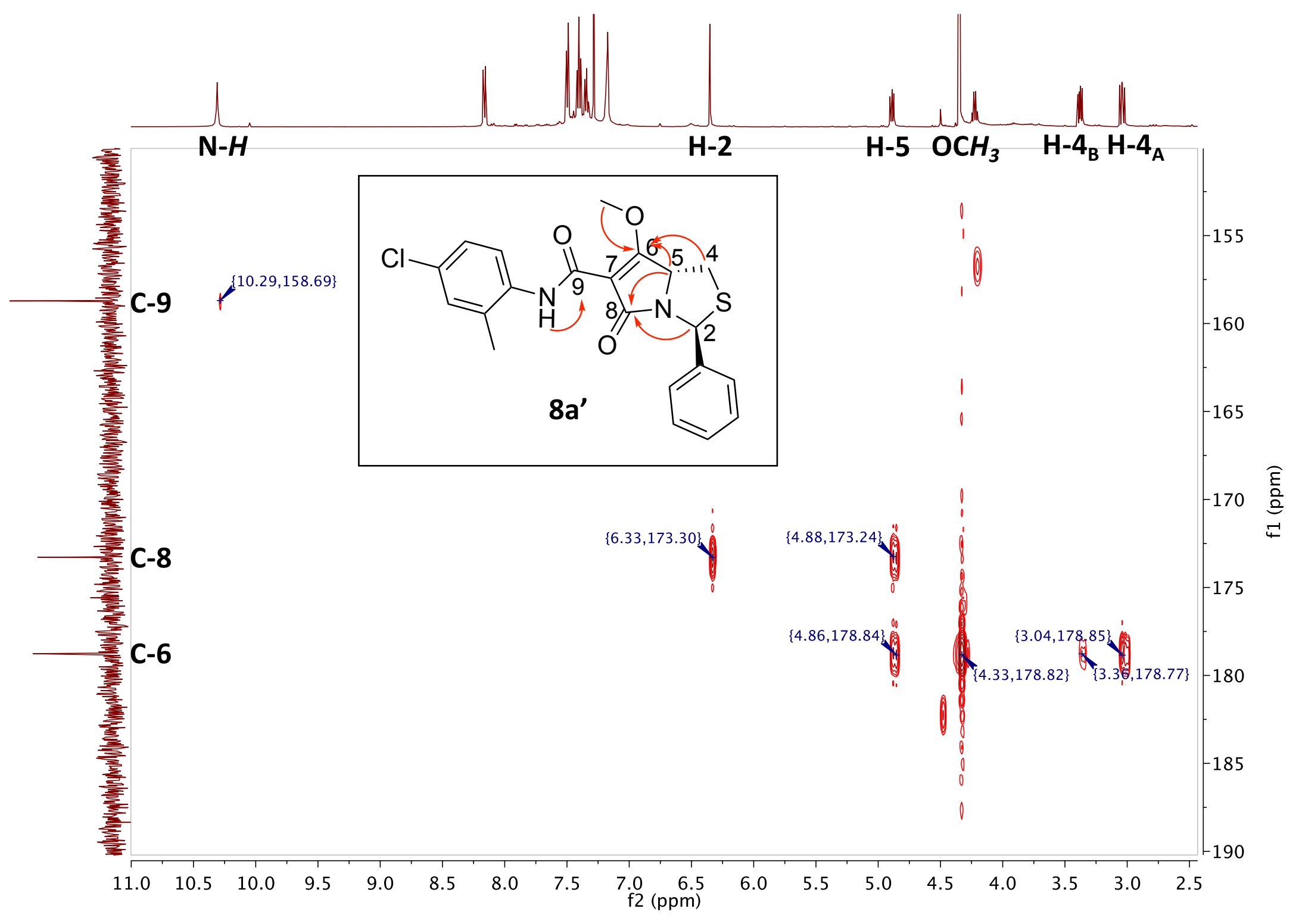

Figure S2: HMBC correlation for $\mathbf{8 a}$ 


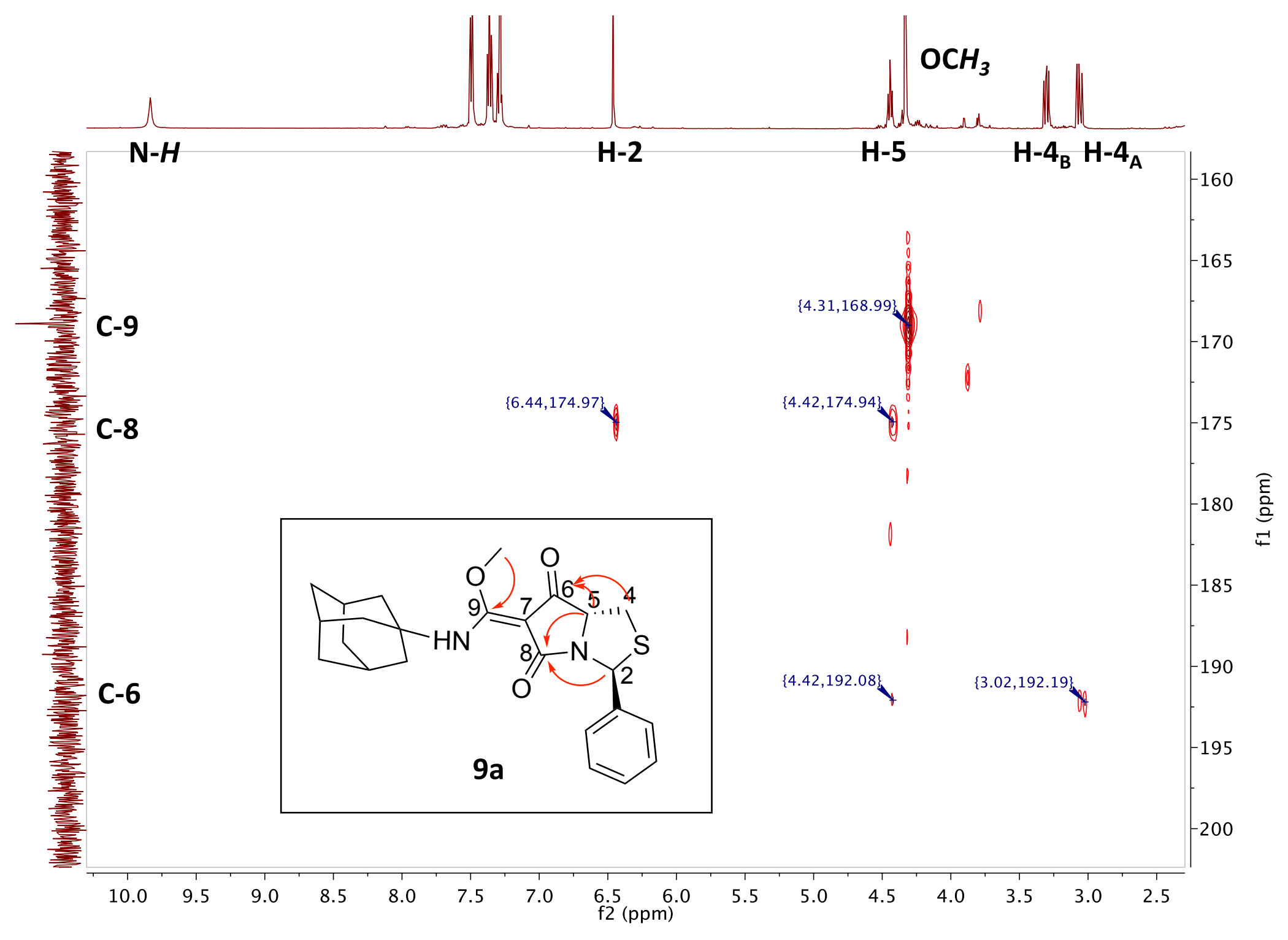

Figure S3: HMBC correlation for 9a 

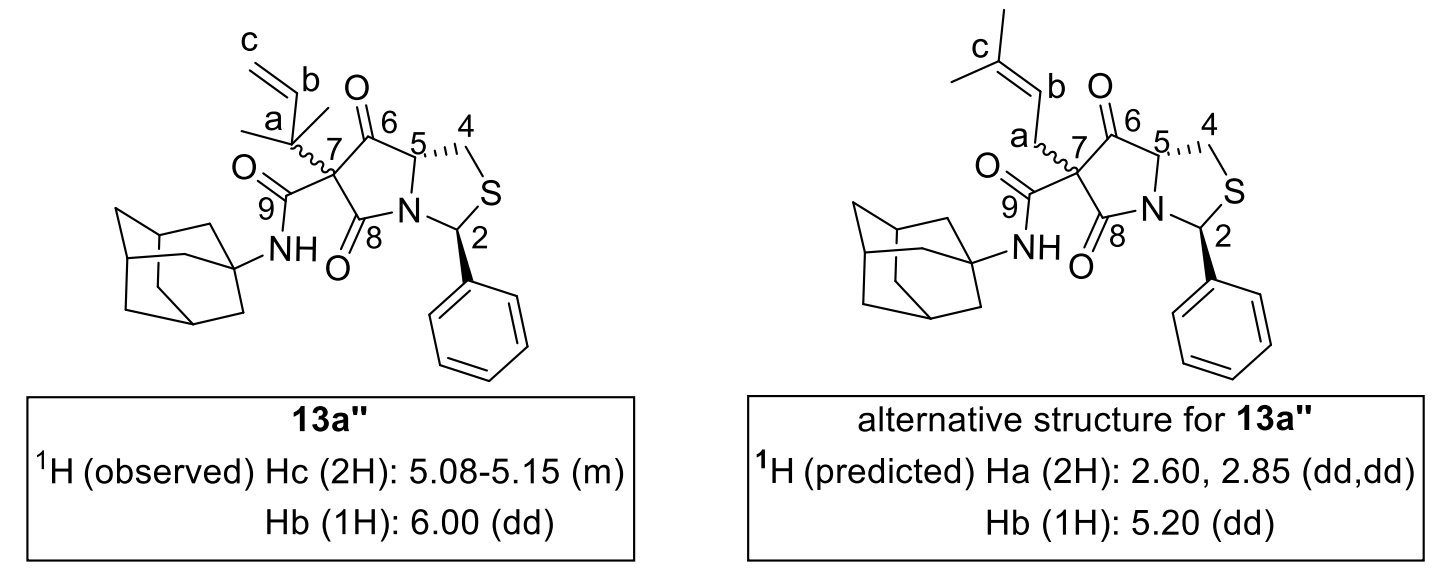

Figure S4. Chemical shifts of alkyl chain protons of tetramate carboxamide 13a". The predicted ${ }^{1} \mathrm{H}$ chemical shifts were calculated by ChewDraw Professional 19.1.1.32. 

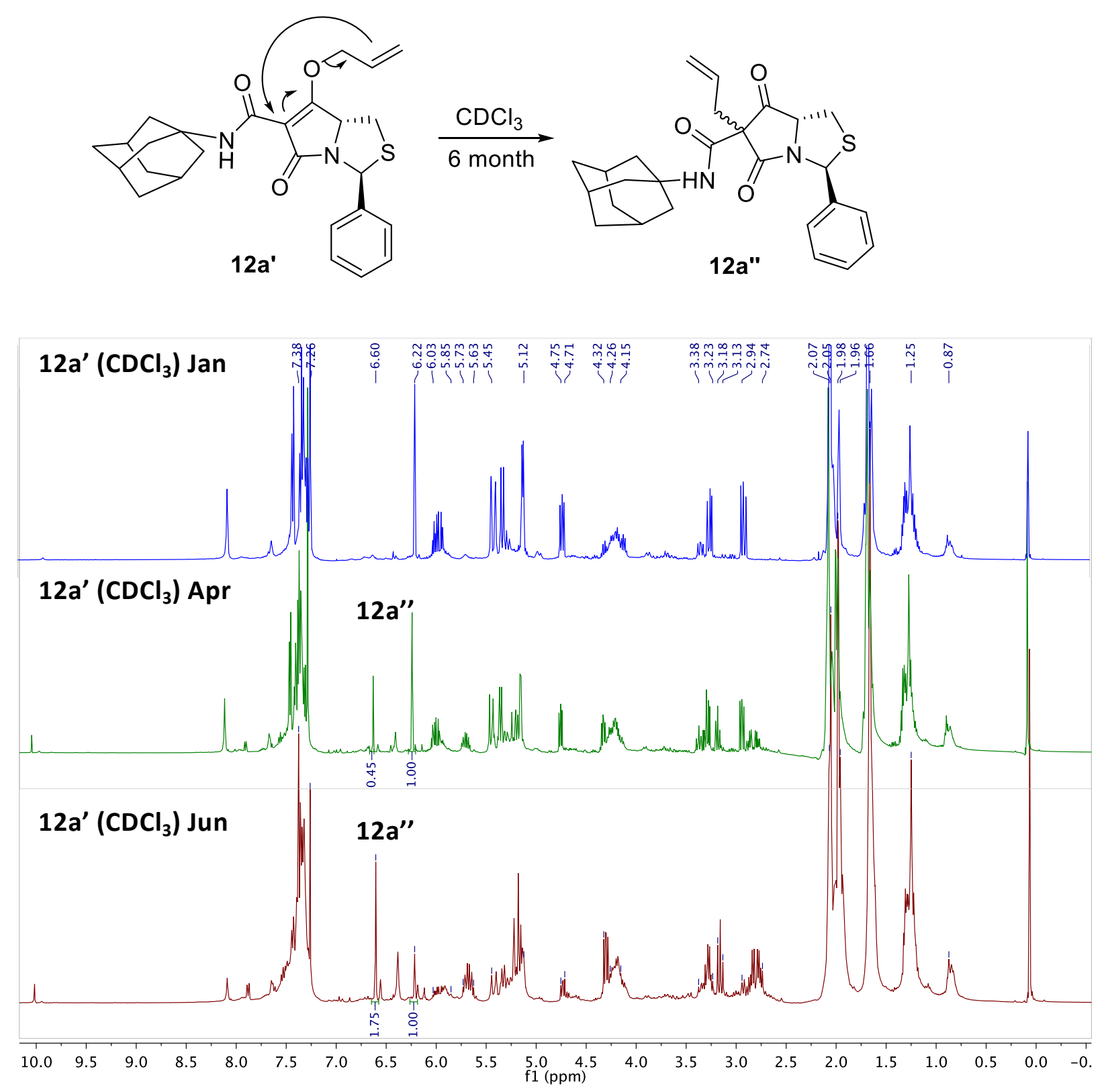

Figure S5. ${ }^{1} \mathrm{H}$ NMR spectra $\left(\mathrm{CDCl}_{3}, 400 \mathrm{MHz}\right)$ of $12 \mathrm{a}$ ' over time. 


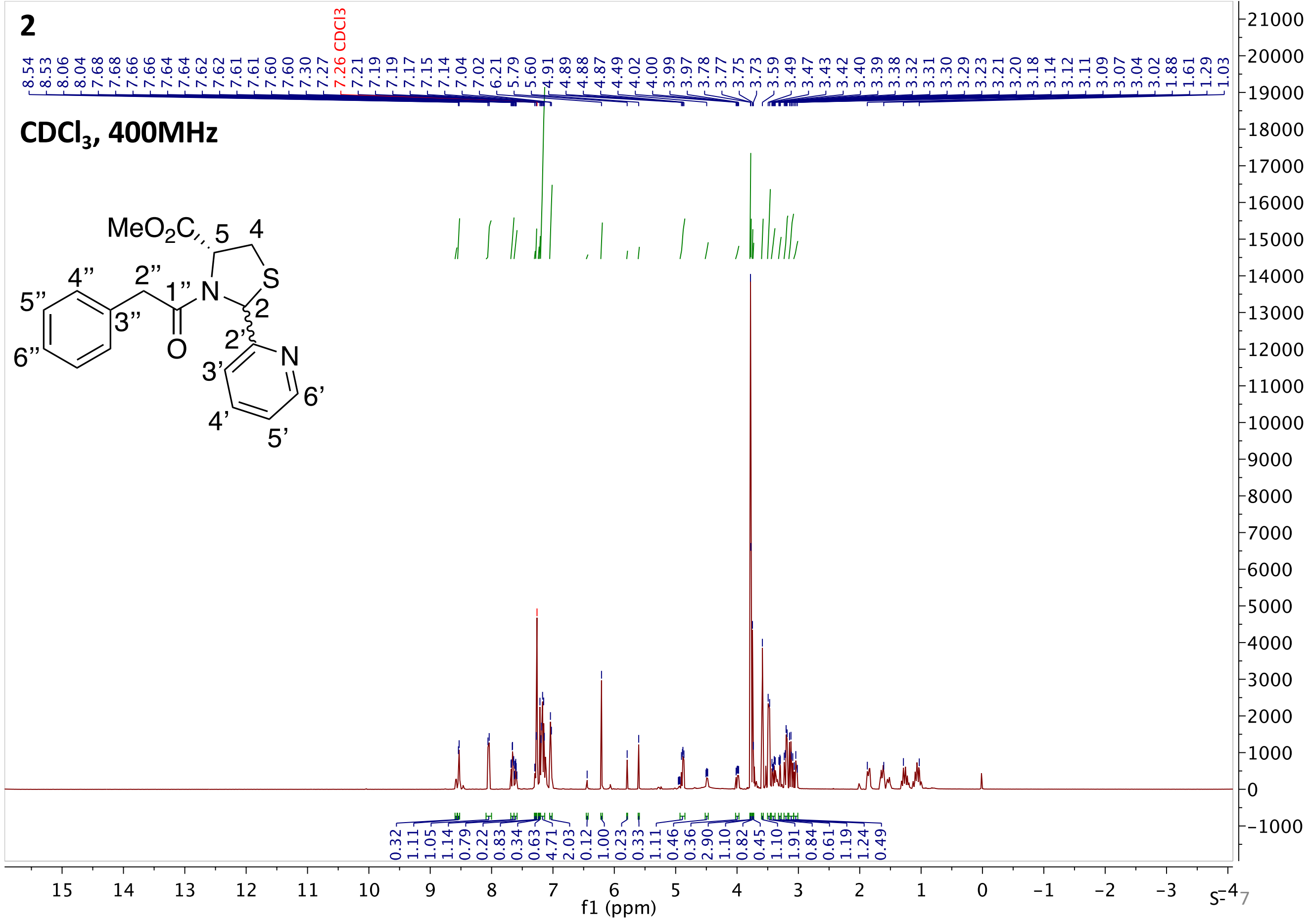




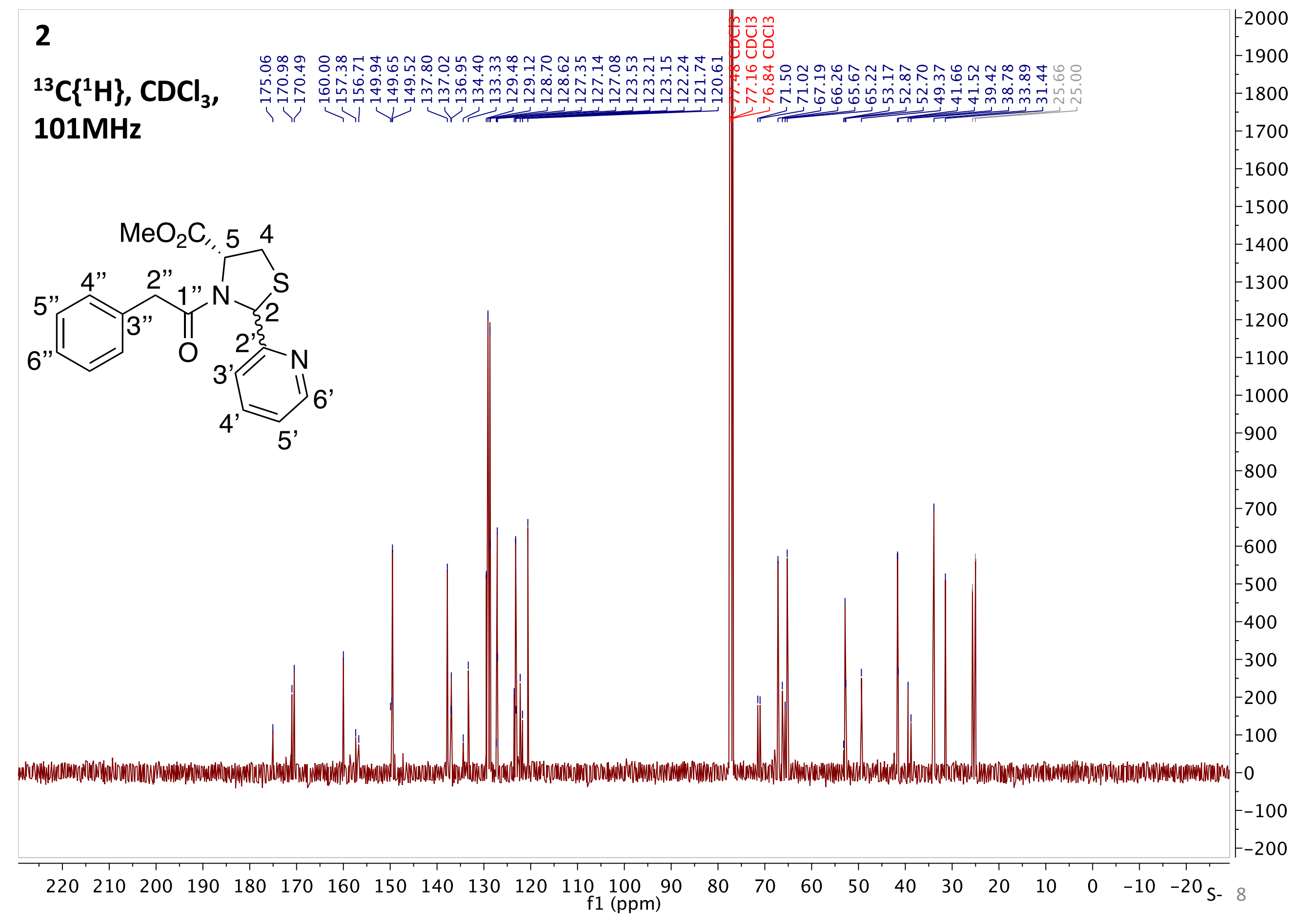




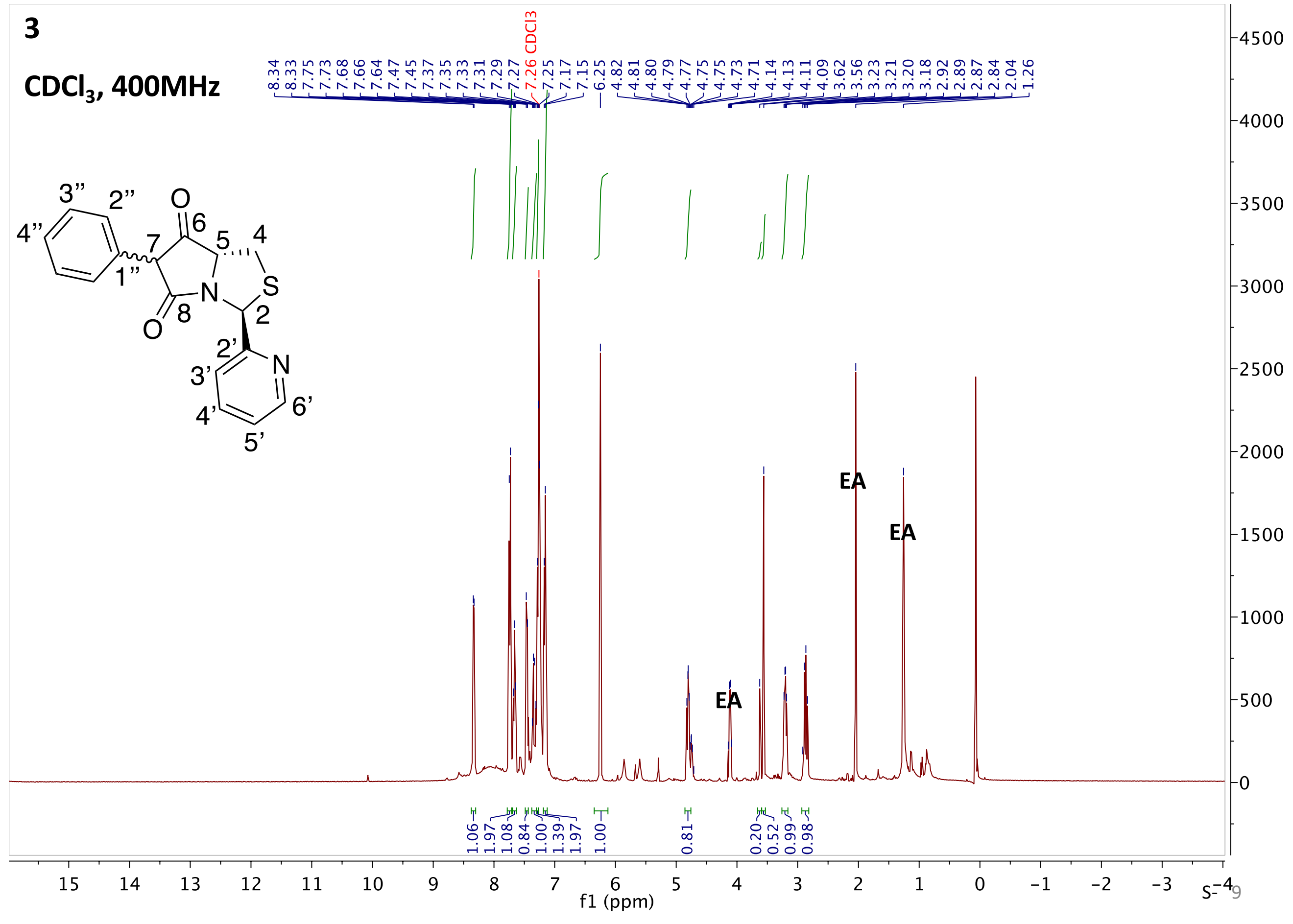




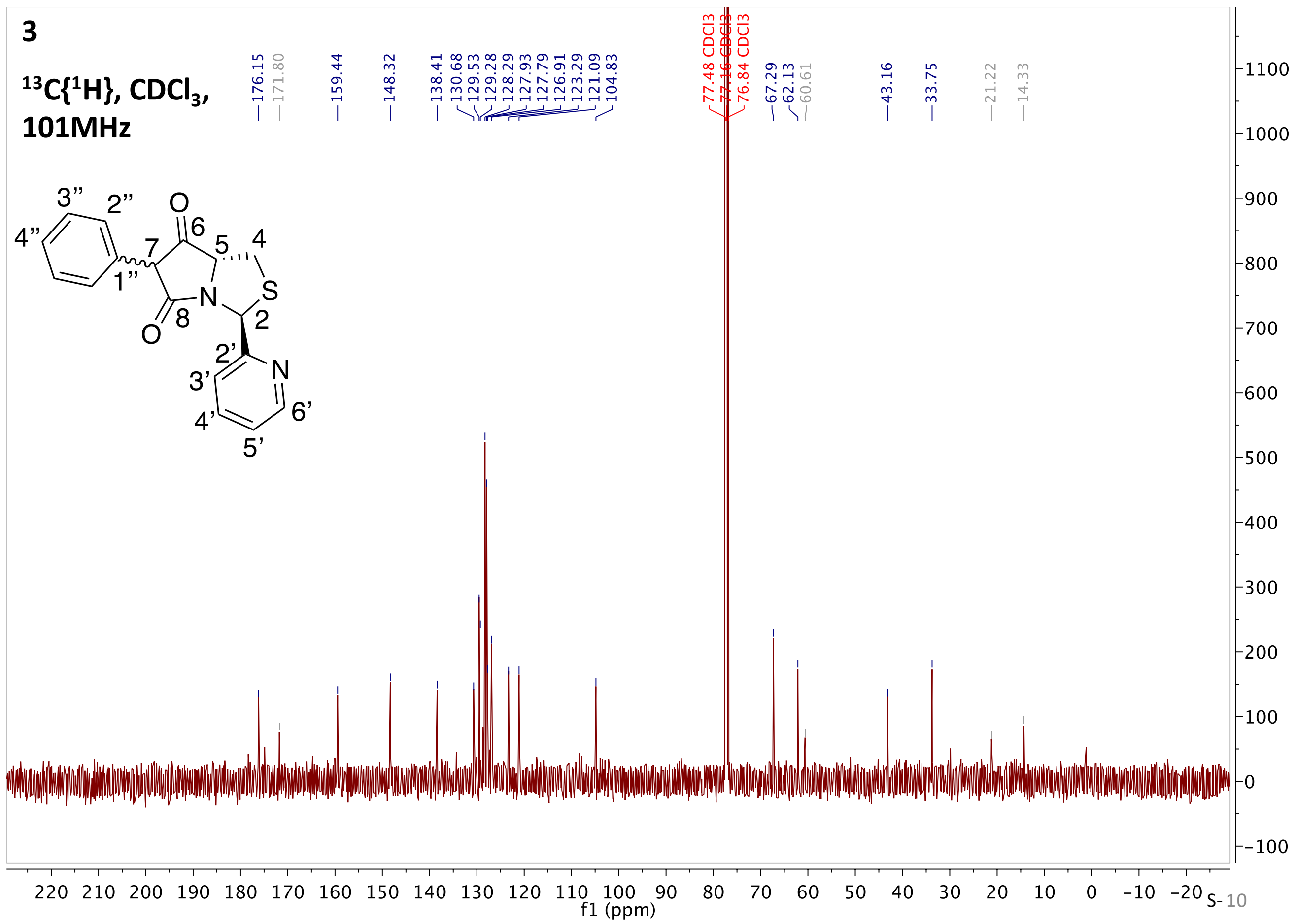




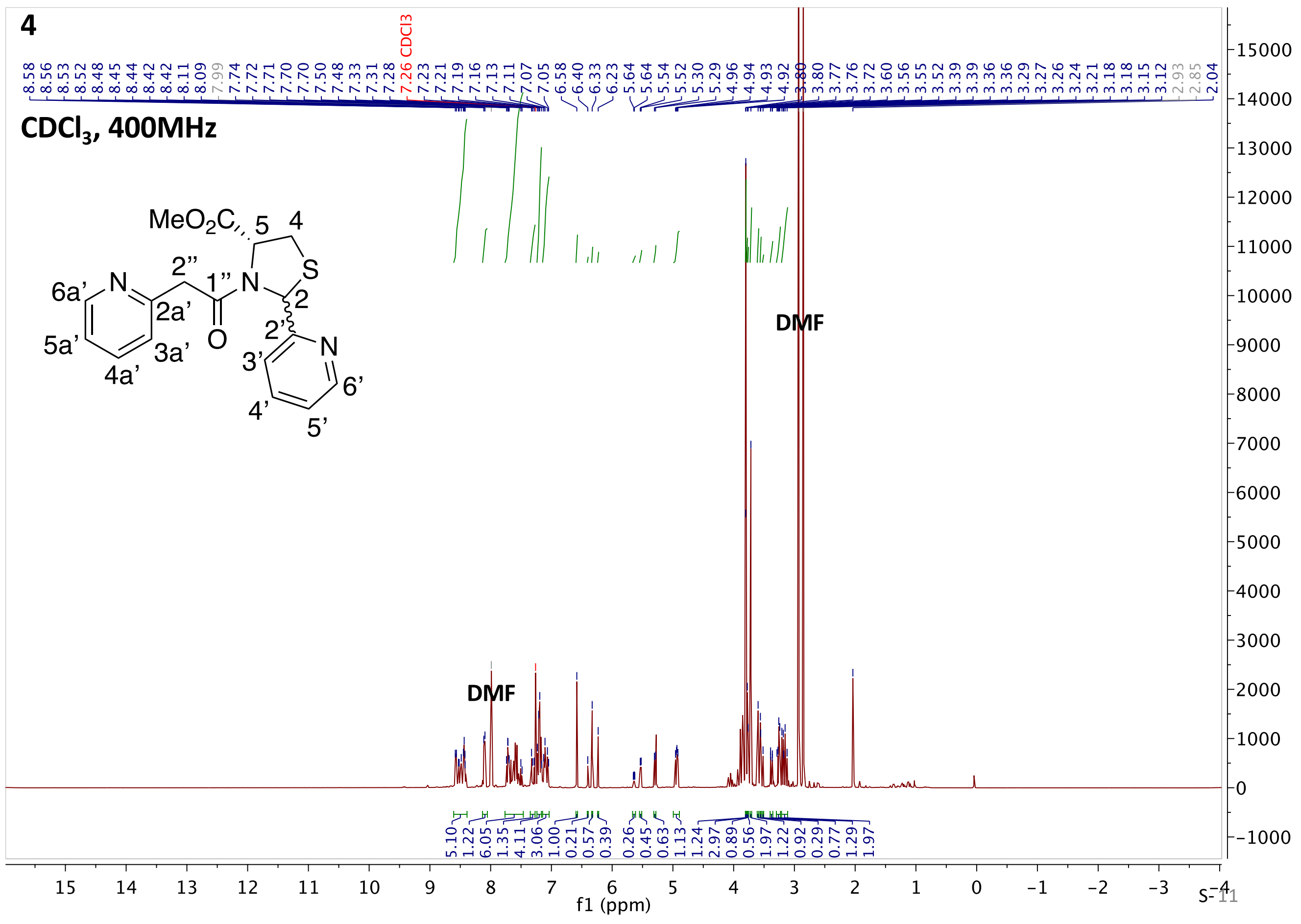




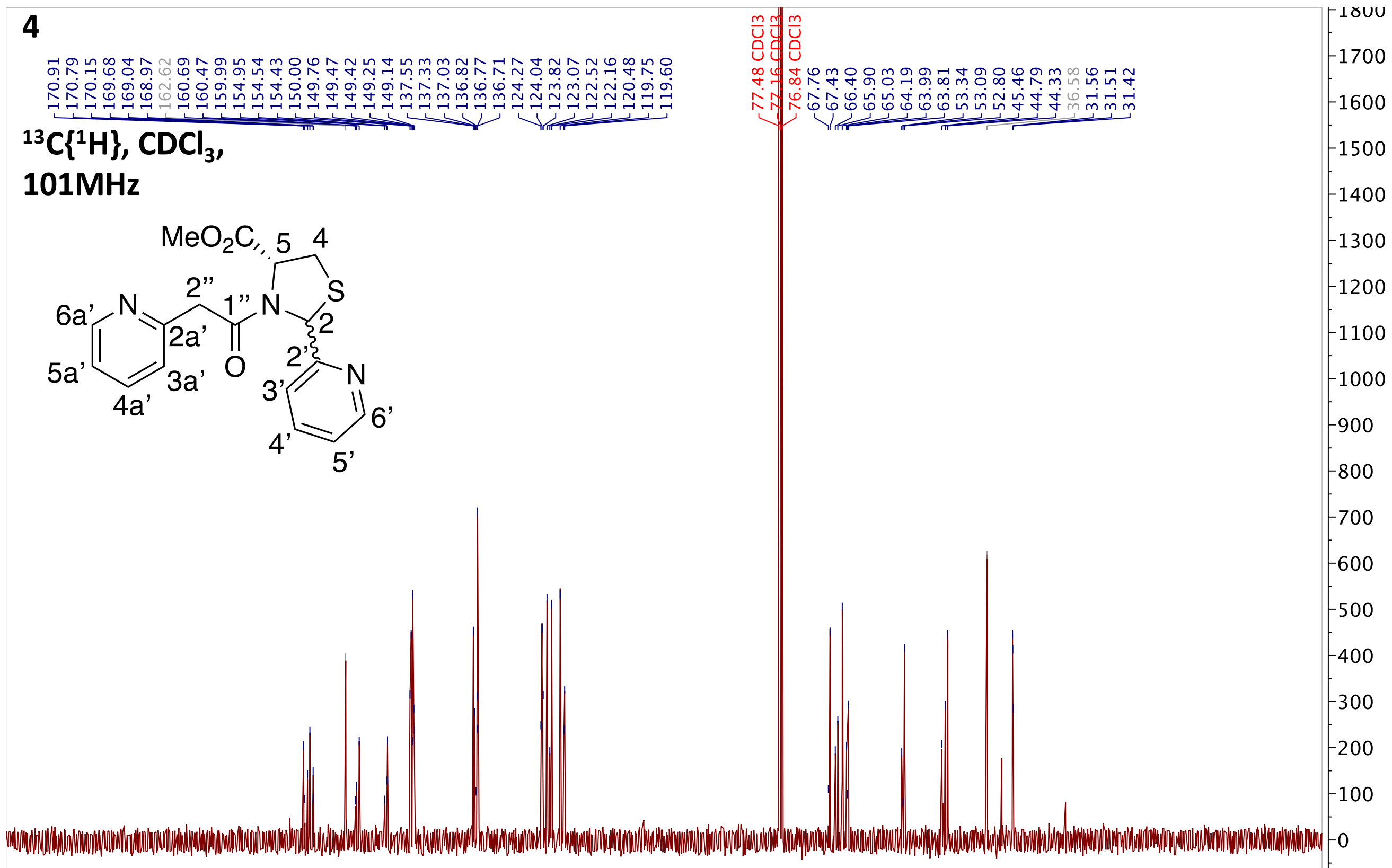

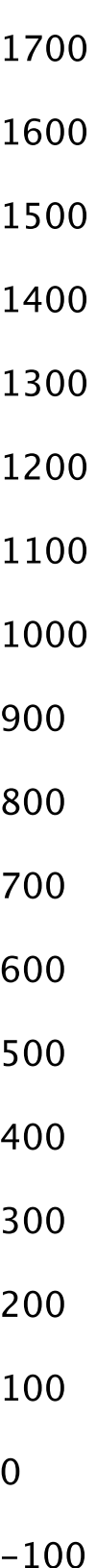

$\begin{array}{lllllllllllllllllllllll}220 & 210 & 200 & 190 & 180 & 170 & 160 & 150 & 140 & 130 & 120 & 110 \\ \mathrm{f} 1 & 100 \\ (\mathrm{ppm})\end{array}$ 


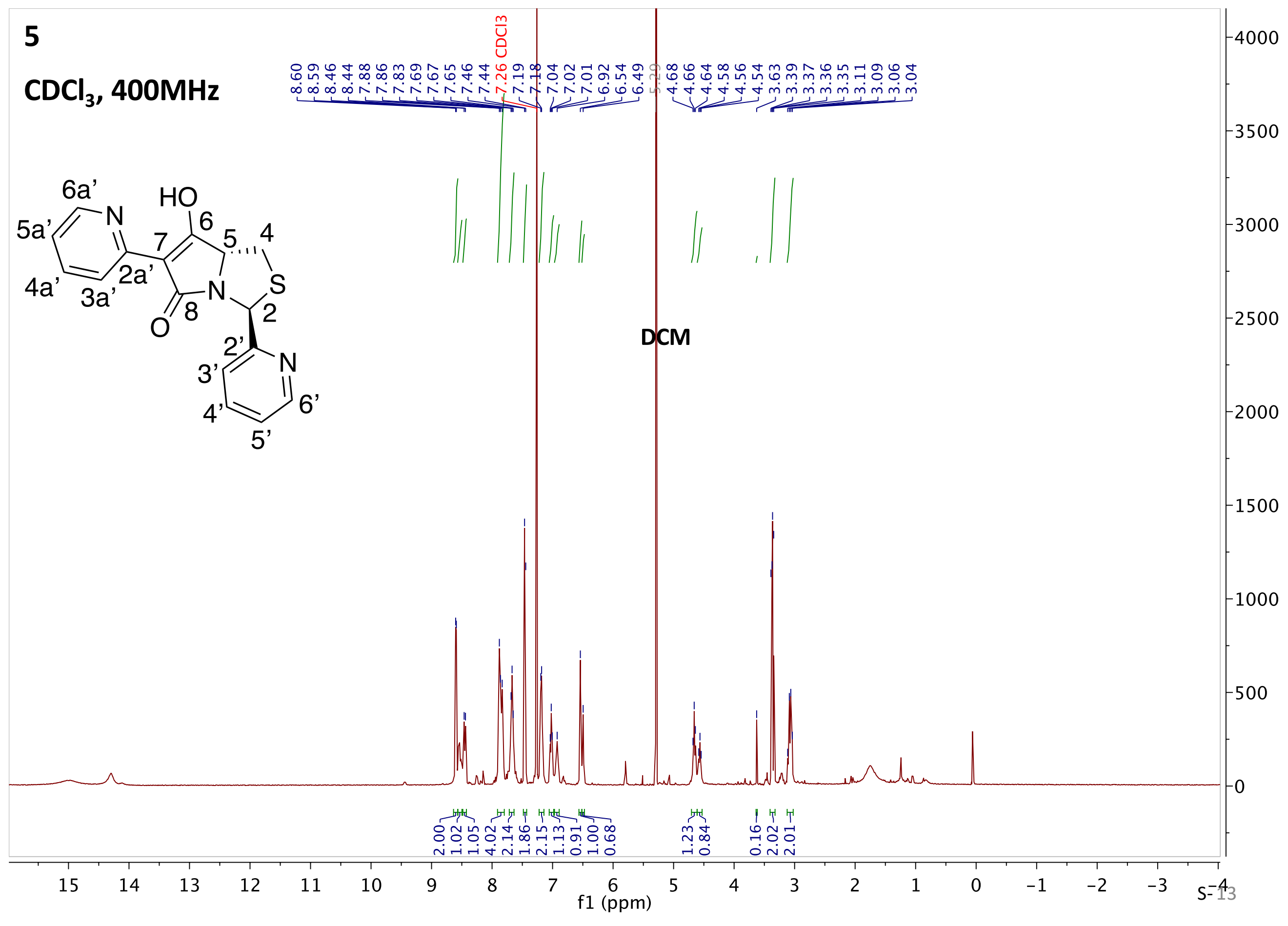


5

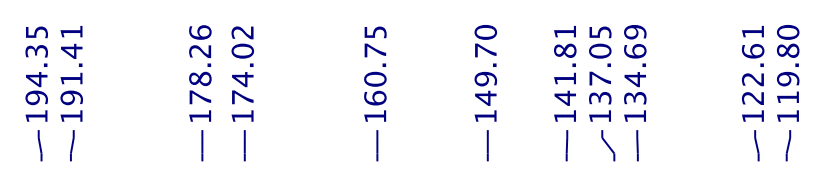

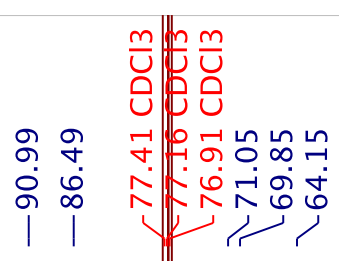

${ }^{13} \mathrm{C}\left\{{ }^{1} \mathrm{H}\right\}, \mathrm{CDCl}_{3}$,

\section{$101 \mathrm{MHz}$}
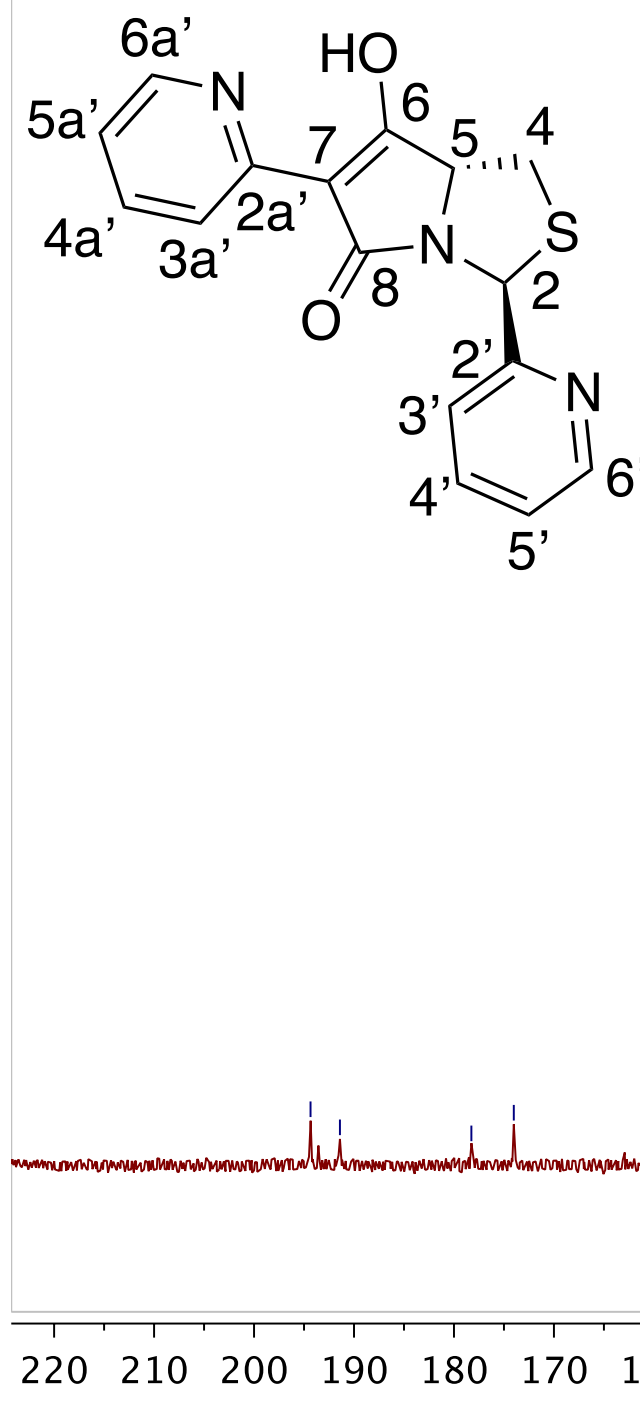

$\begin{array}{llllllllllllll}220 & 210 & 200 & 190 & 180 & 170 & 160 & 150 & 140 & 130 & 120 & 110 & 100 & 90\end{array}$

$\mathrm{f} 1$ (ppm)

80

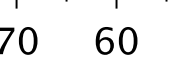

$50 \quad 40 \quad 30$

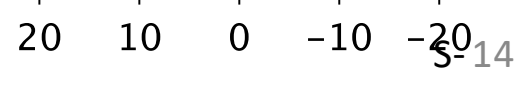




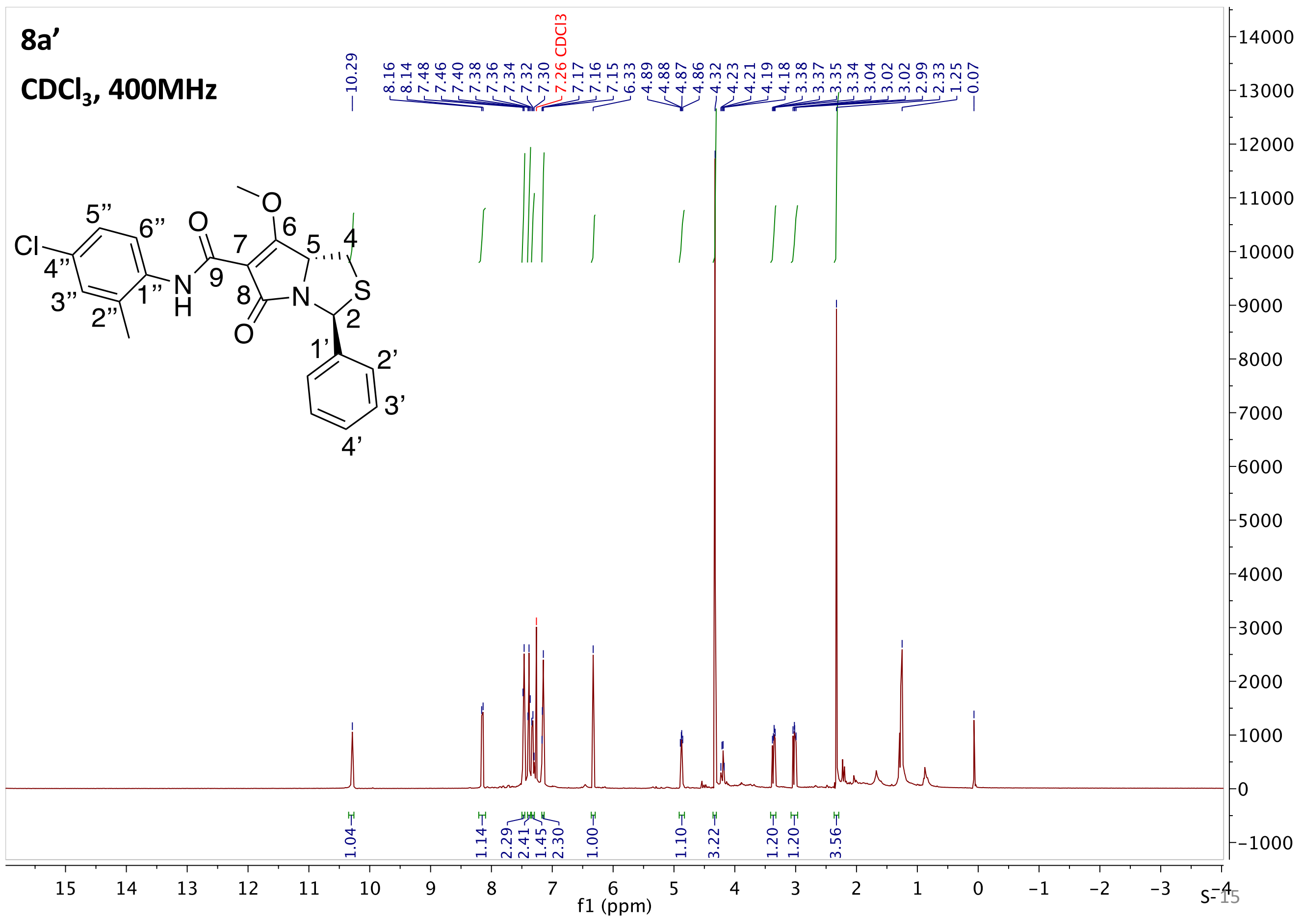




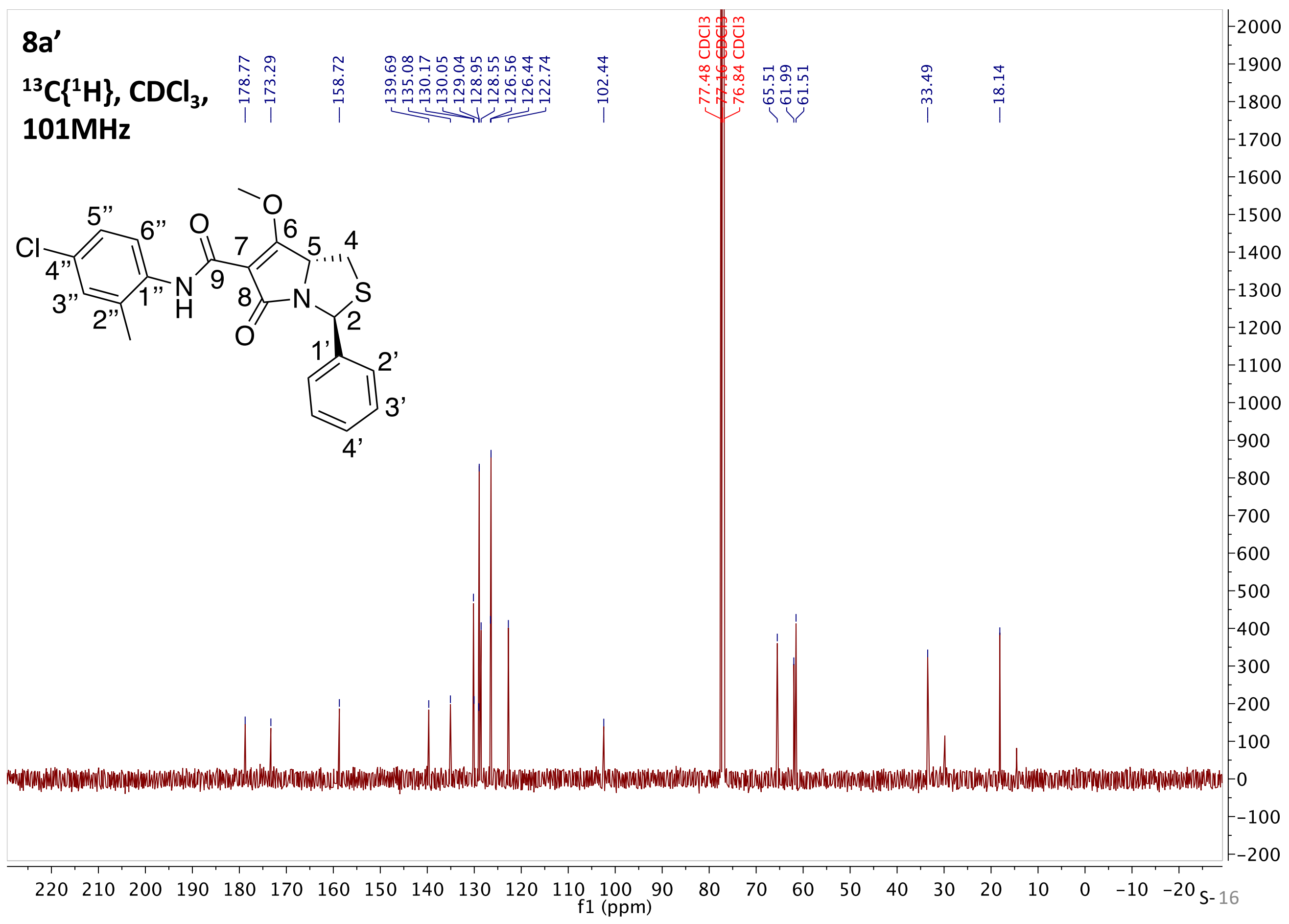




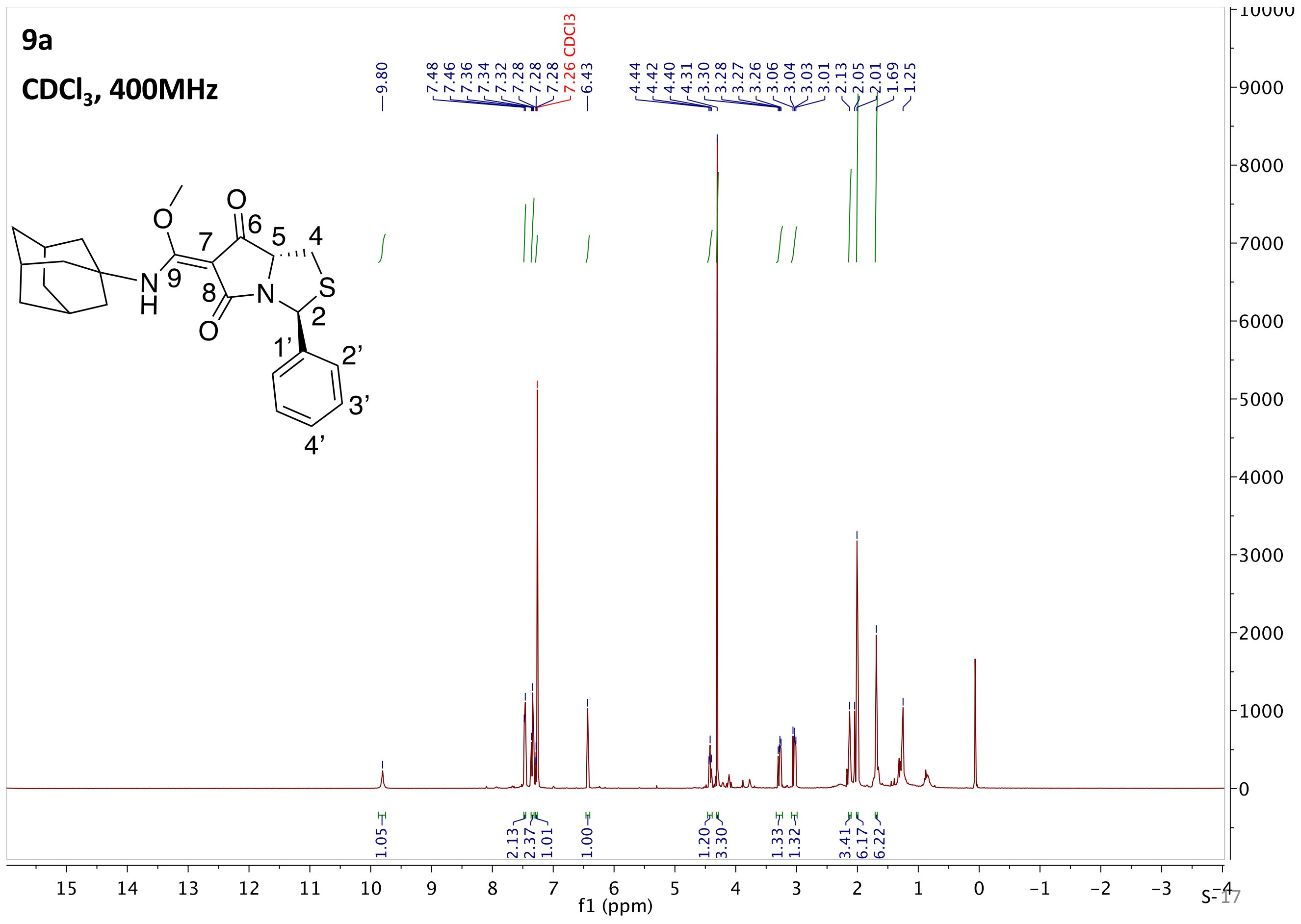


9a

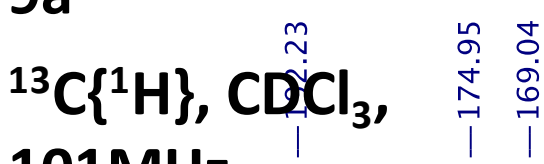
101MHz

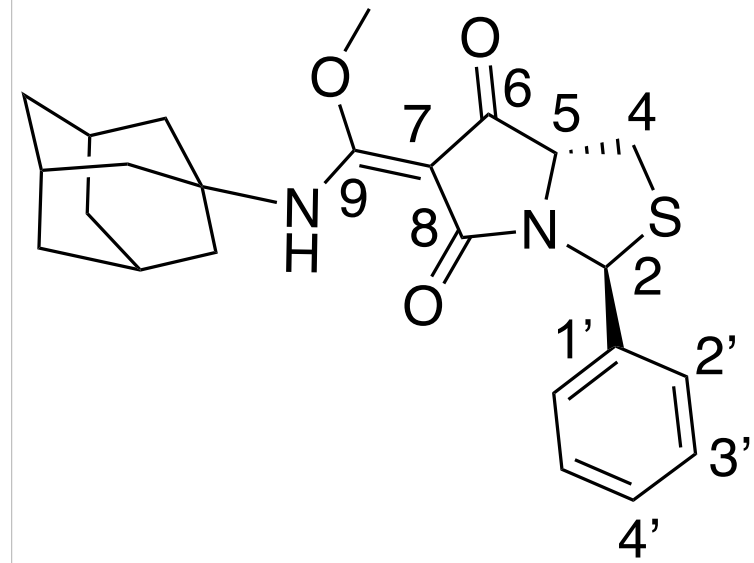




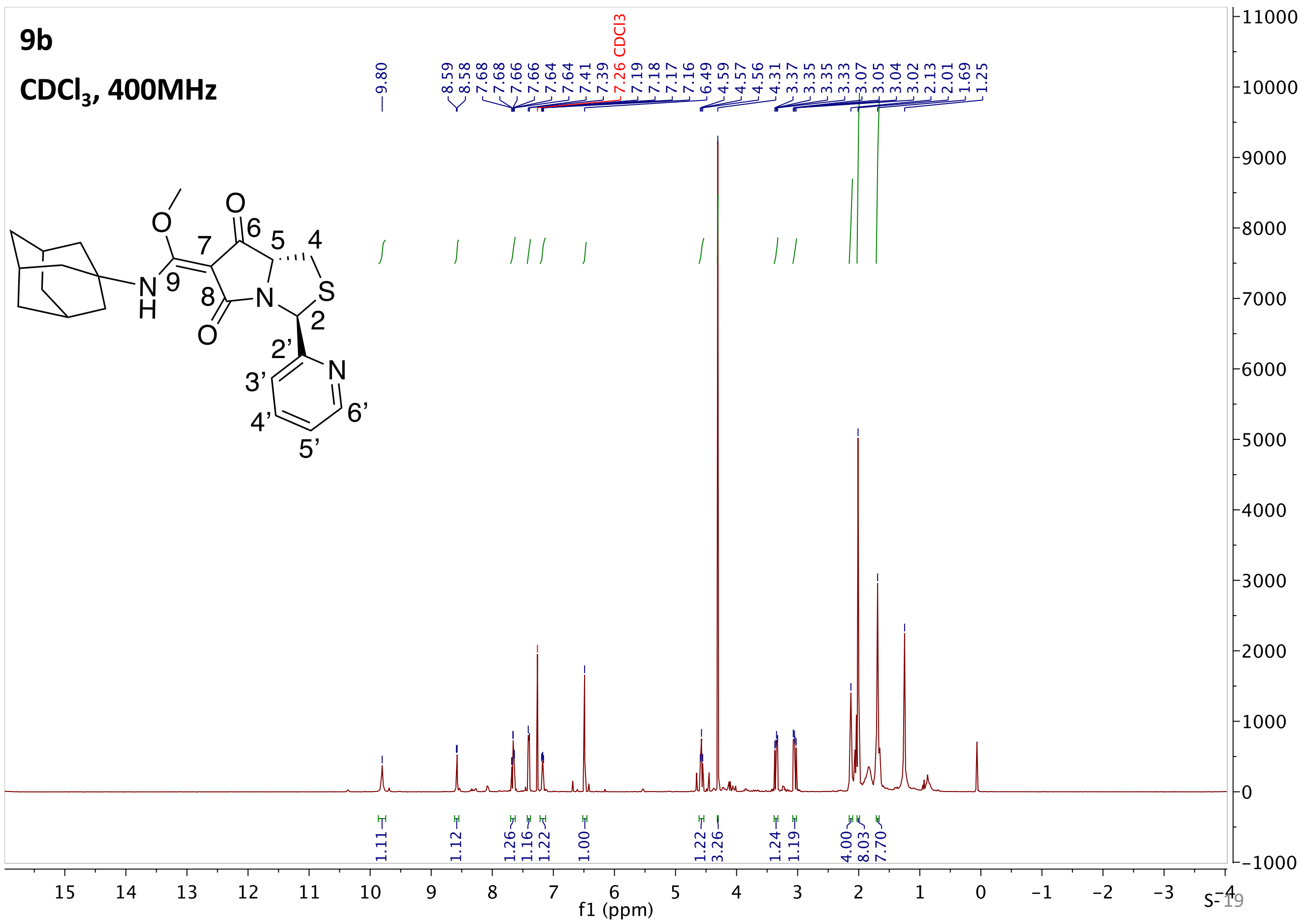


$9 b$

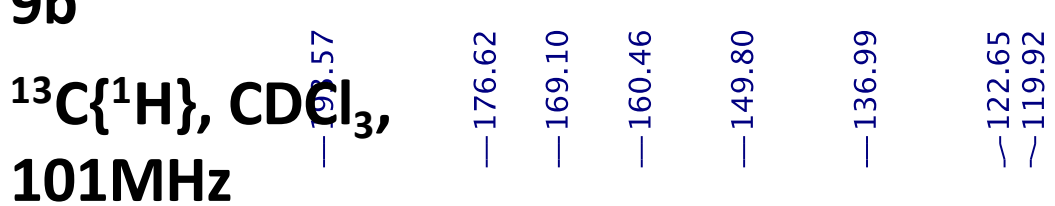

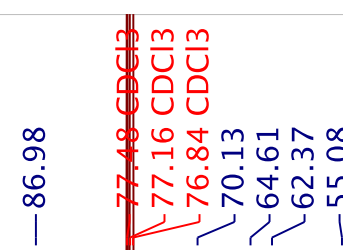

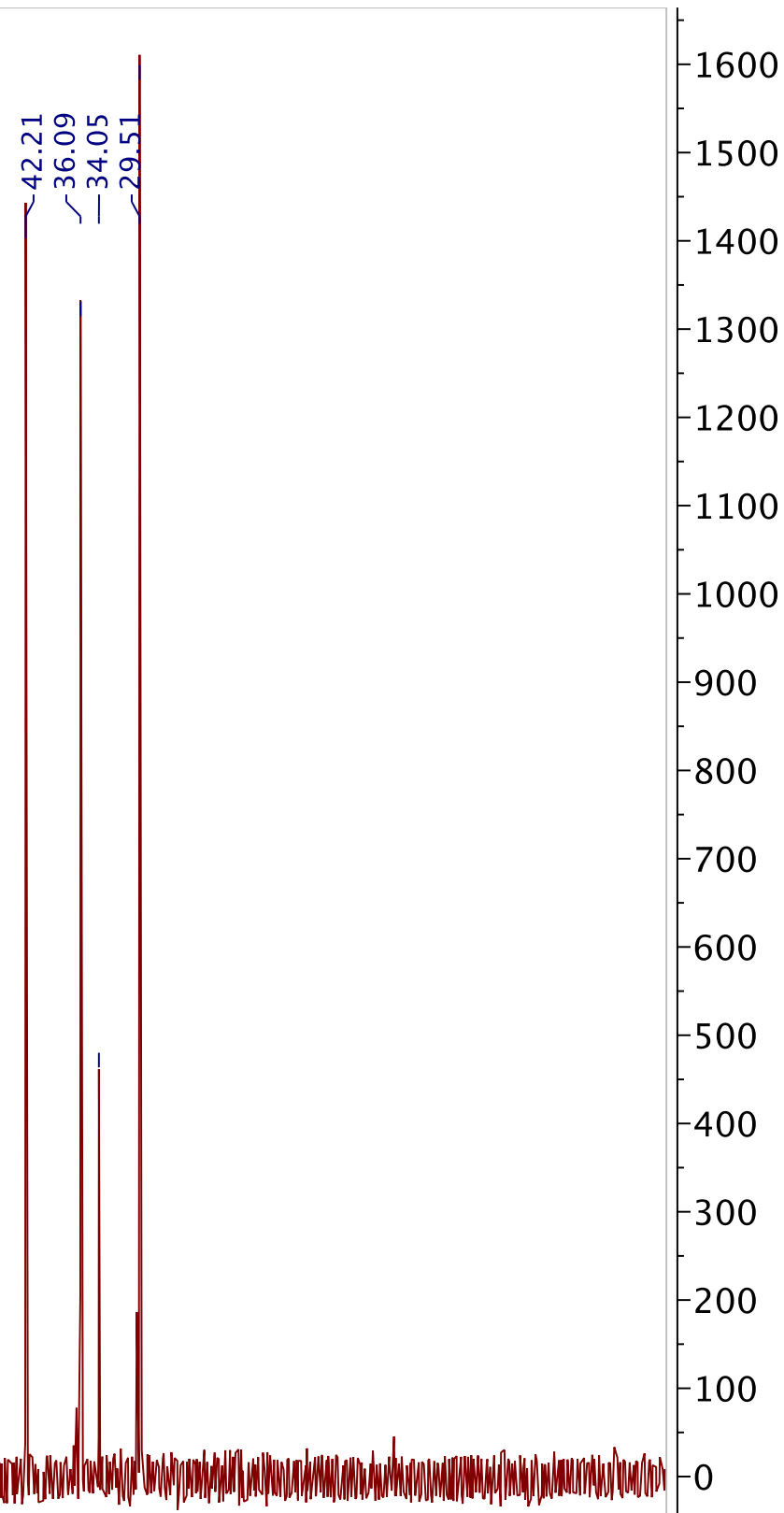

$\underbrace{}_{5}$

200

100

000

00

00

00

600

500

00

00

00

100

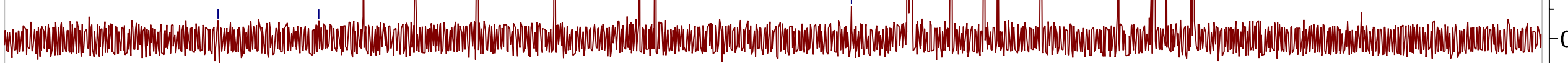




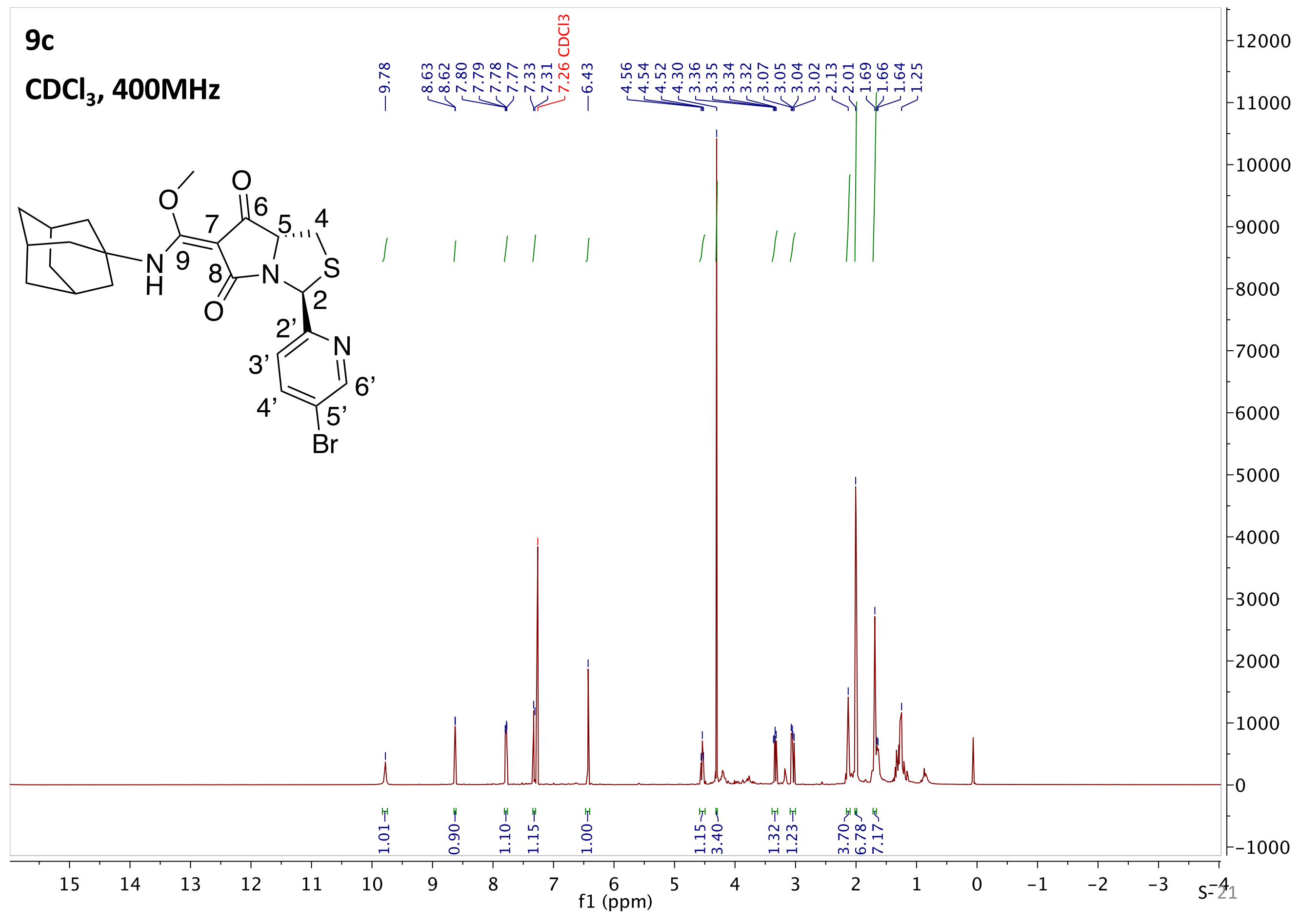


9c

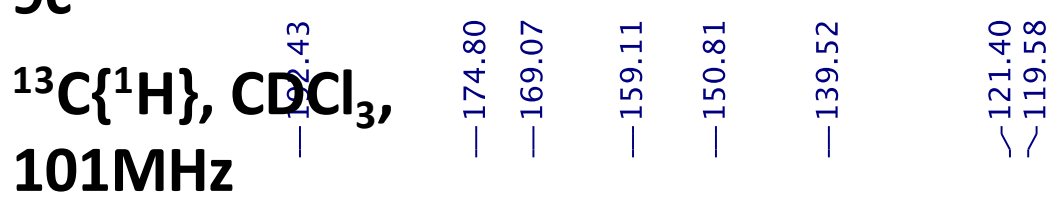

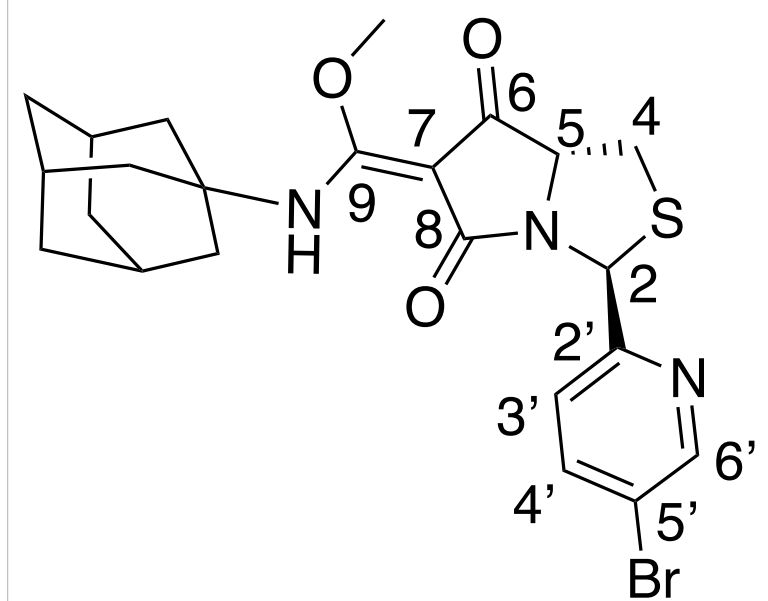

$-75000$

70000

$-65000$

$-60000$

$-55000$

$-50000$

$-45000$

$-40000$

$-35000$

$-30000$

$-25000$

$-20000$

$-15000$

$-10000$

$-5000$ 


\section{0a/10a', $10: 1$}

$\mathrm{CDCl}_{3}, 400 \mathrm{MHz}$

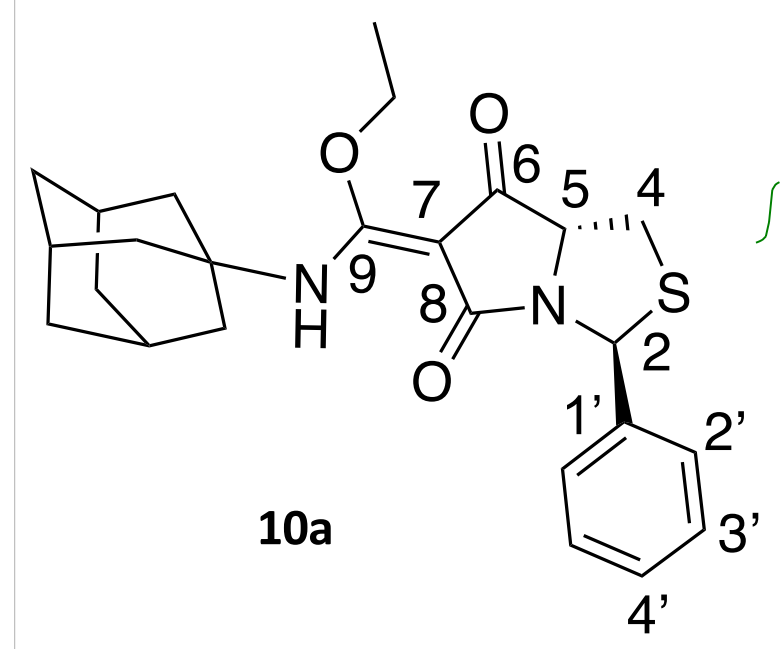

\section{嗏}

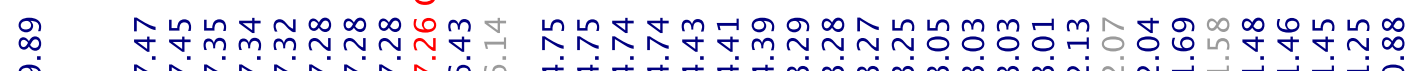

i

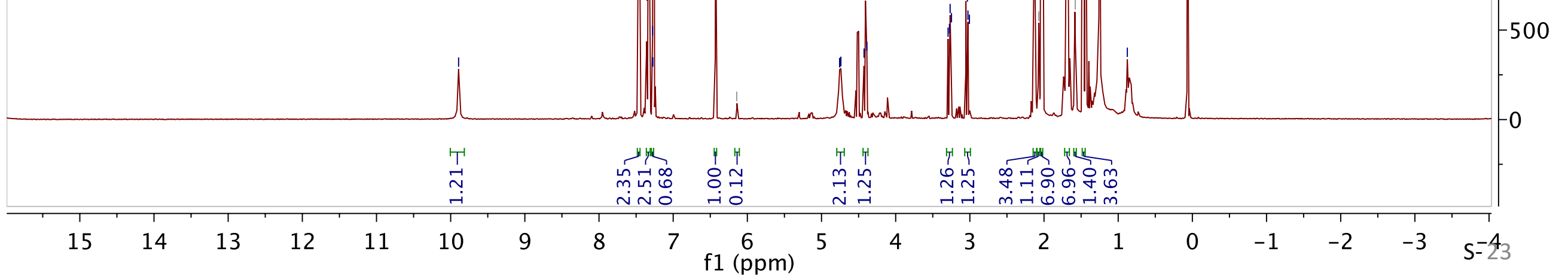




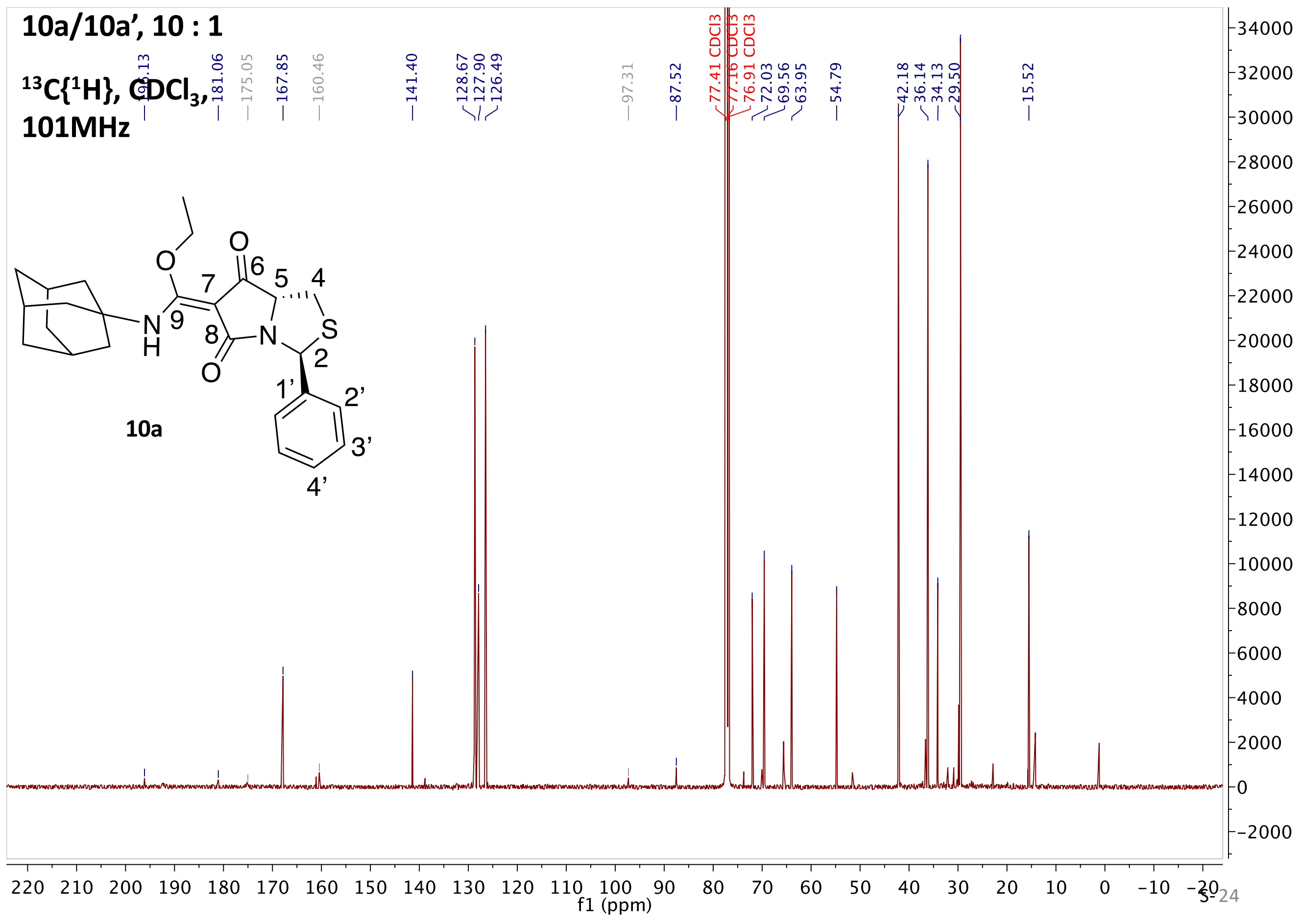




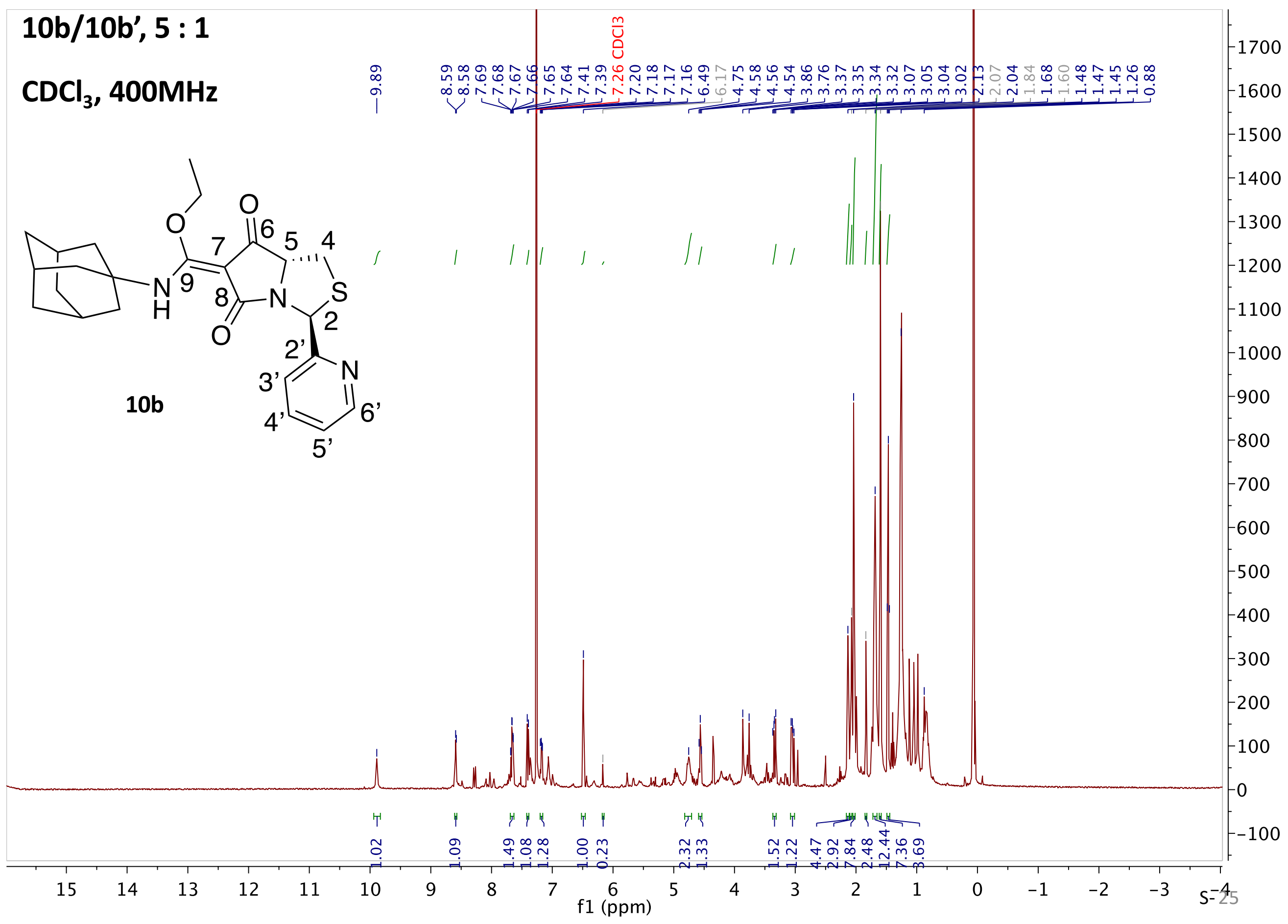




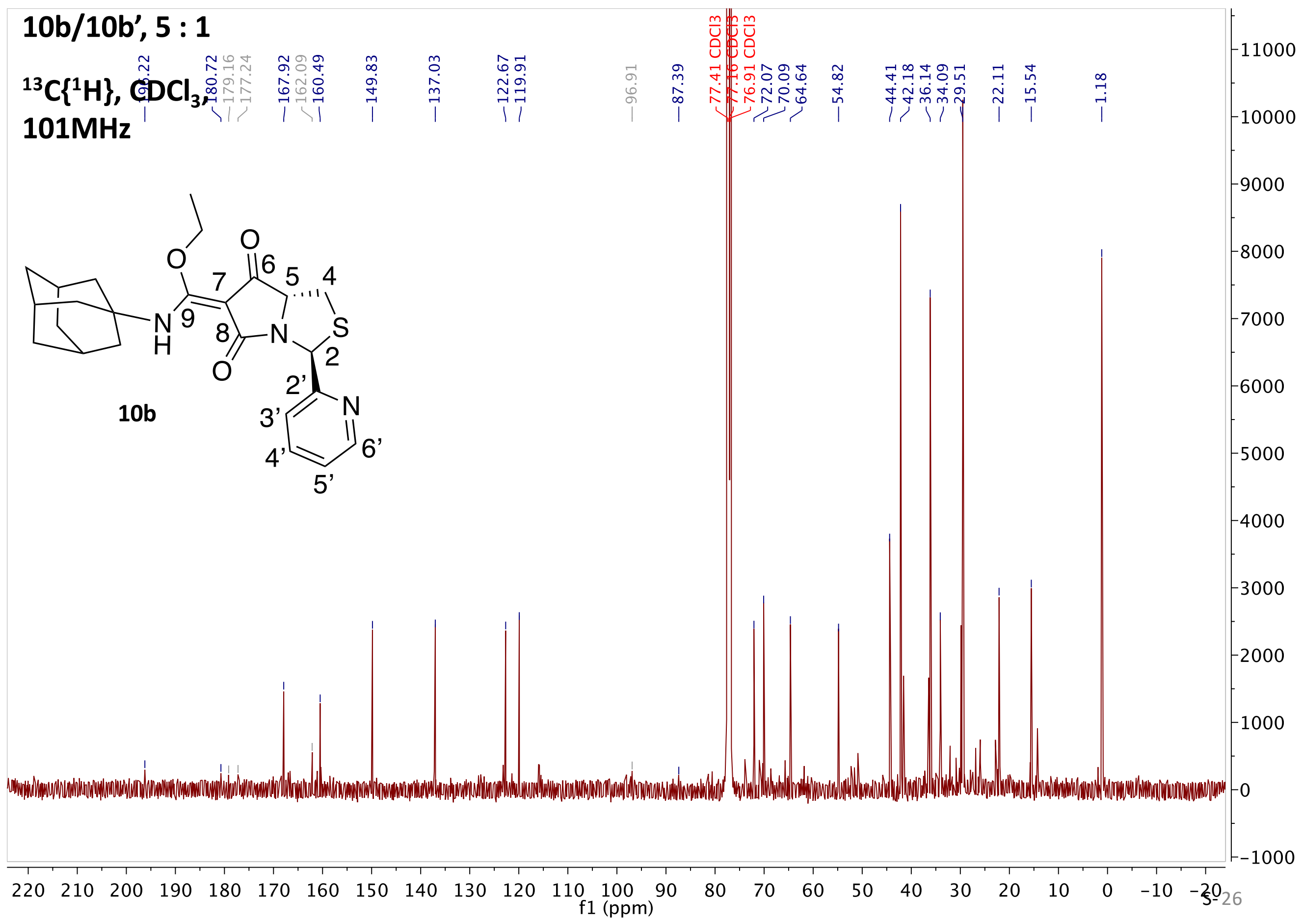




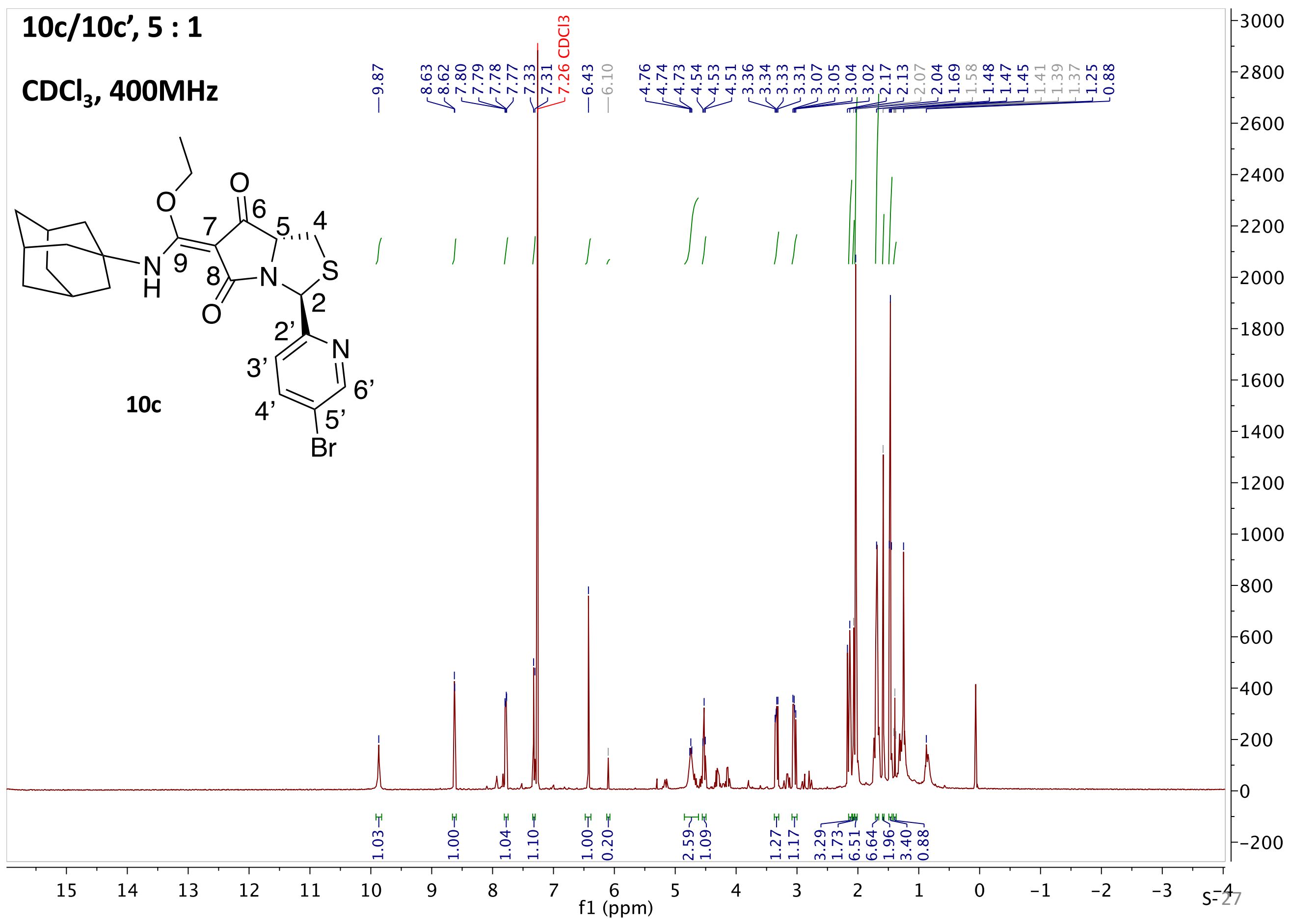




\section{0c/10c', $5: 1$}

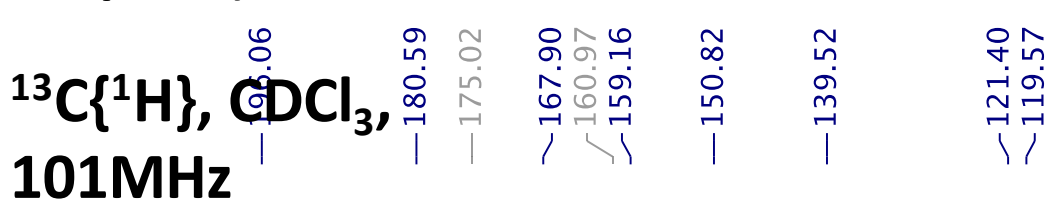
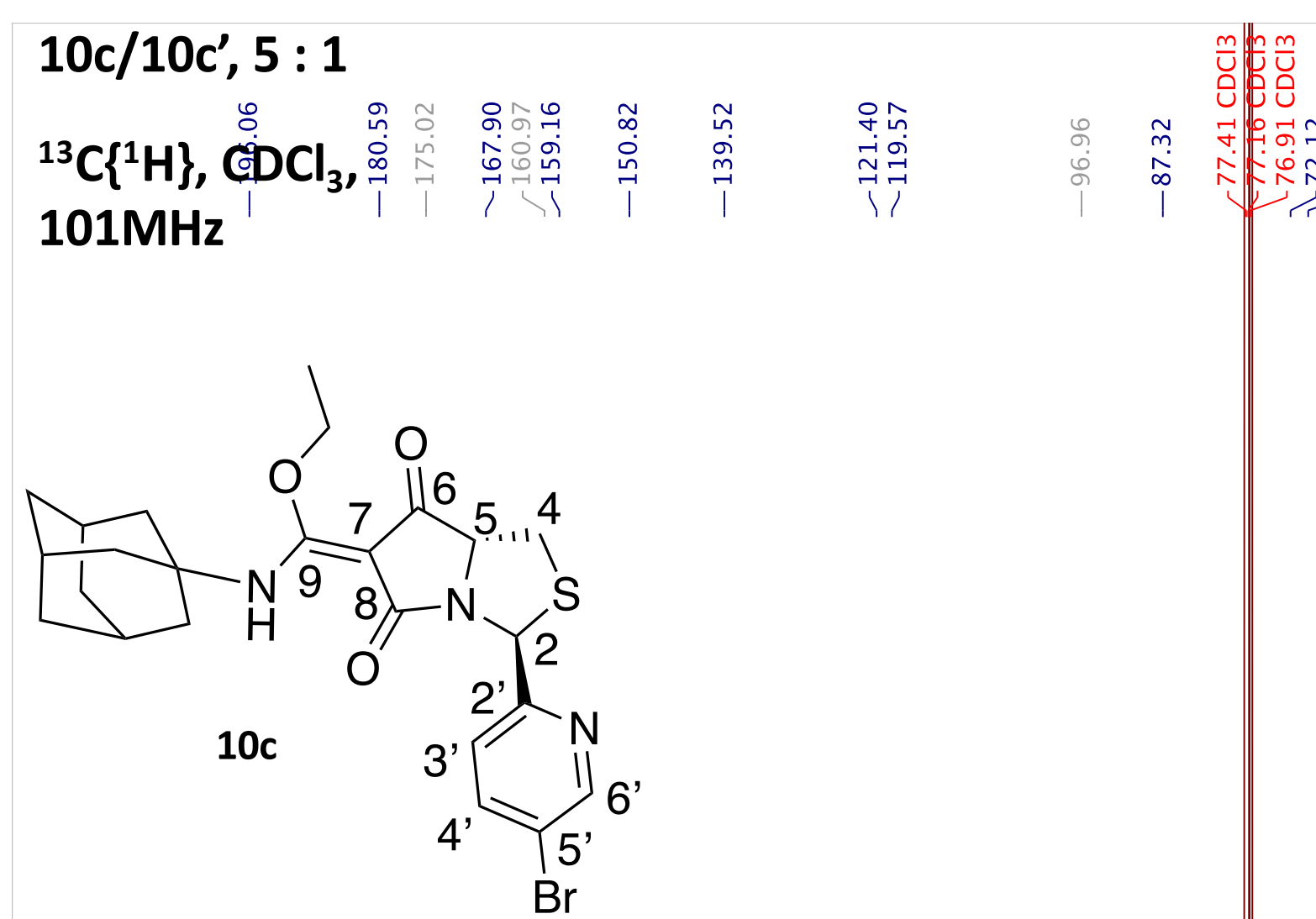

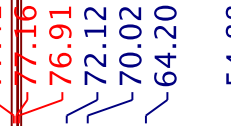

23000

$-22000$

$-21000$

$-20000$

$-19000$

$-18000$

$-17000$

$-16000$

$-15000$

$-14000$

$-13000$

$-12000$

$-11000$

$-10000$

9000

$-8000$

$-7000$

$-6000$

5000

$-4000$

$-3000$

$-2000$

$-1000$

0

$-1000$

$-2000$

$\begin{array}{llllllllllllllllllllllll}220 & 210 & 200 & 190 & 180 & 170 & 160 & 150 & 140 & 130 & 120 & 110 \underset{\mathrm{f} 1}{100}(\mathrm{ppm}) & 90 & 80 & 70 & 60 & 50 & 40 & 30 & 20 & 10 & 0 & -10 & -z_{\zeta} 0_{28}\end{array}$ 


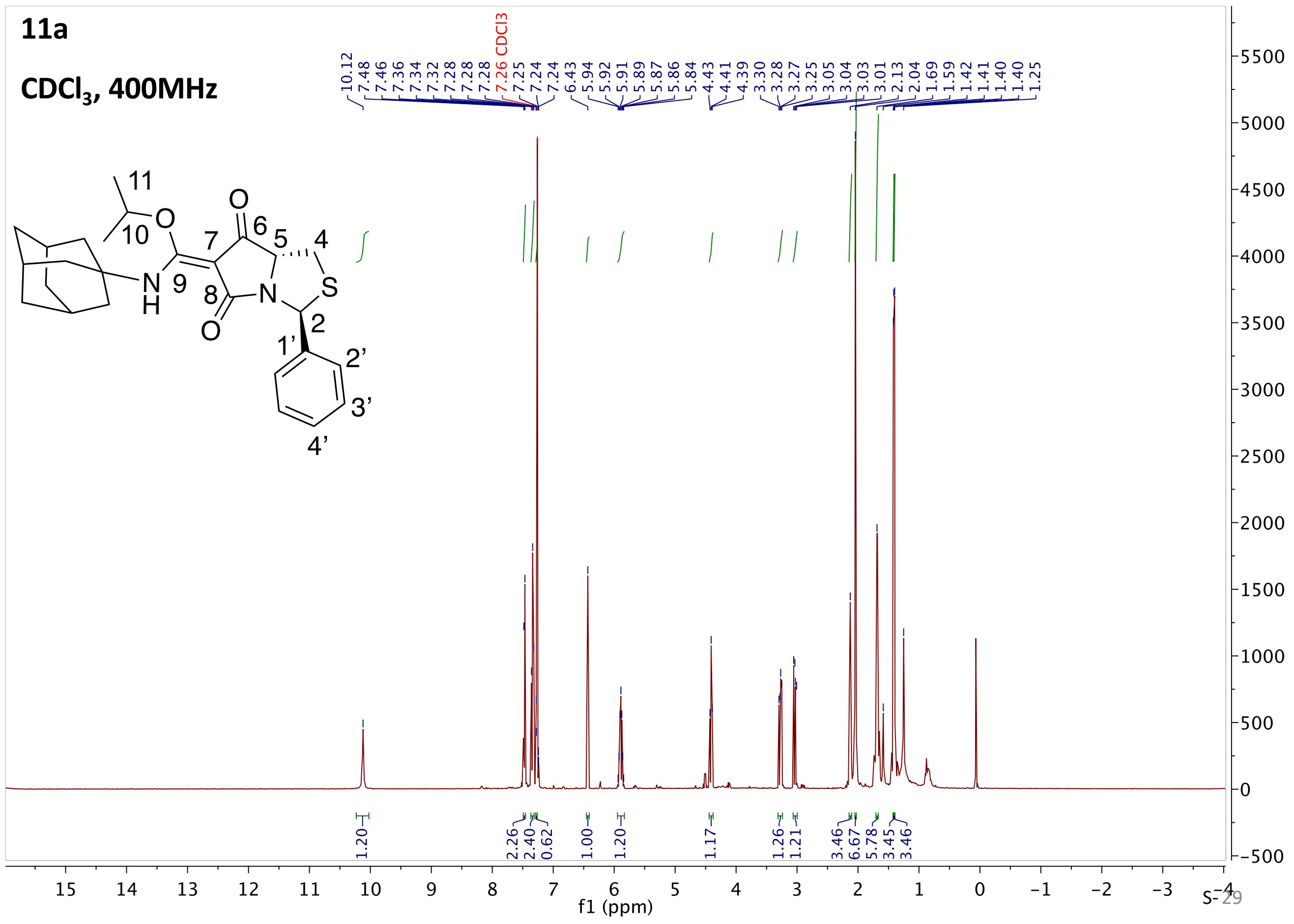




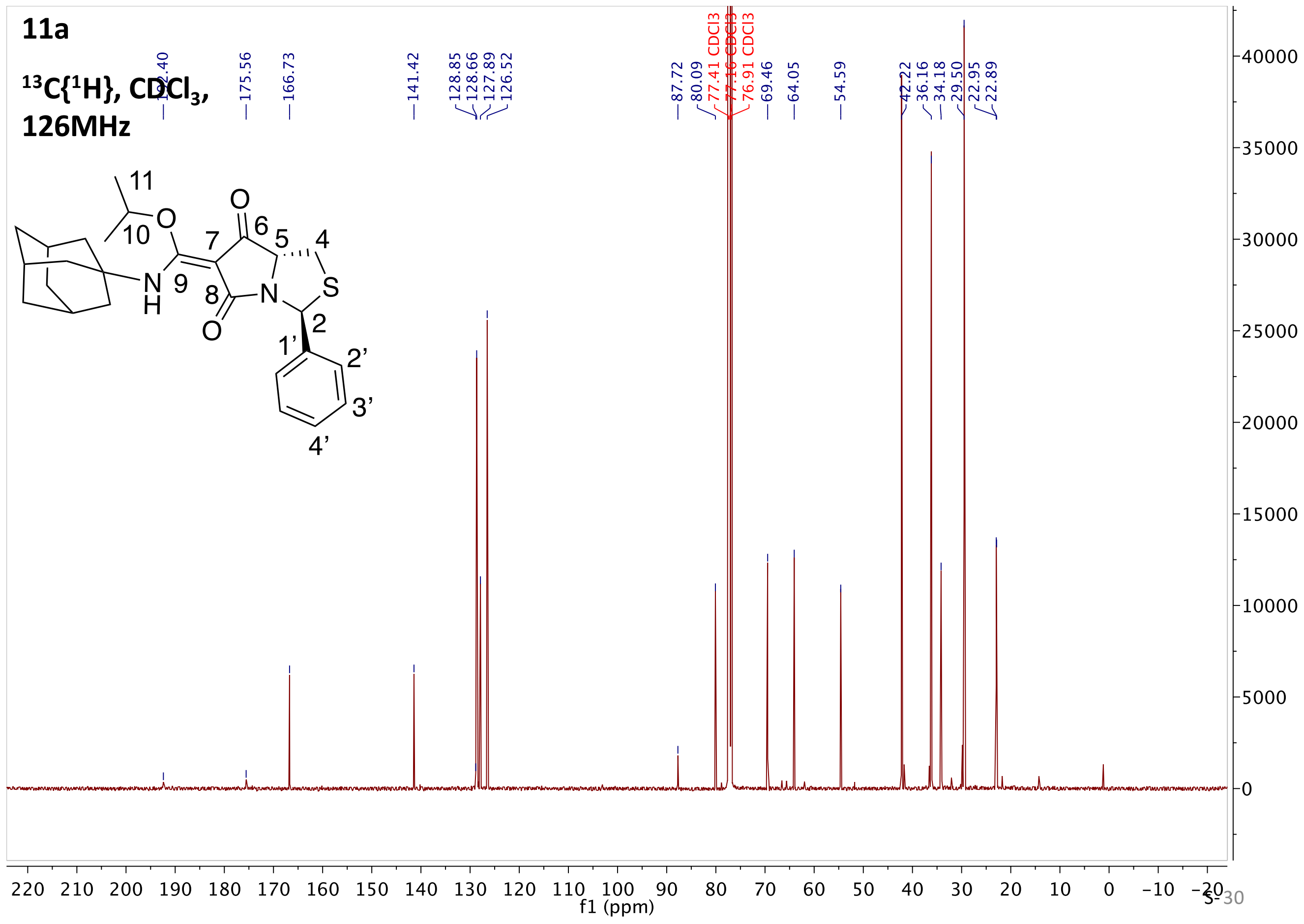




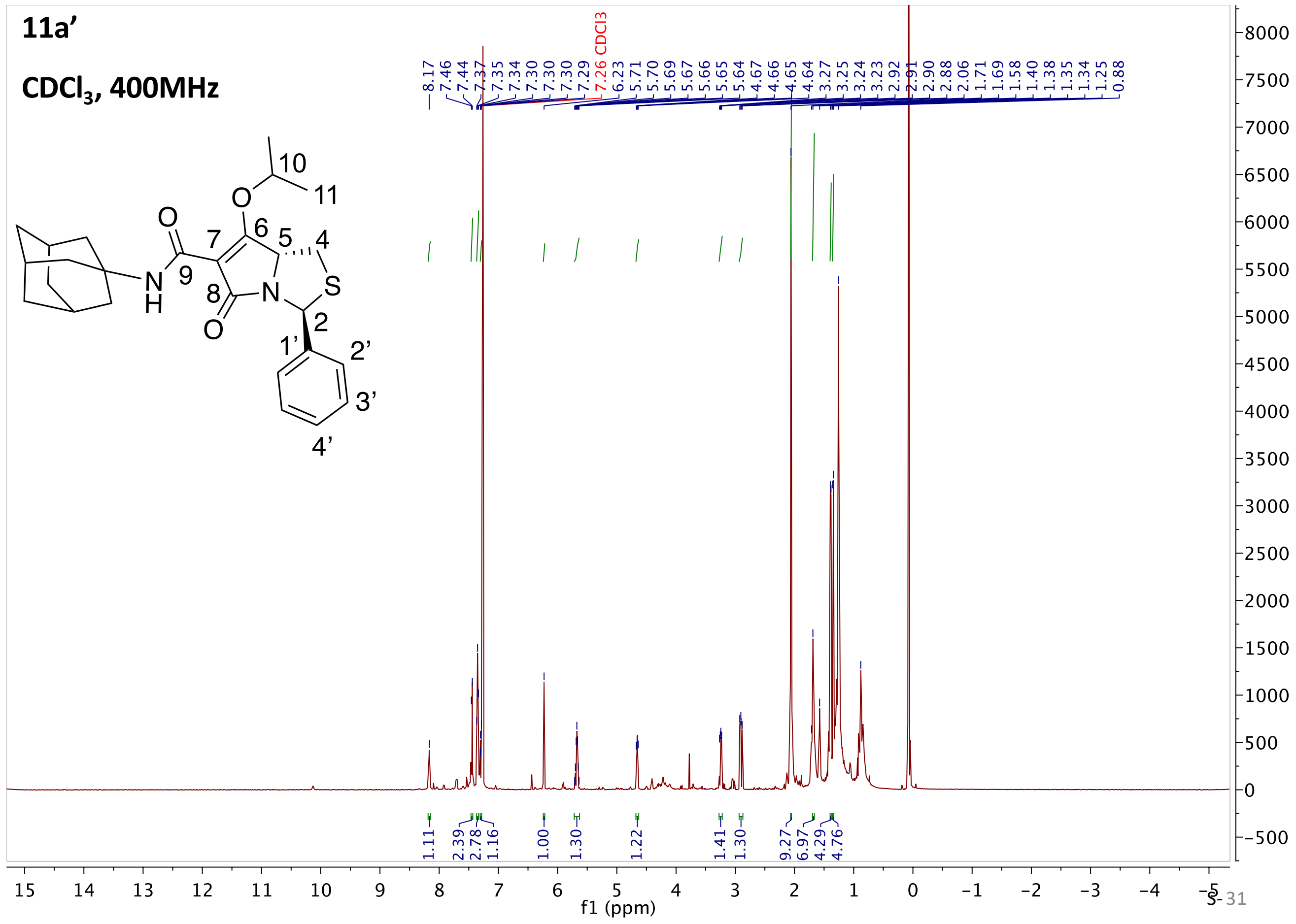




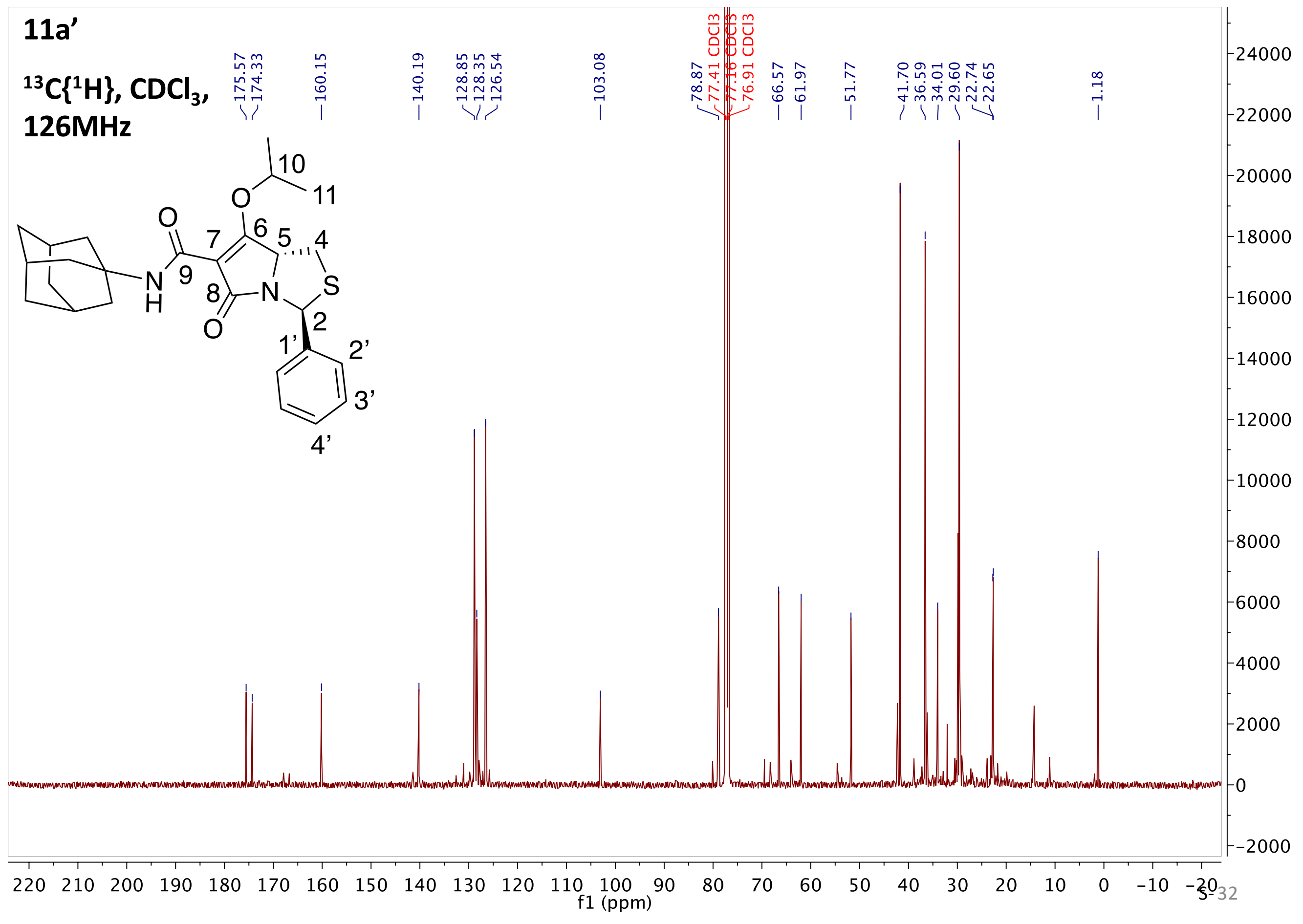




\section{$11 b / 11 b^{\prime}, 1.7: 1$}

\section{$\mathrm{CDCl}_{3}, 400 \mathrm{MHz}$}
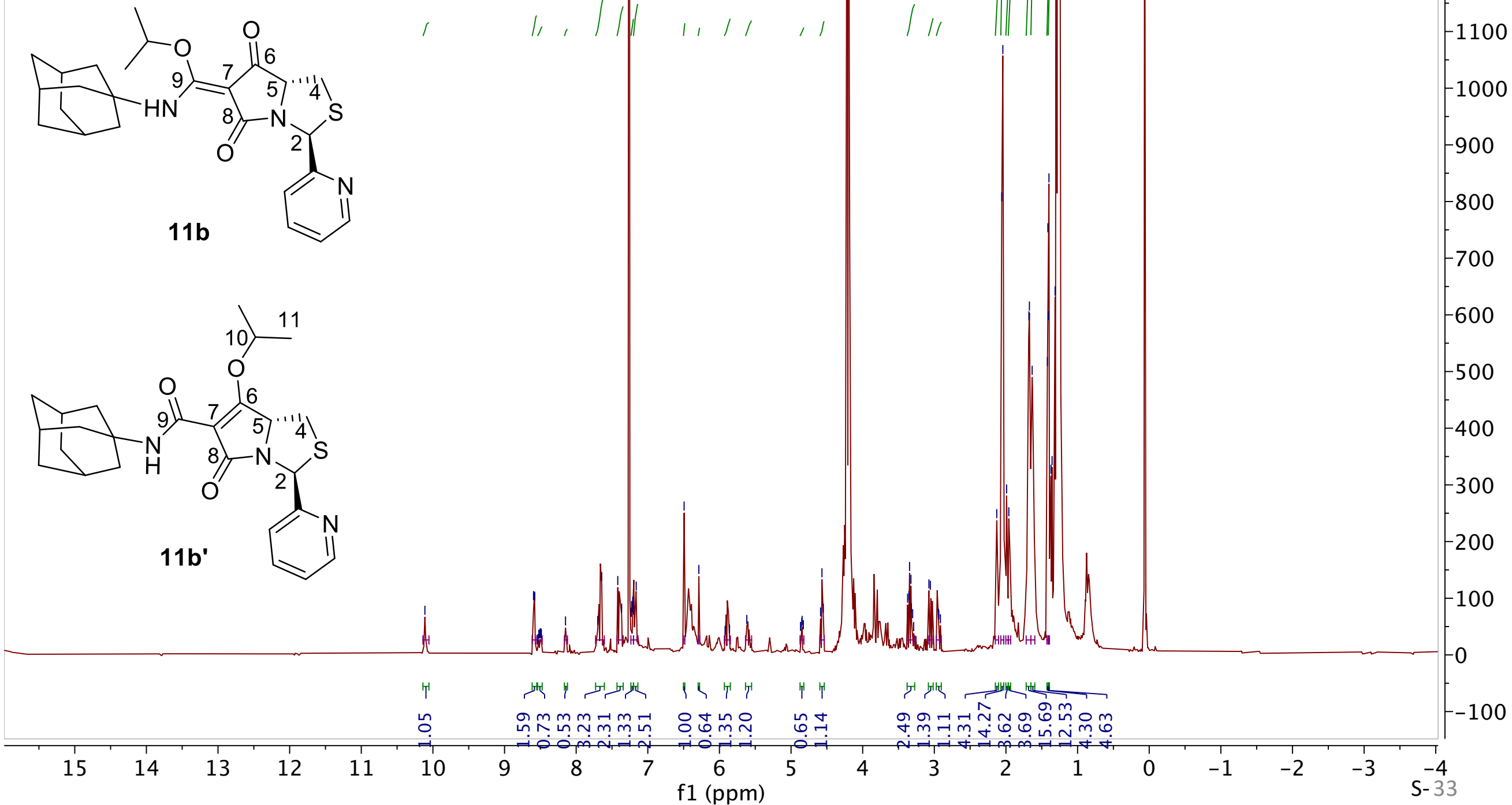


\section{1b/11b', 1.7 : 1}

${ }^{13} \mathrm{C}\left\{{ }^{1} \mathrm{H}\right\}, \mathrm{CD} \stackrel{\circ}{\mathrm{a}}$

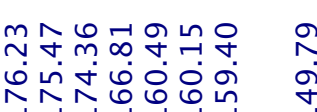
$126 \mathrm{MHz}$
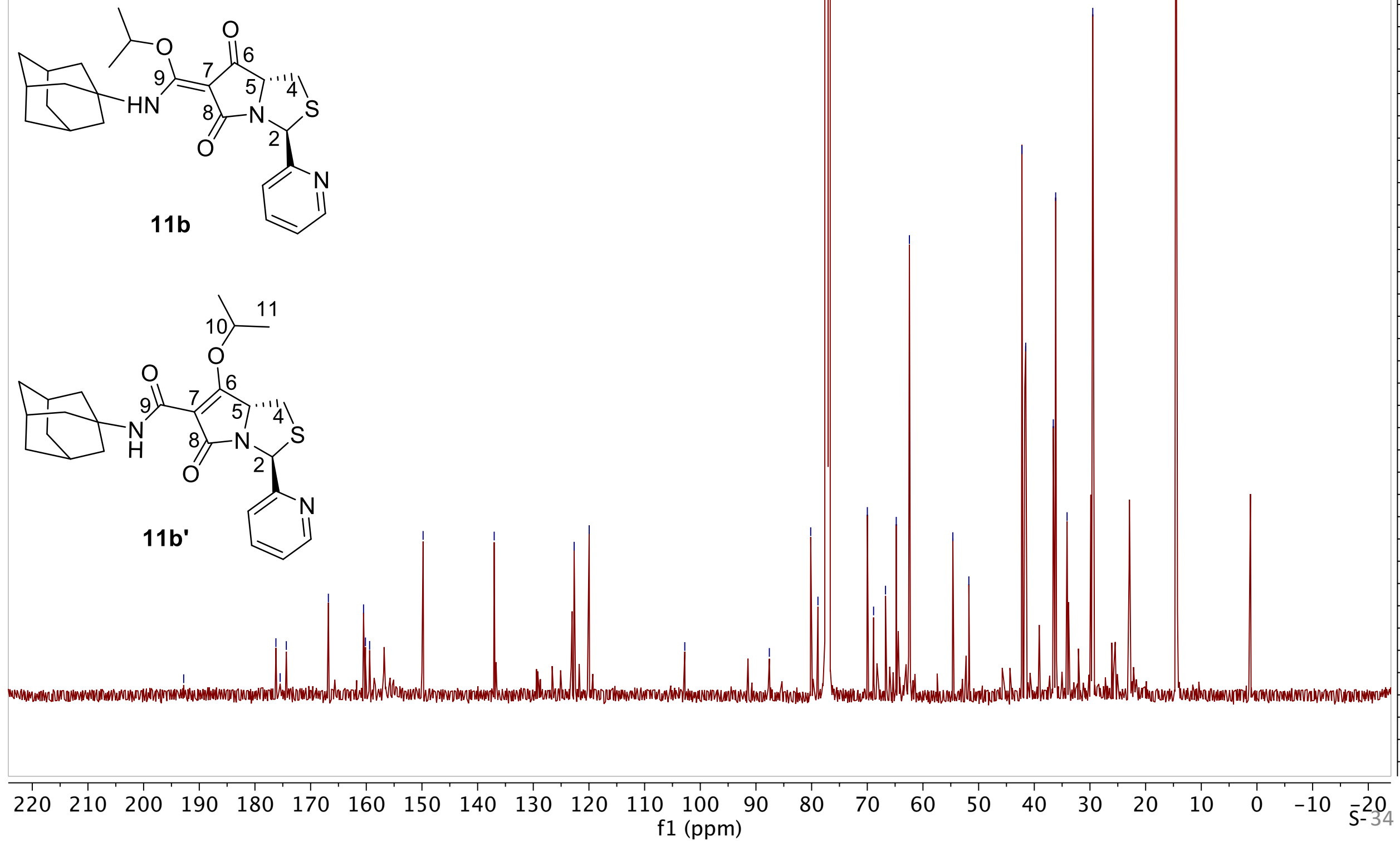


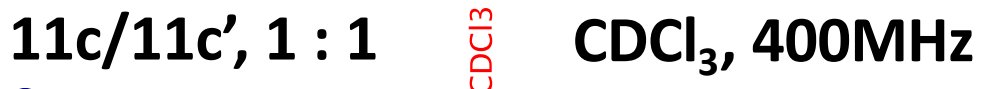

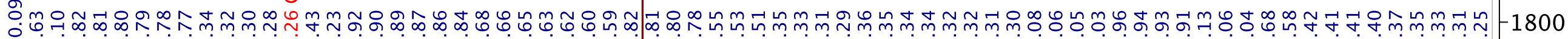
-
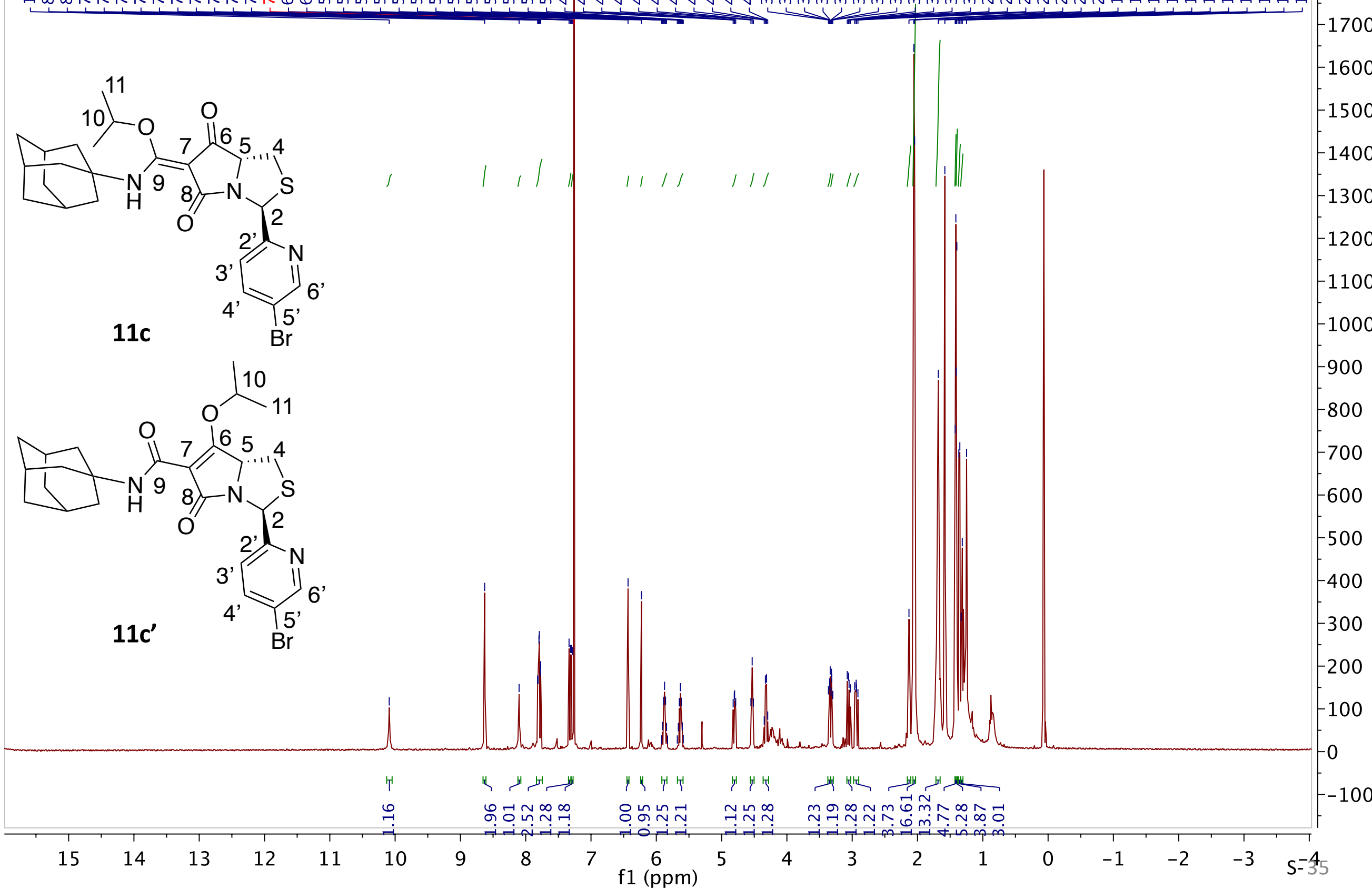


\section{1c/11c', $1: 1$}

${ }^{13} \mathrm{C}\left\{{ }^{1} \mathrm{H}\right\}, \mathrm{CDCl}_{3}$,

\section{MHz}
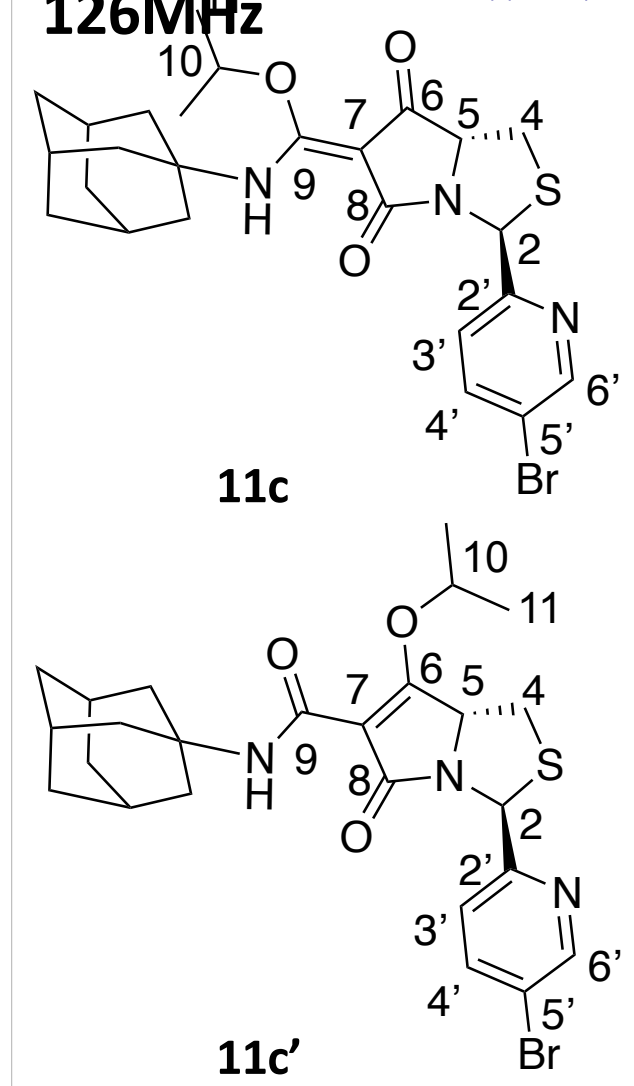

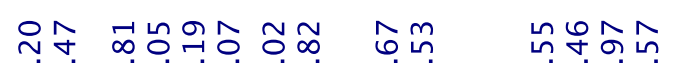
ம் ம்ல் 궉

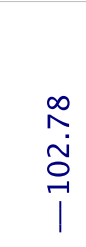

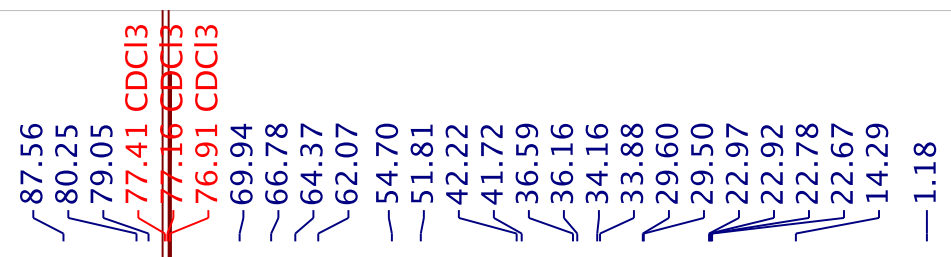

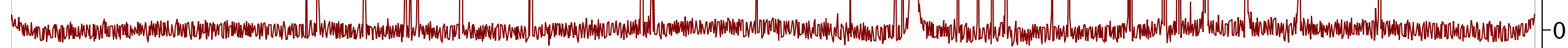




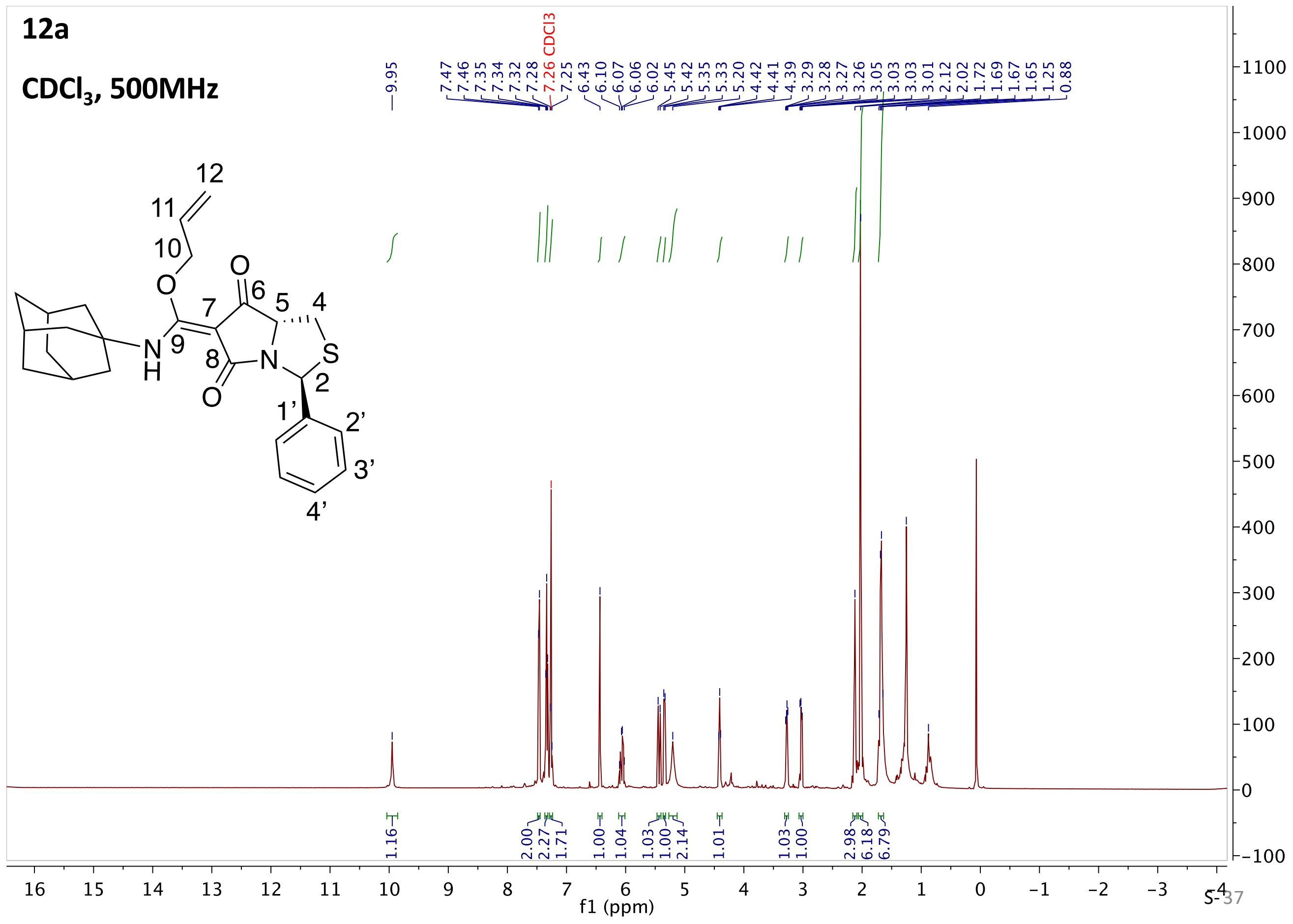




\section{$12 a$}

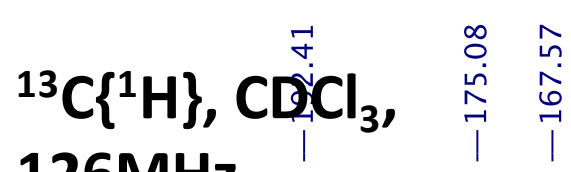

$m$ môำ.

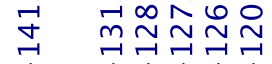

$126 \mathrm{MHz}$

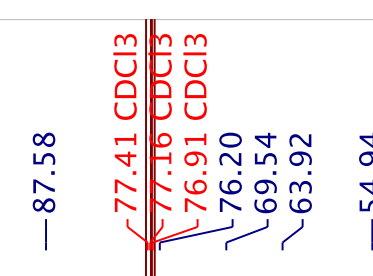

$-30000$
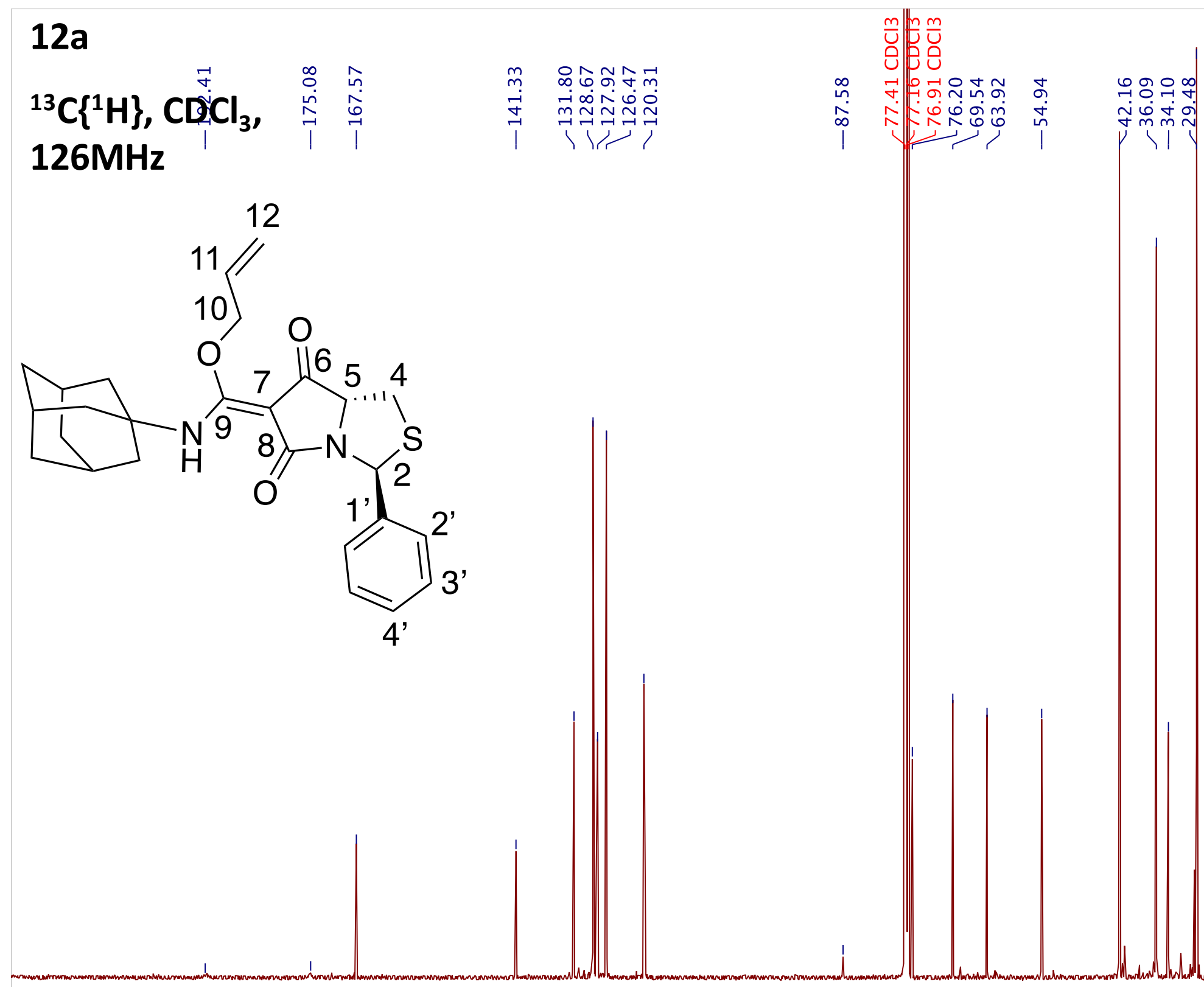

28000

$-26000$

$-24000$

$-22000$

$-20000$

$-18000$

$-16000$

$-14000$

$-12000$

$-10000$

$-8000$

$-6000$

$-4000$

$-2000$

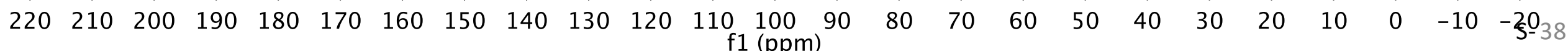




\section{$12 a^{\prime}$ \\ $\mathrm{CDCl}_{3}, 400 \mathrm{MHz}$}

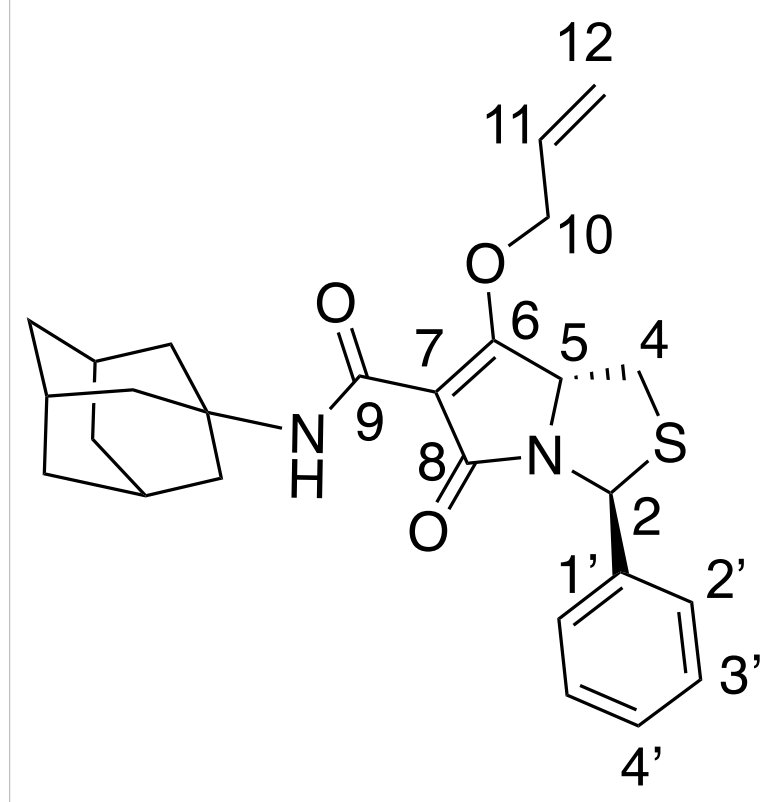

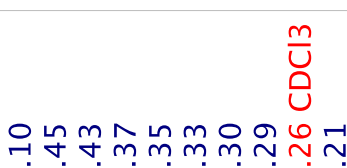

法

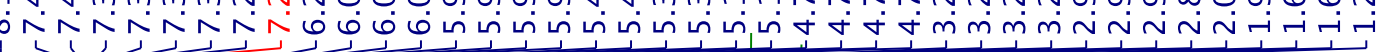




\section{$12 a^{\prime}$}

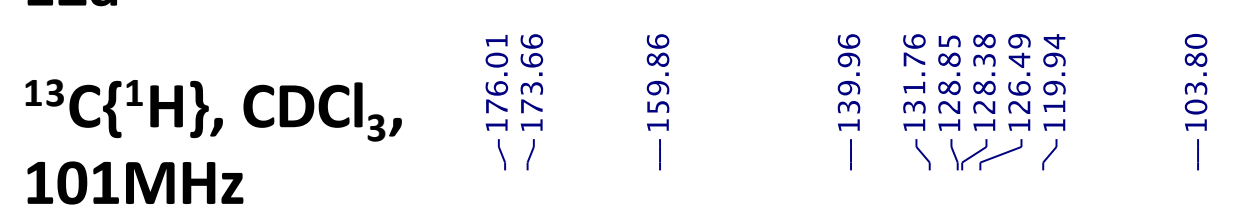
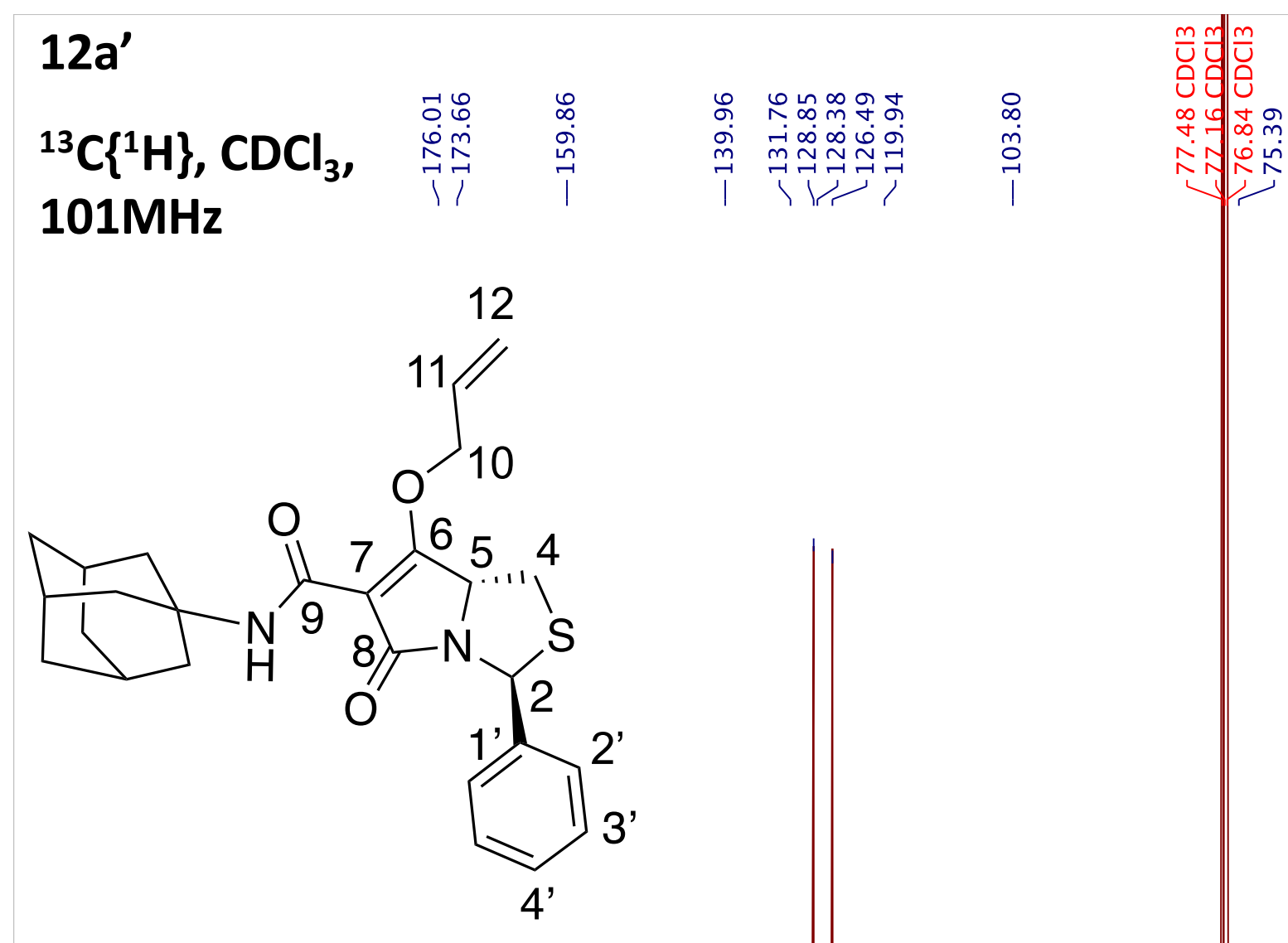

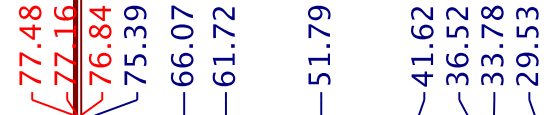

$-2100$

$-2000$

$-1900$

$-1800$

$-1700$

$-1600$

$-1500$

$-1400$

$-1300$

$-1200$

$-1100$

$-1000$

-900

$-800$

$-700$

600

$-500$

$-400$

$-300$

$-200$

$-100$

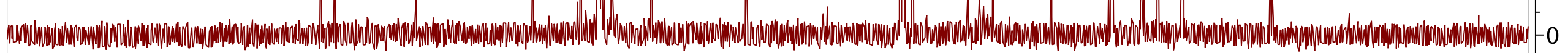




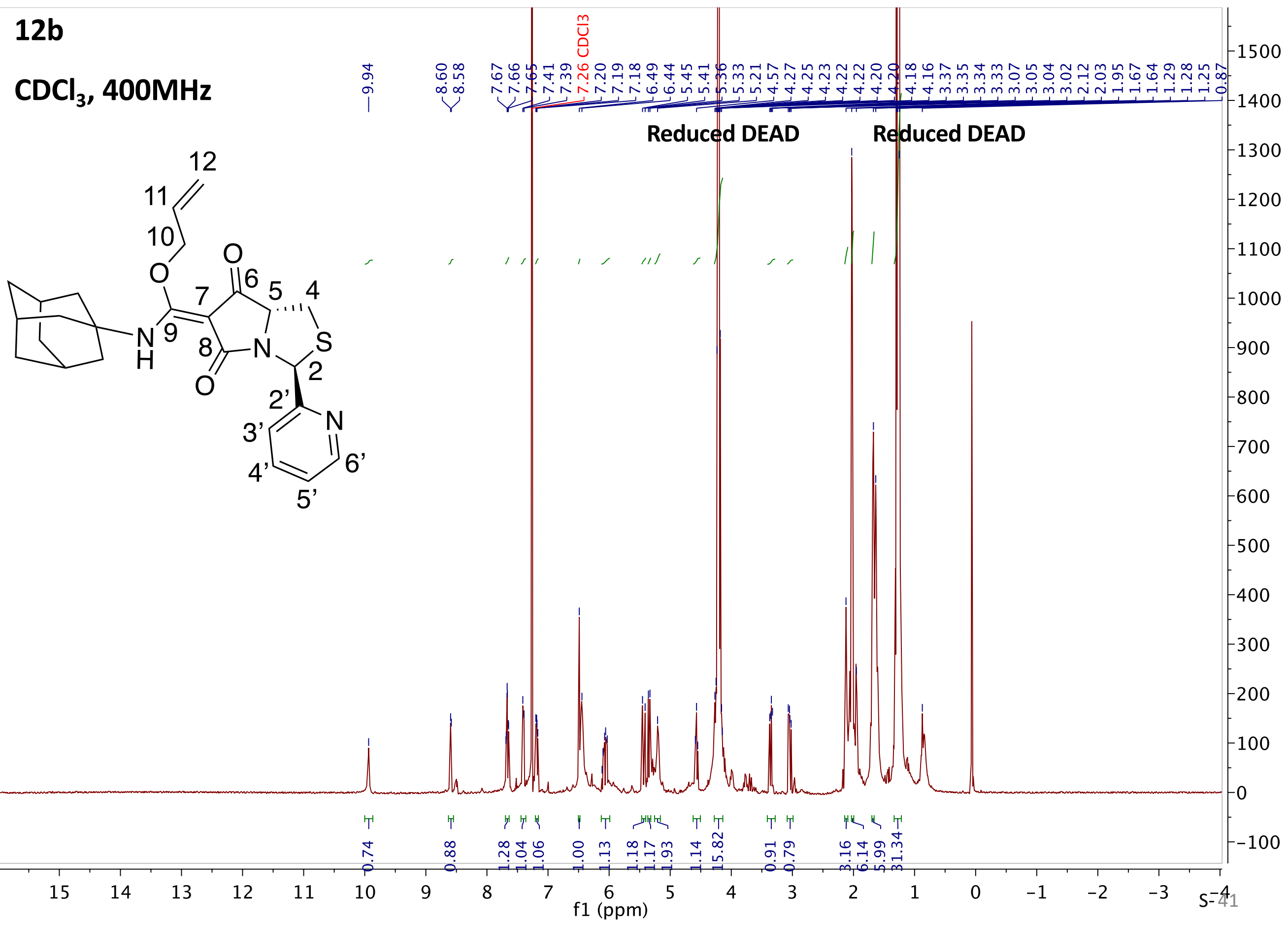




\section{$12 b$}

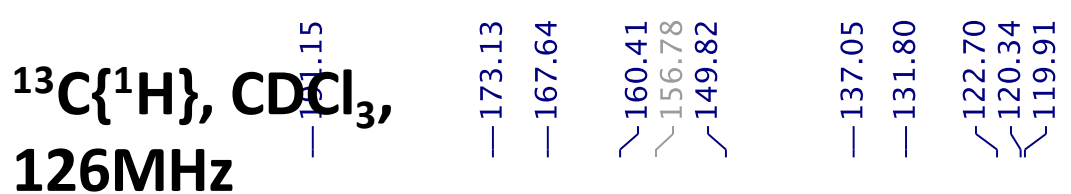

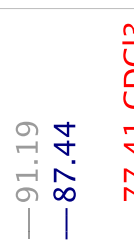

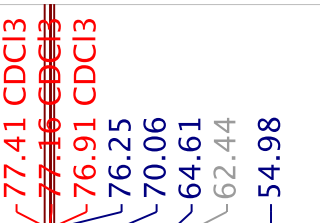

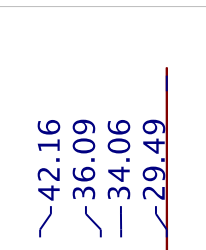

12<smiles>[Z][2H]</smiles>

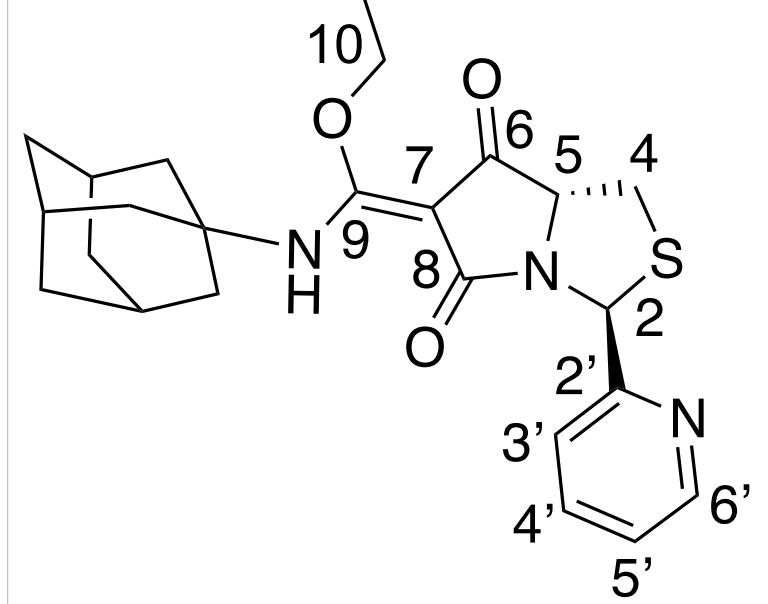


융우웅ㅎํ

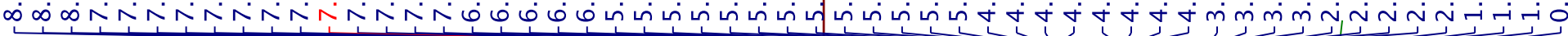

\section{$\mathrm{CDCl}_{3}, 500 \mathrm{MHz}$}
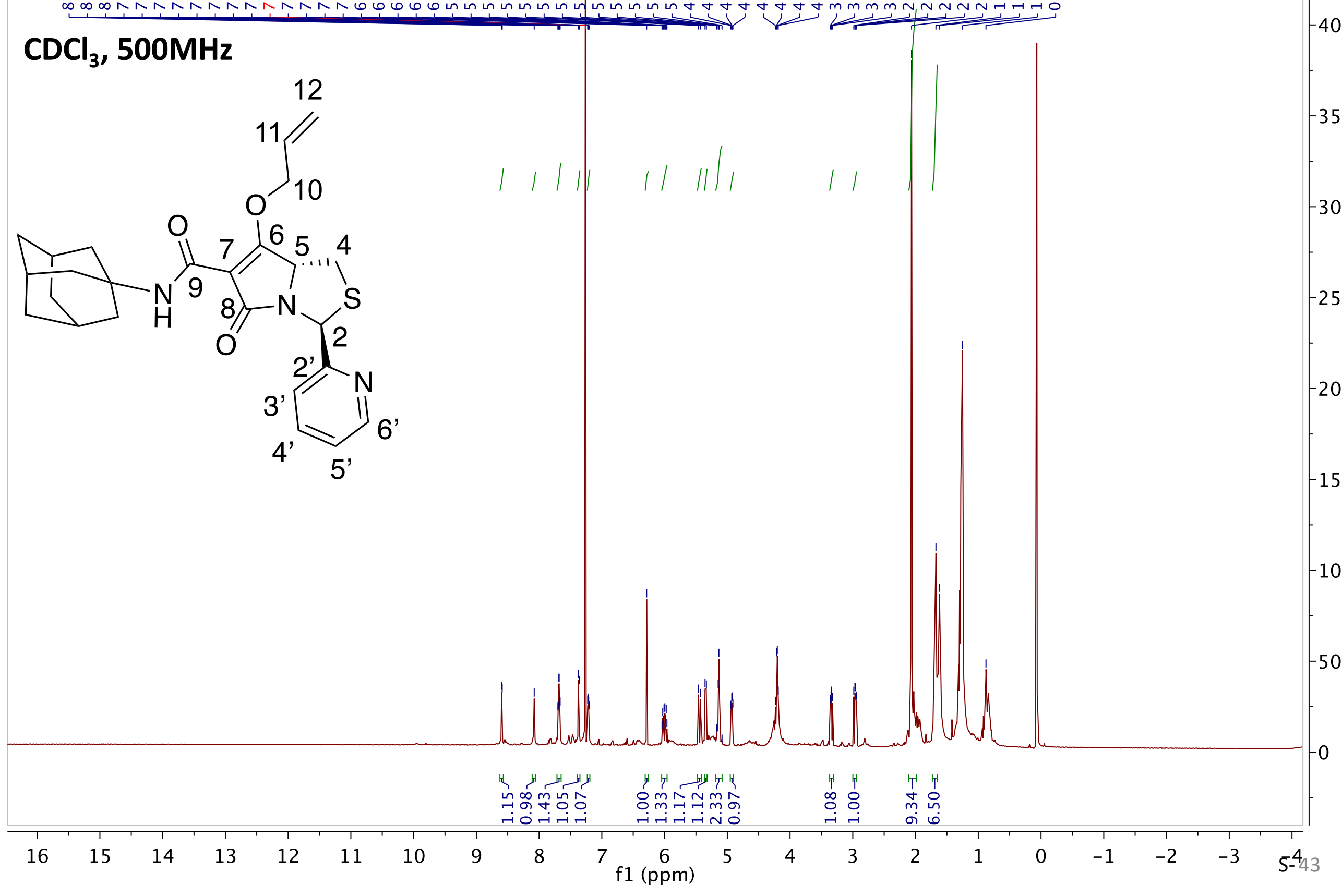


\section{$12 b^{\prime}$}

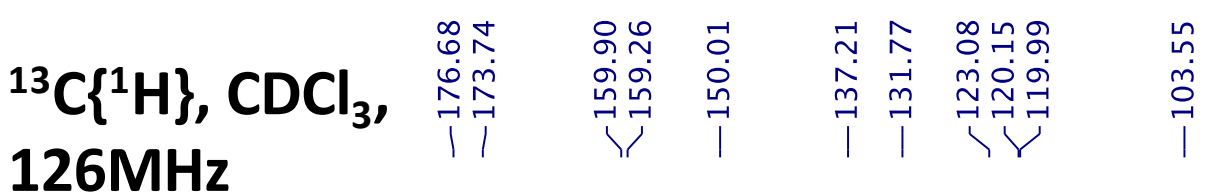
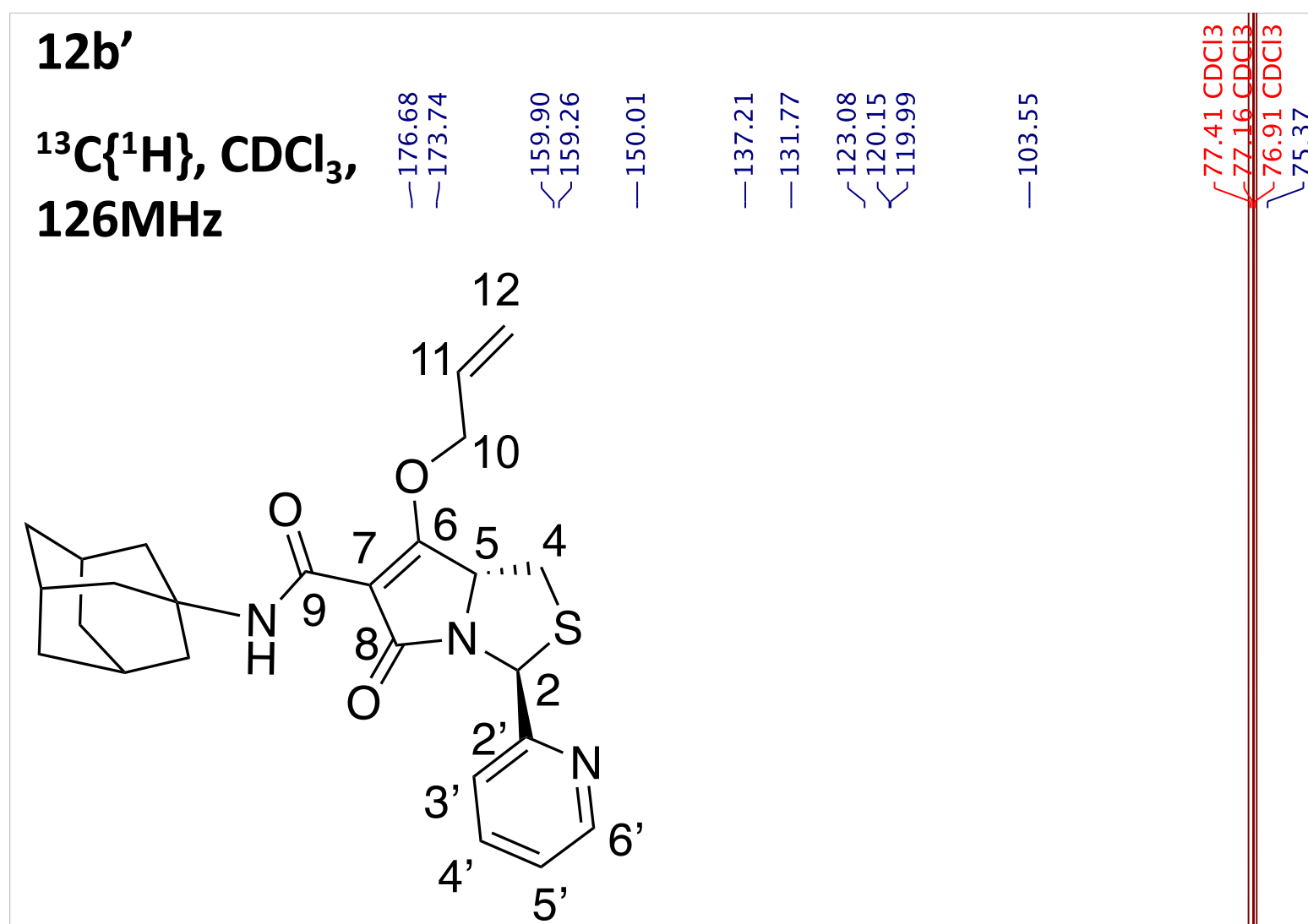


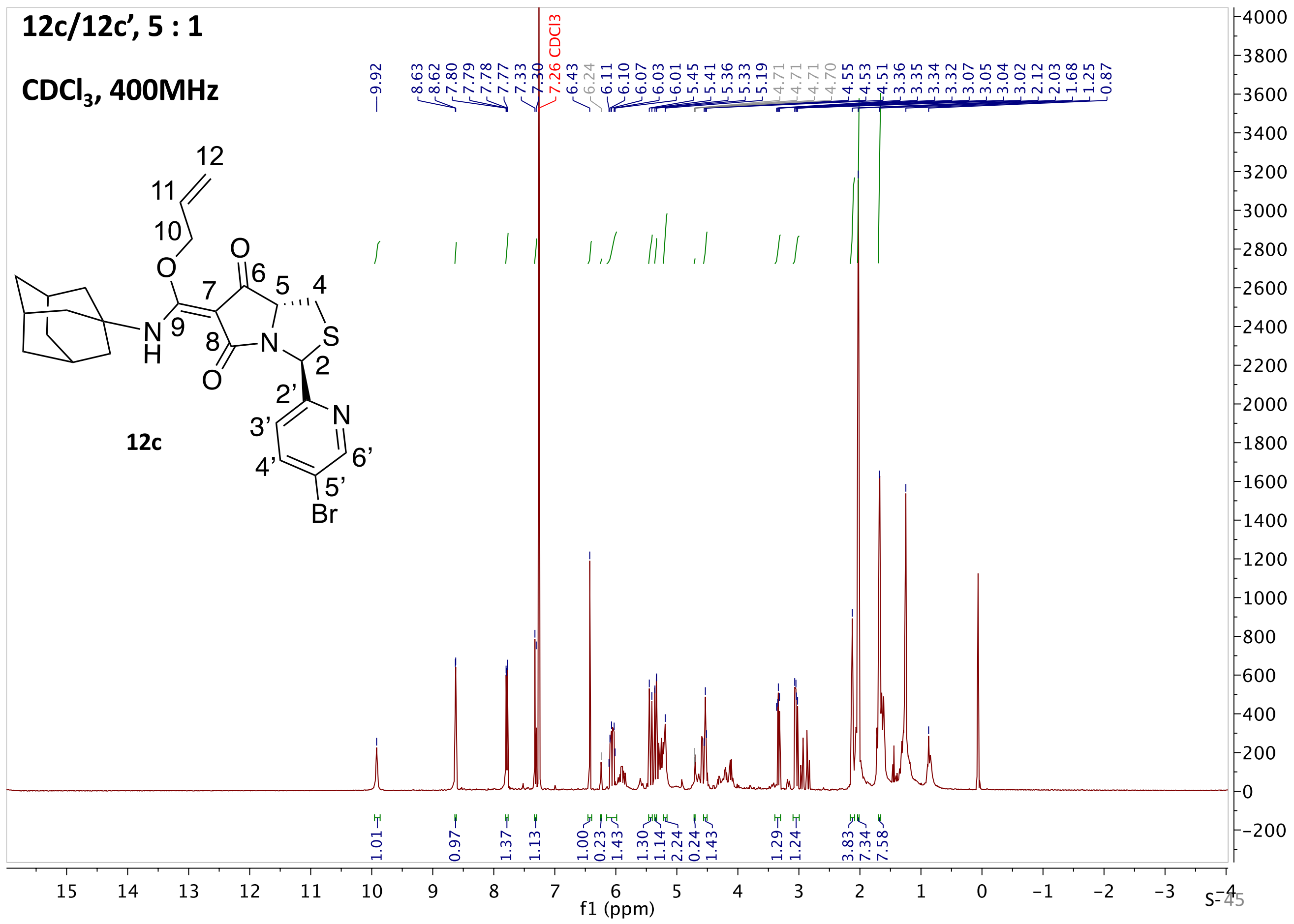




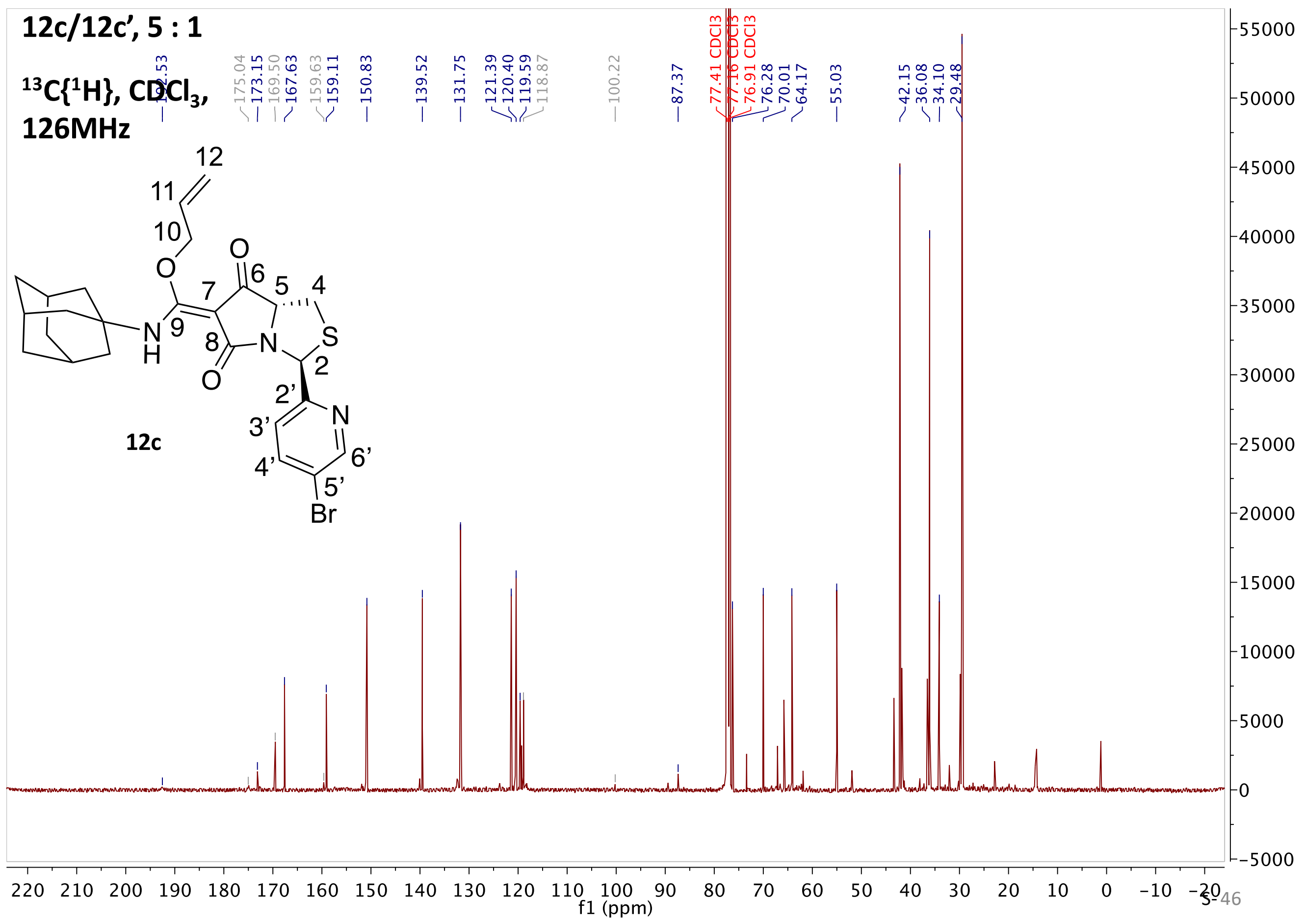




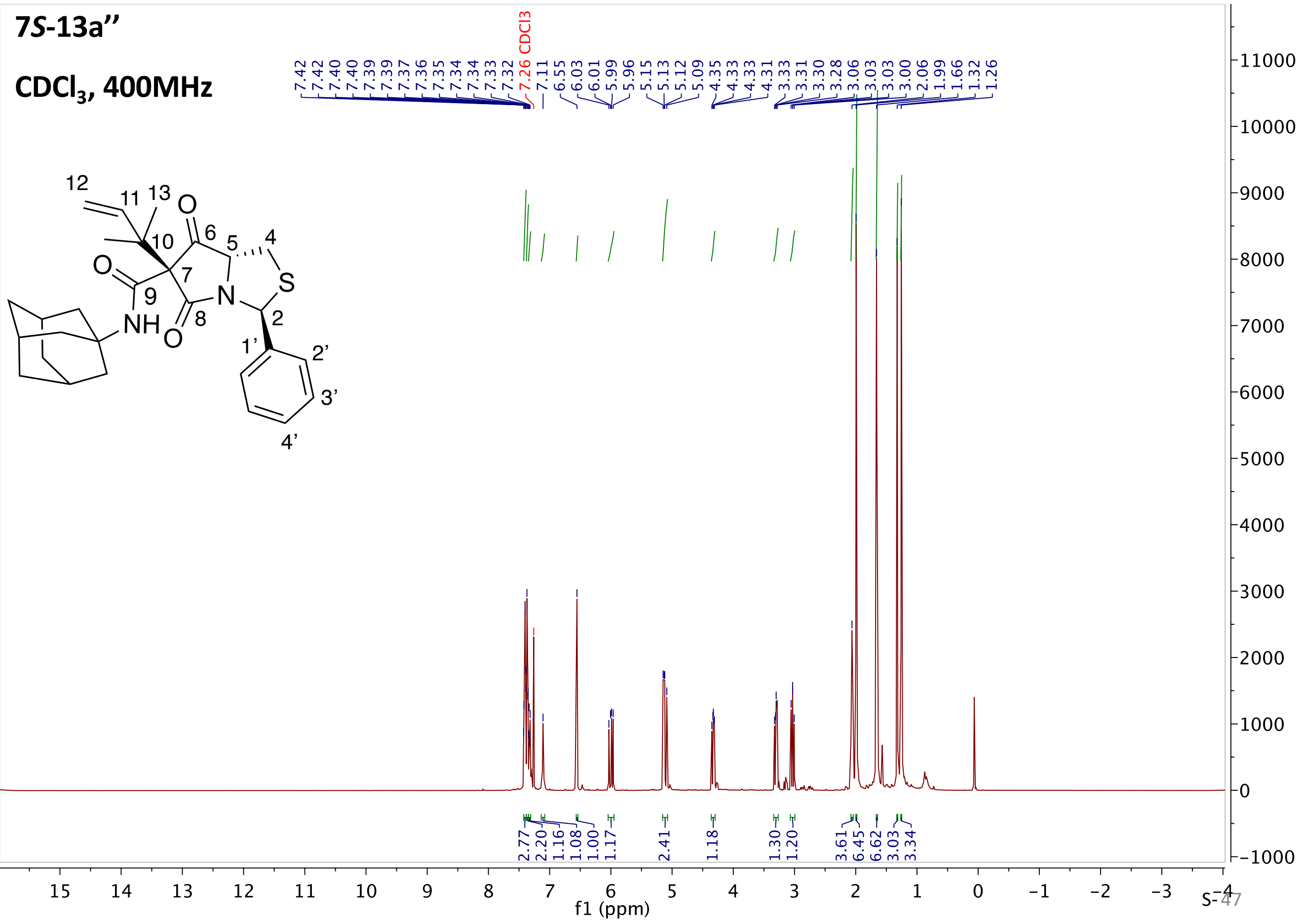


7S-13a"

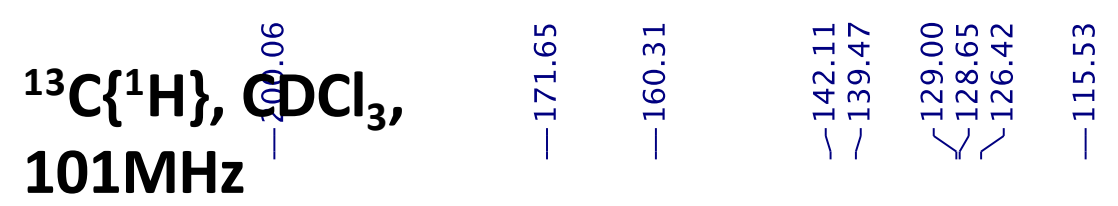

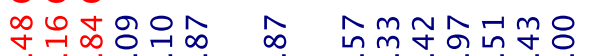

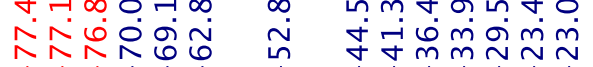
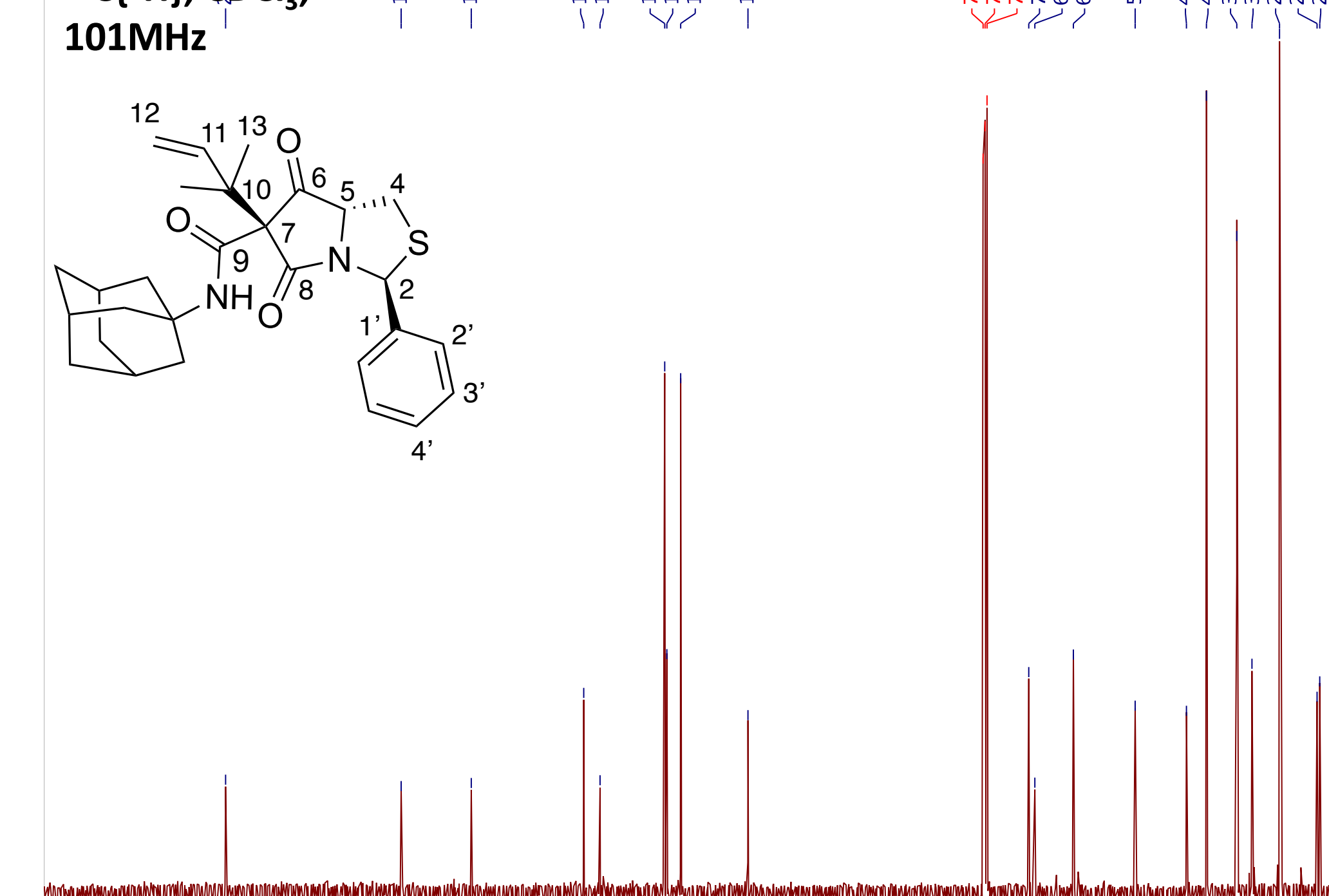


\section{R/S-13a", 1.3 : 1}

$\mathrm{CDCl}_{3}, 400 \mathrm{MHz}$
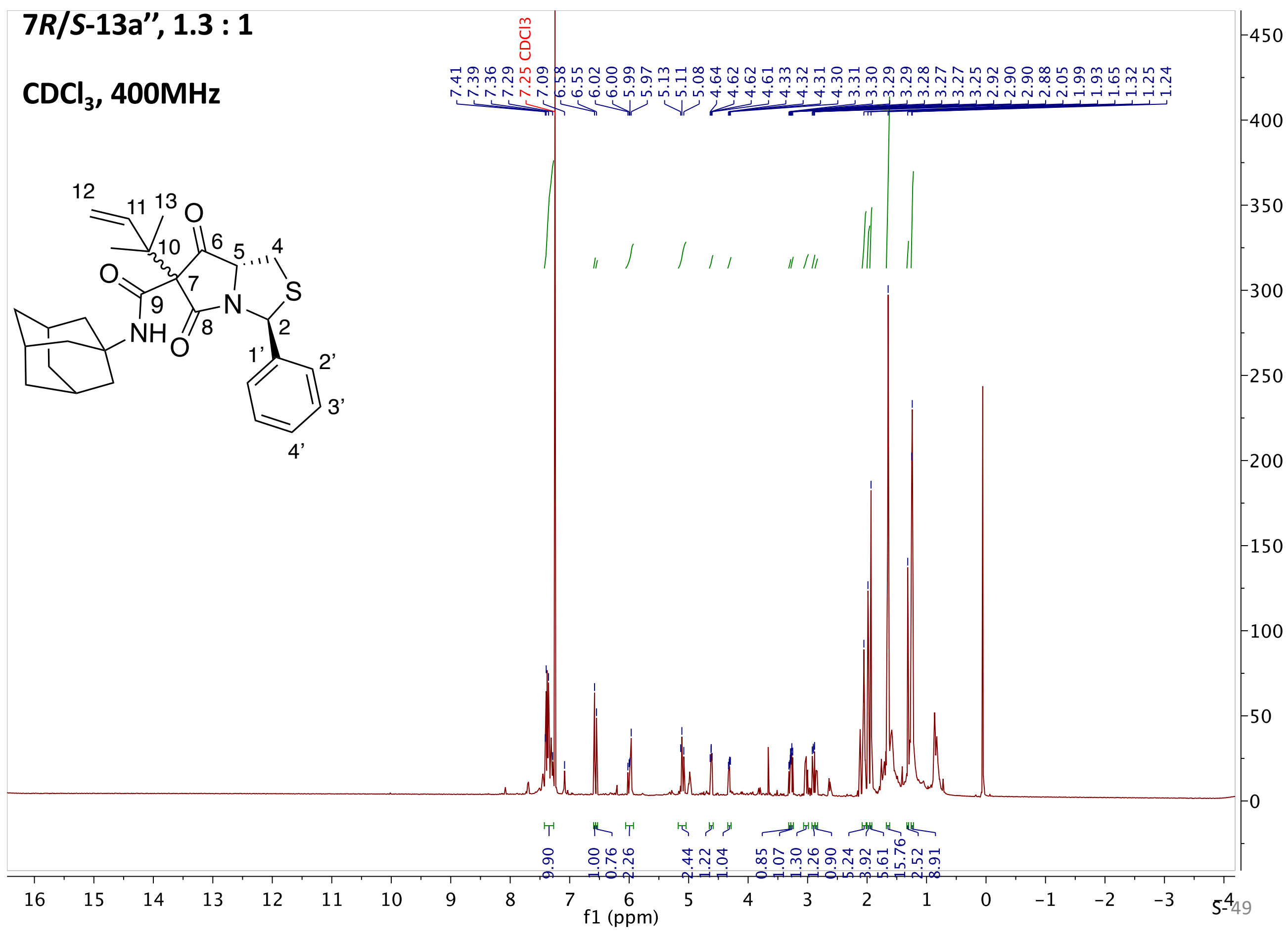
7R/S-13a", 1.3 : 1

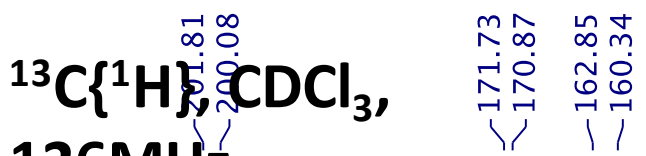

126MHz

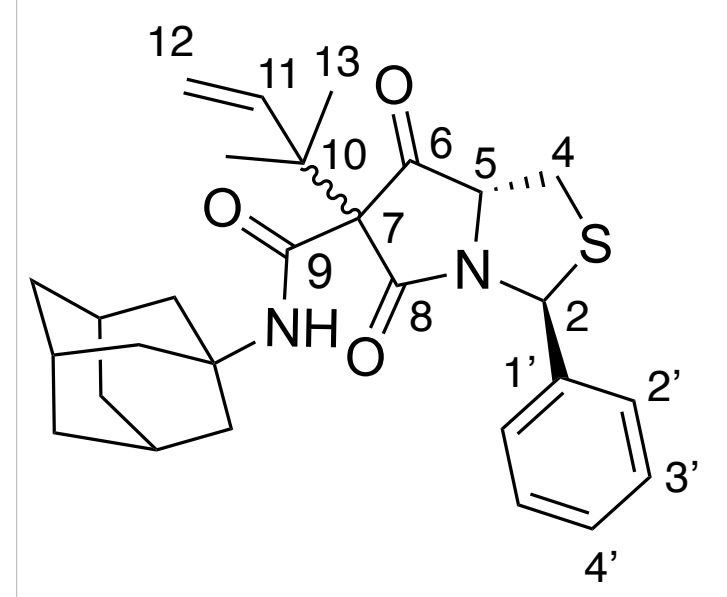

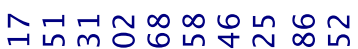

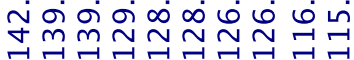


$7 R / S-13 d^{\prime \prime}, 1: 1$

$\mathrm{CDCl}_{3}, 400 \mathrm{MHz}$

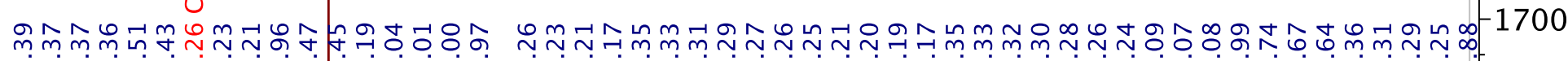

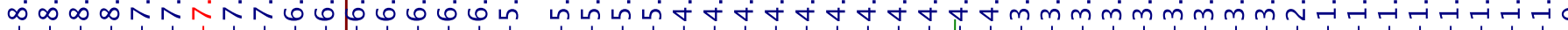

$-1600$

$-1500$

$-1400$

(112)

1300

$-1200$

$-1100$

$-1000$

$-900$

$-800$

$-700$

$-600$

$-500$

$-400$

$-300$

$-200$

$-100$

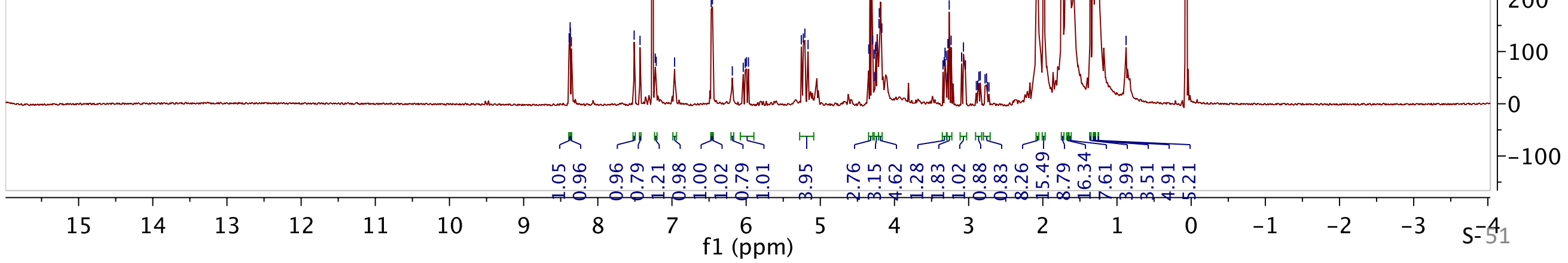


7R/S-13d", $1: 1$

ำ

${ }^{13} \mathrm{C}\left\{{ }^{1} \mathrm{H}\right\}$ ก극ำ

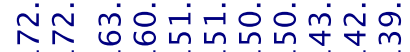
126MHz

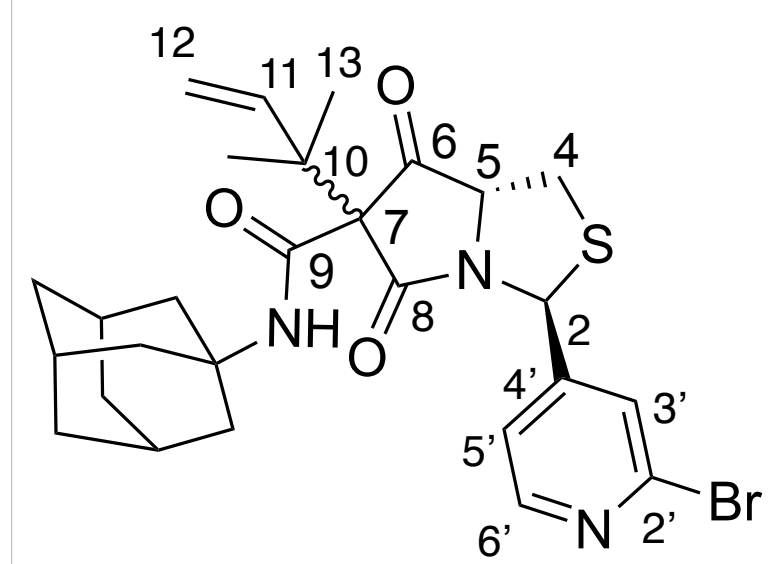

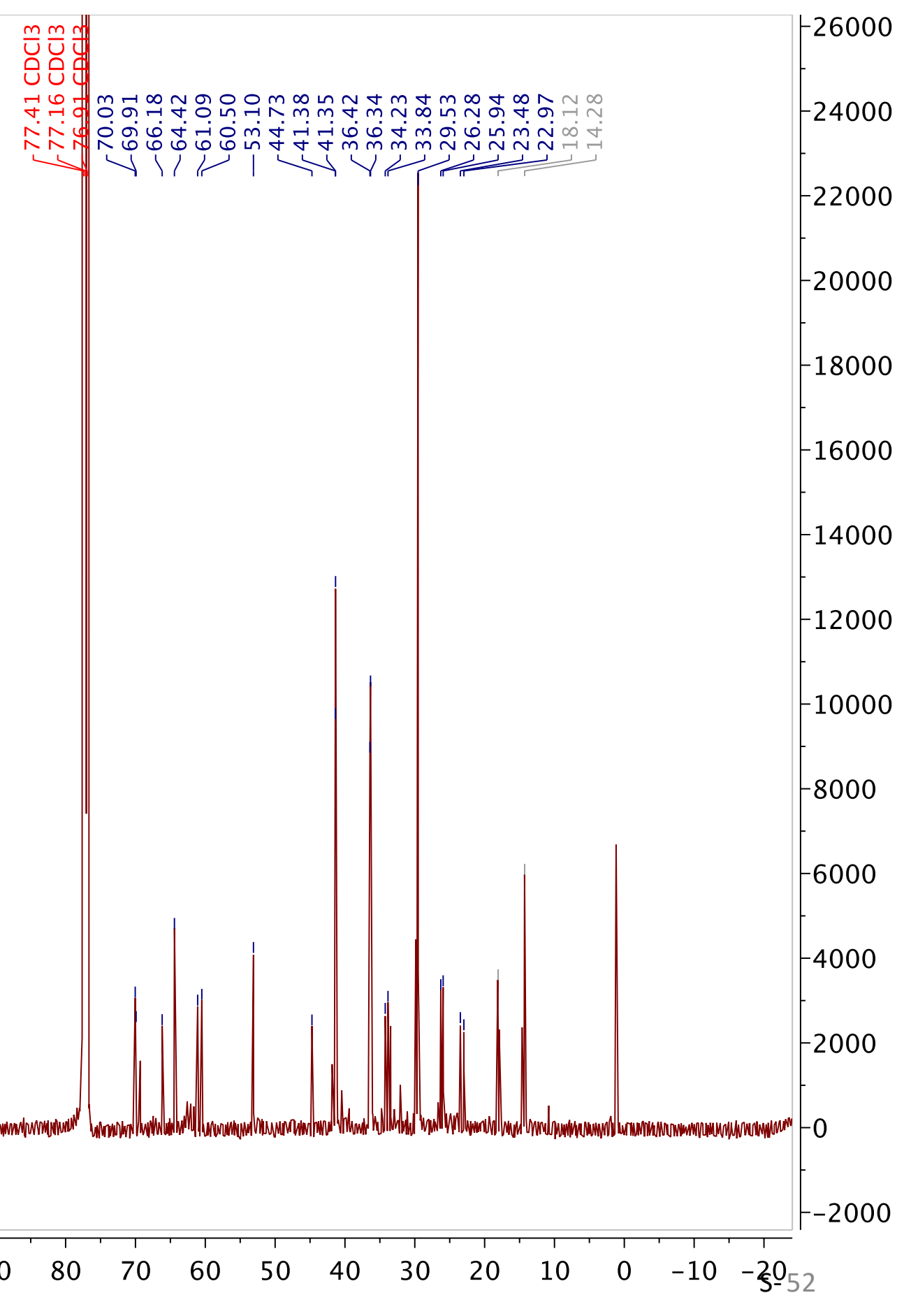




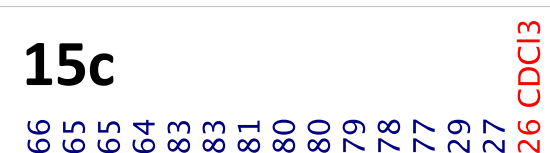

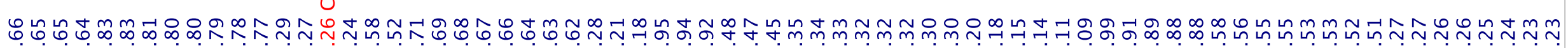

\section{$\mathrm{CDCl}_{3}, 400 \mathrm{MHz}$}

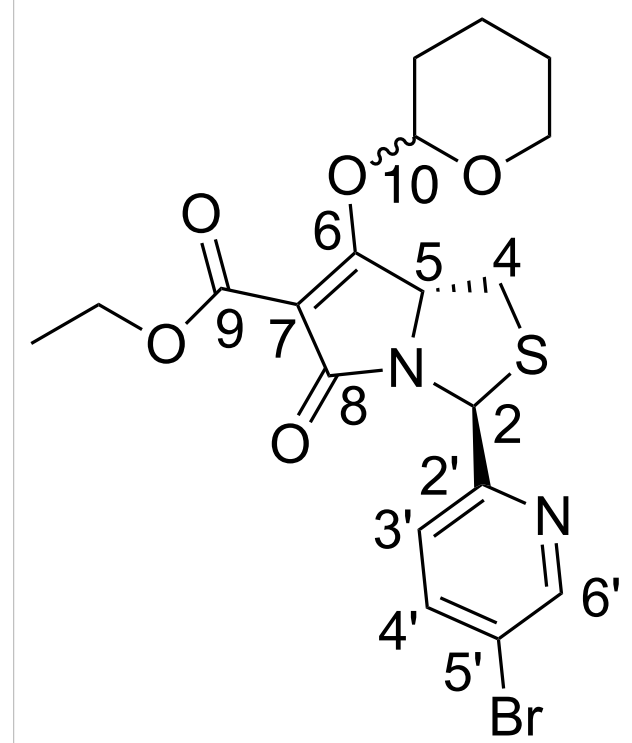
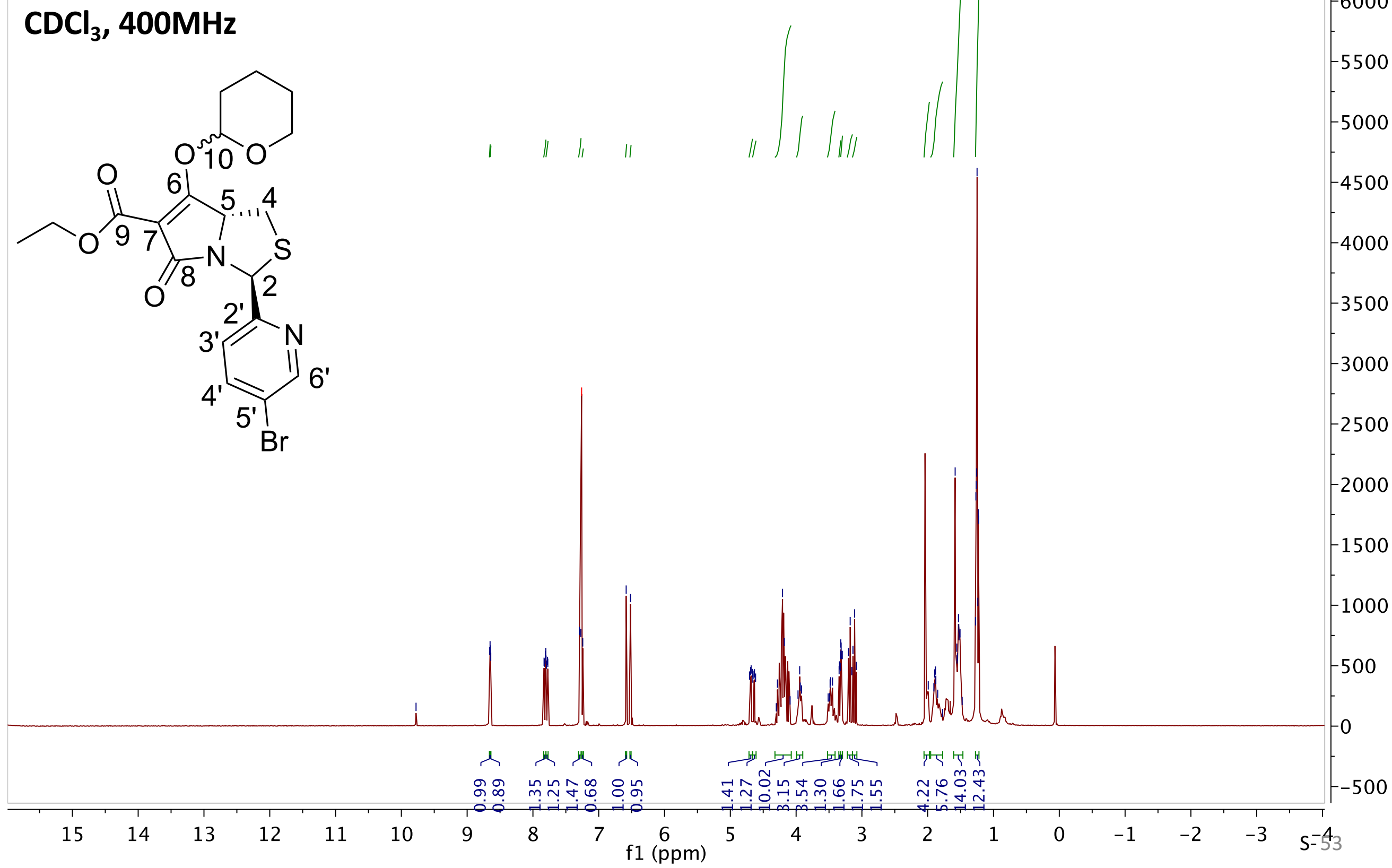


\section{$15 c$}

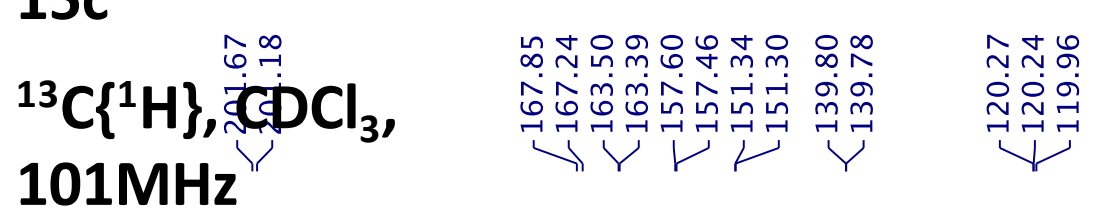

ๆ

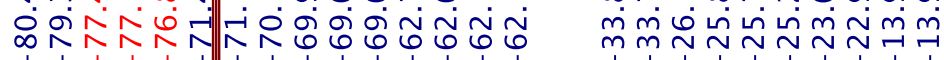

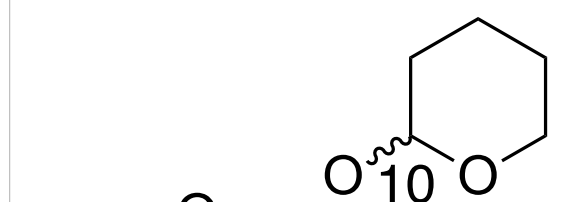




\section{5d}

\section{$\mathrm{CDCl}_{3}, 400 \mathrm{MHz}$}
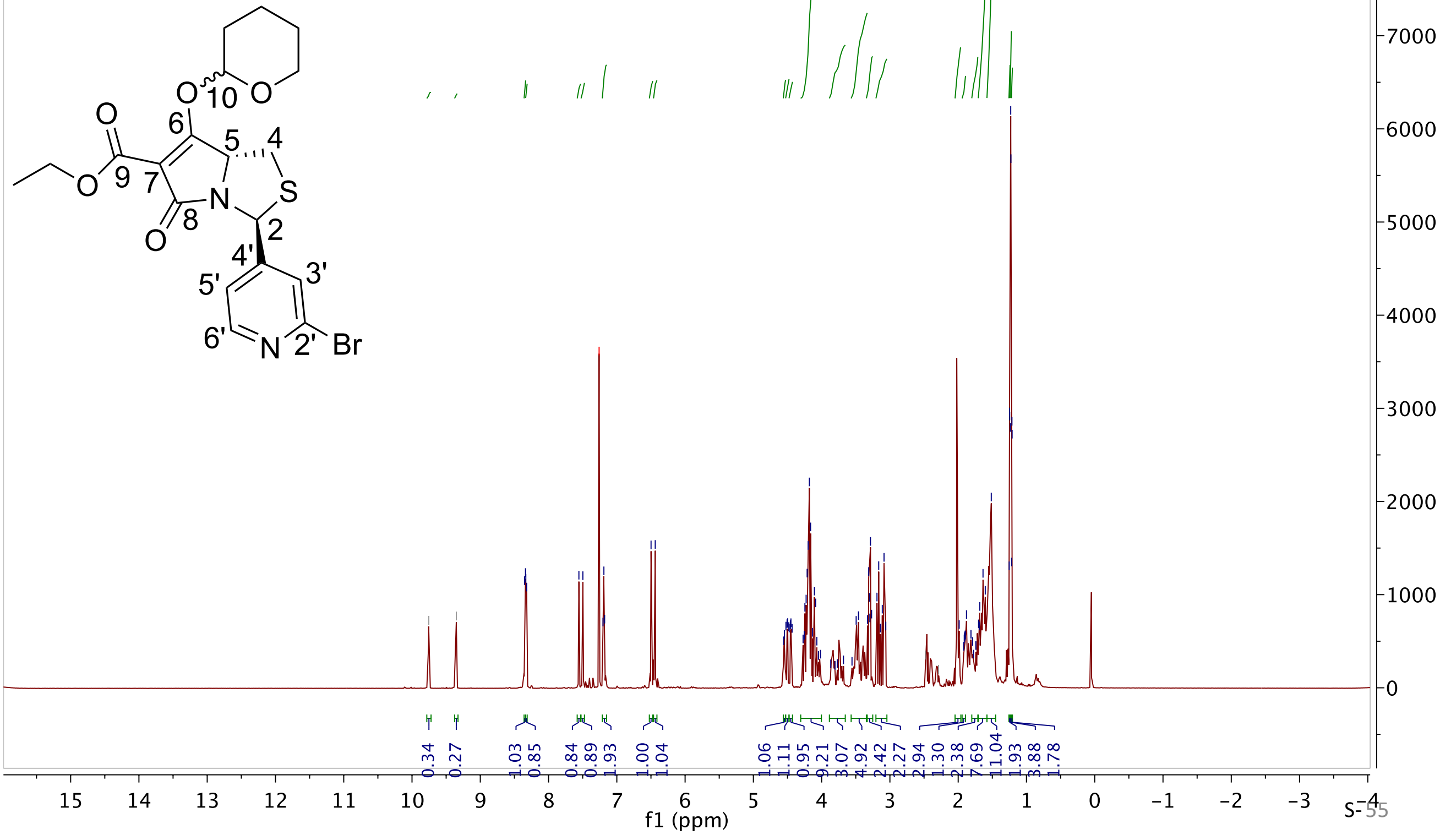

15

$13 \quad 12$

11

f1 (ppm)

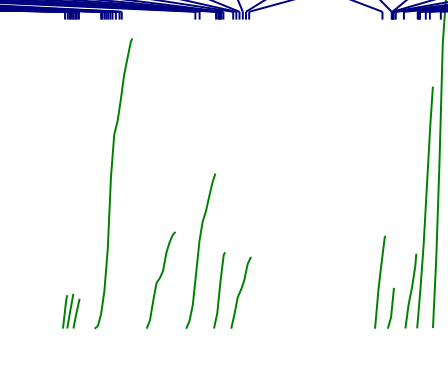




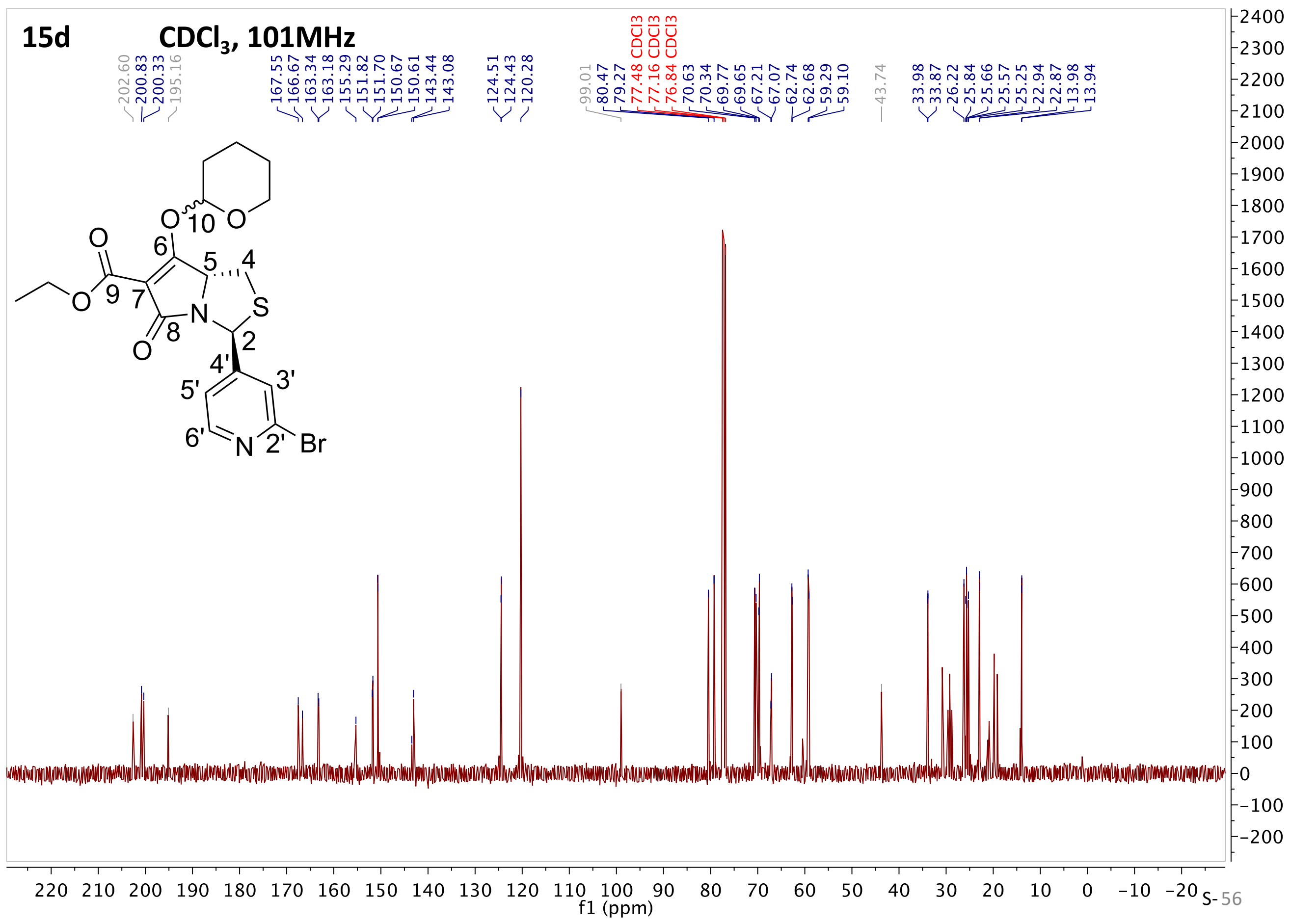




\section{$15 e$}

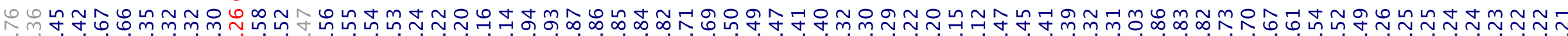
निं क्ष

\section{$\mathrm{CDCl}_{3}, 400 \mathrm{MHz}$}

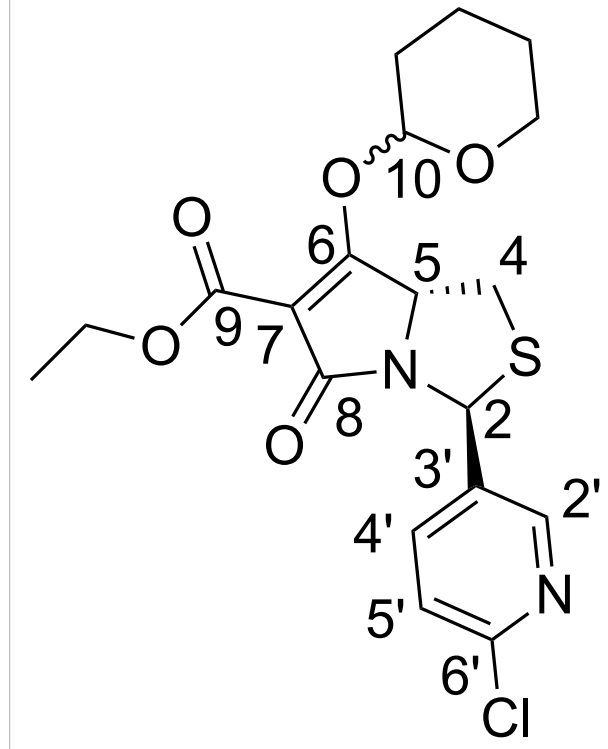
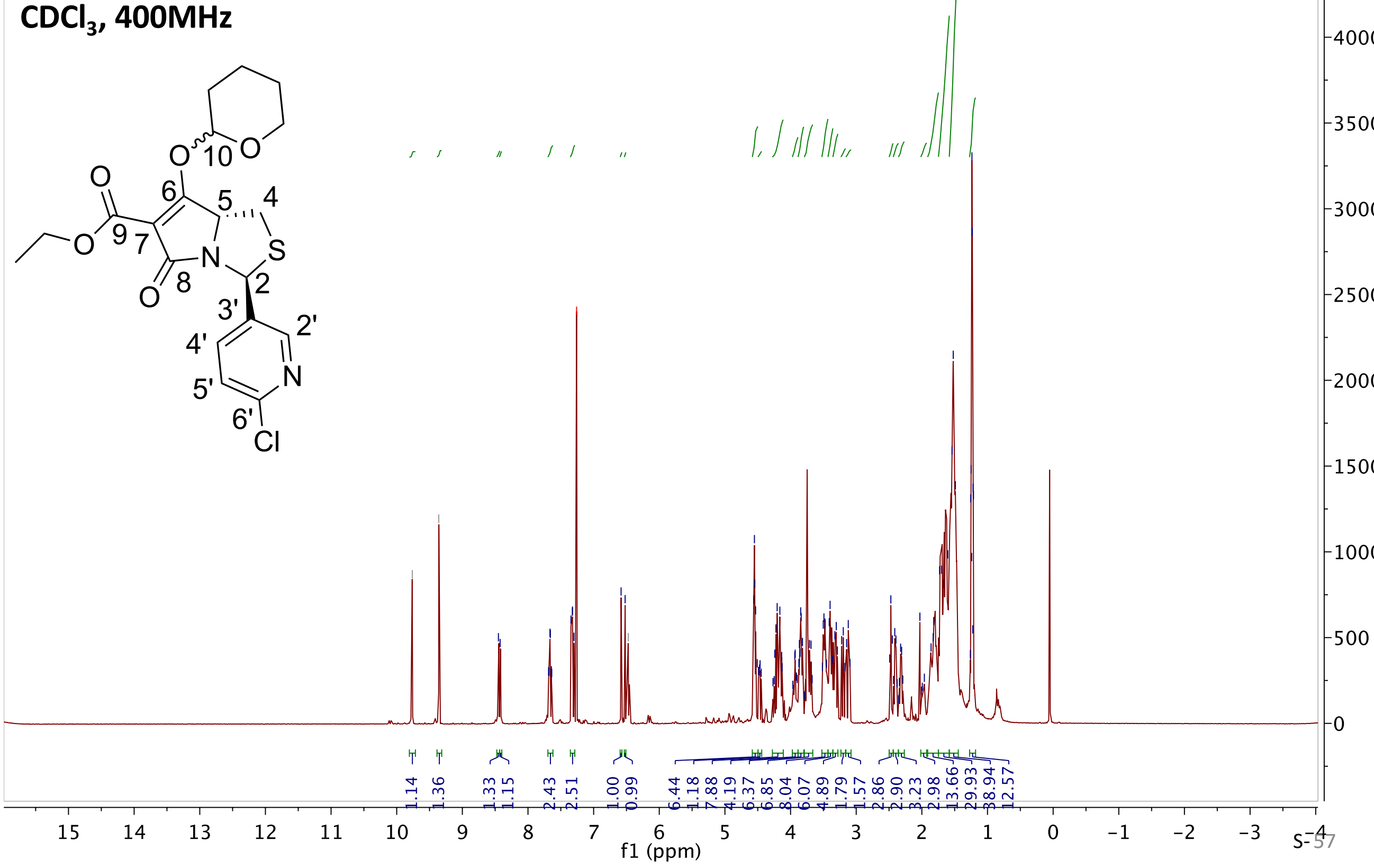


\section{$15 e$}

\section{${ }^{13} \mathrm{C}\left\{{ }^{1} \mathrm{H}\right\}, \mathrm{EDCC}{ }_{3}$,

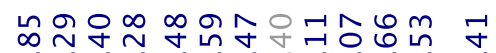

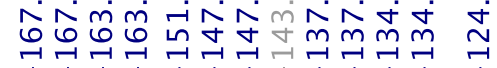 101MHz}

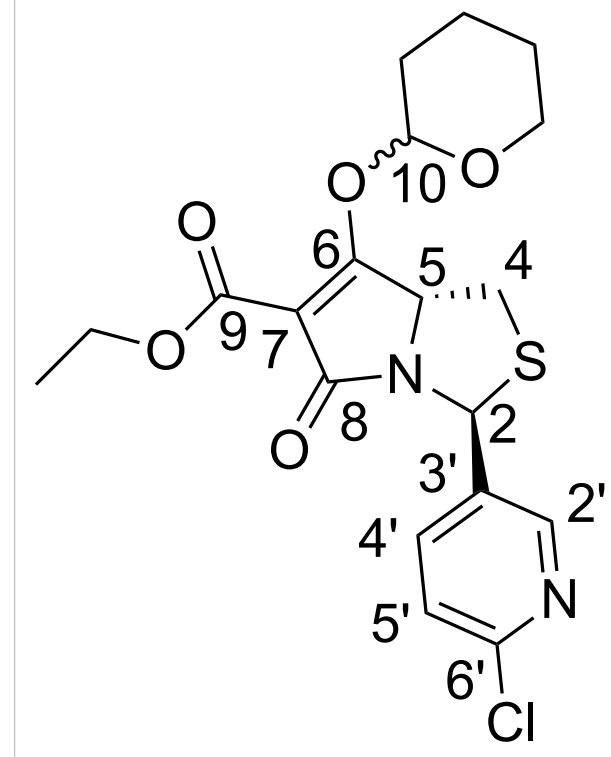




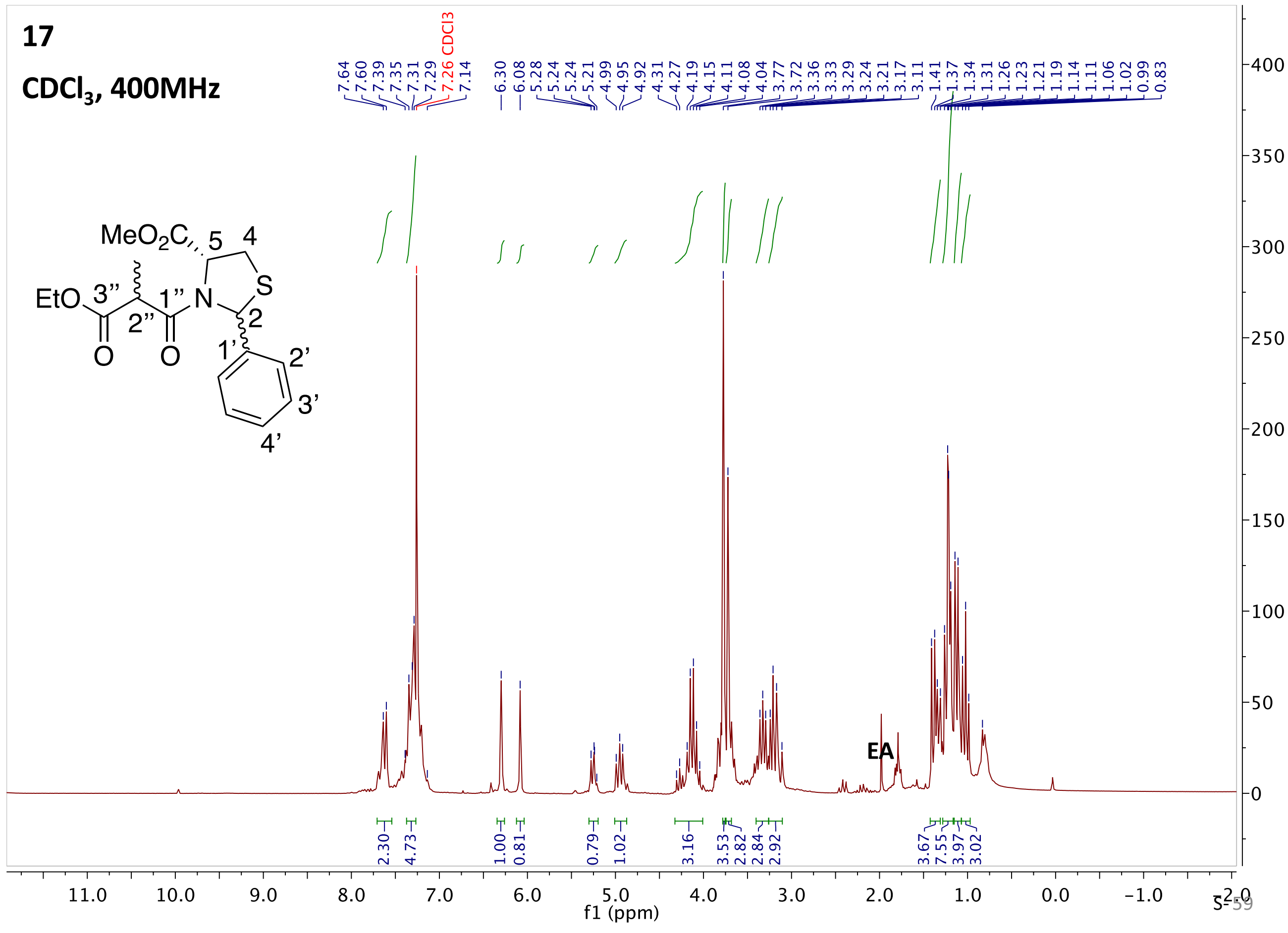




\section{$\mathrm{CDCl}_{3}, 400 \mathrm{MHz}$}
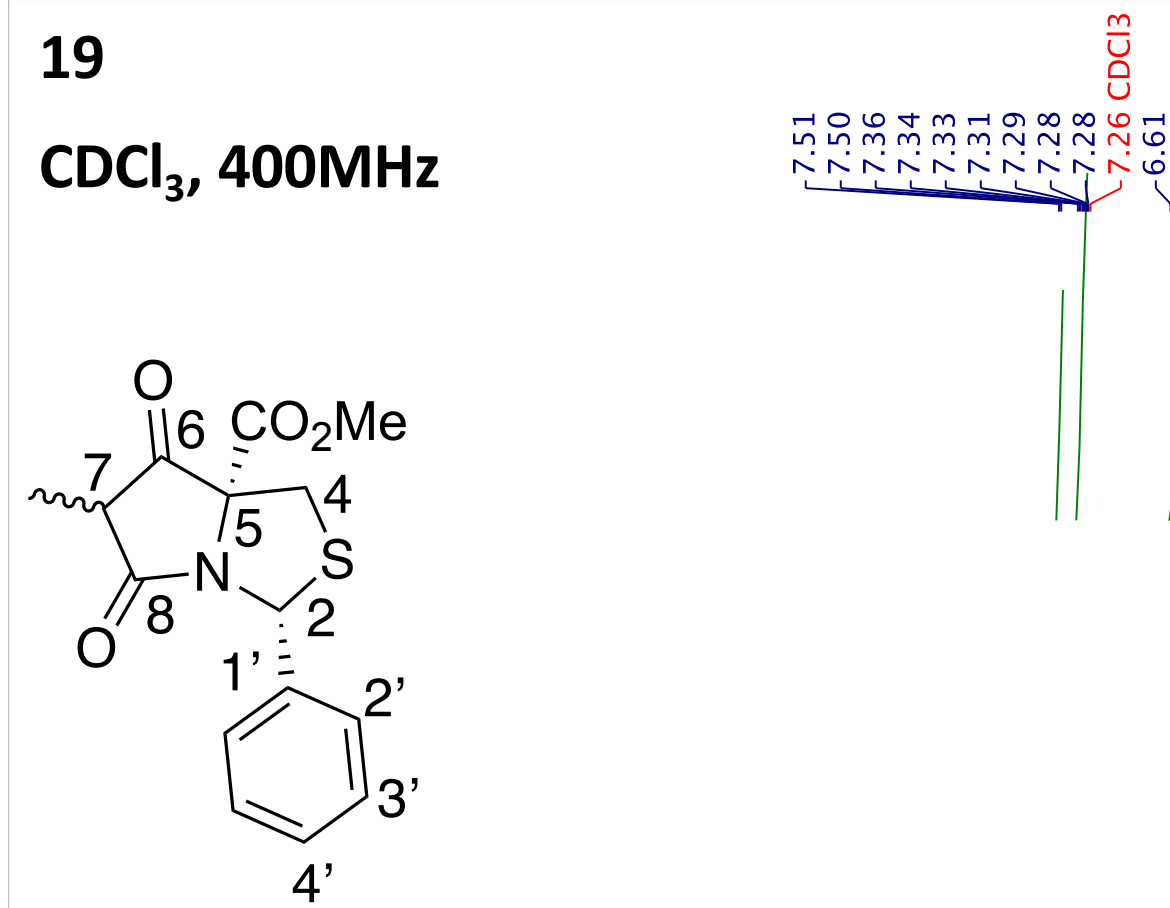

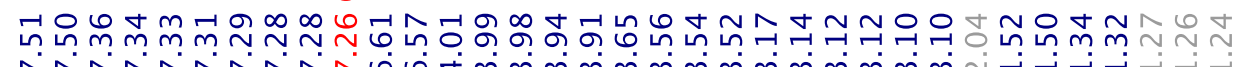

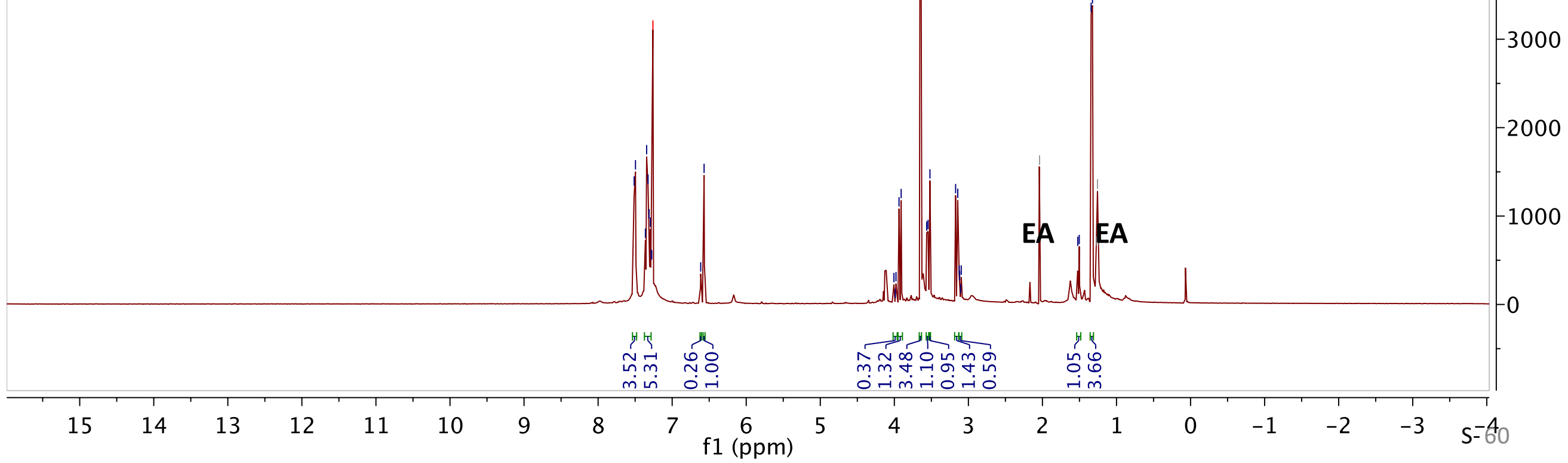




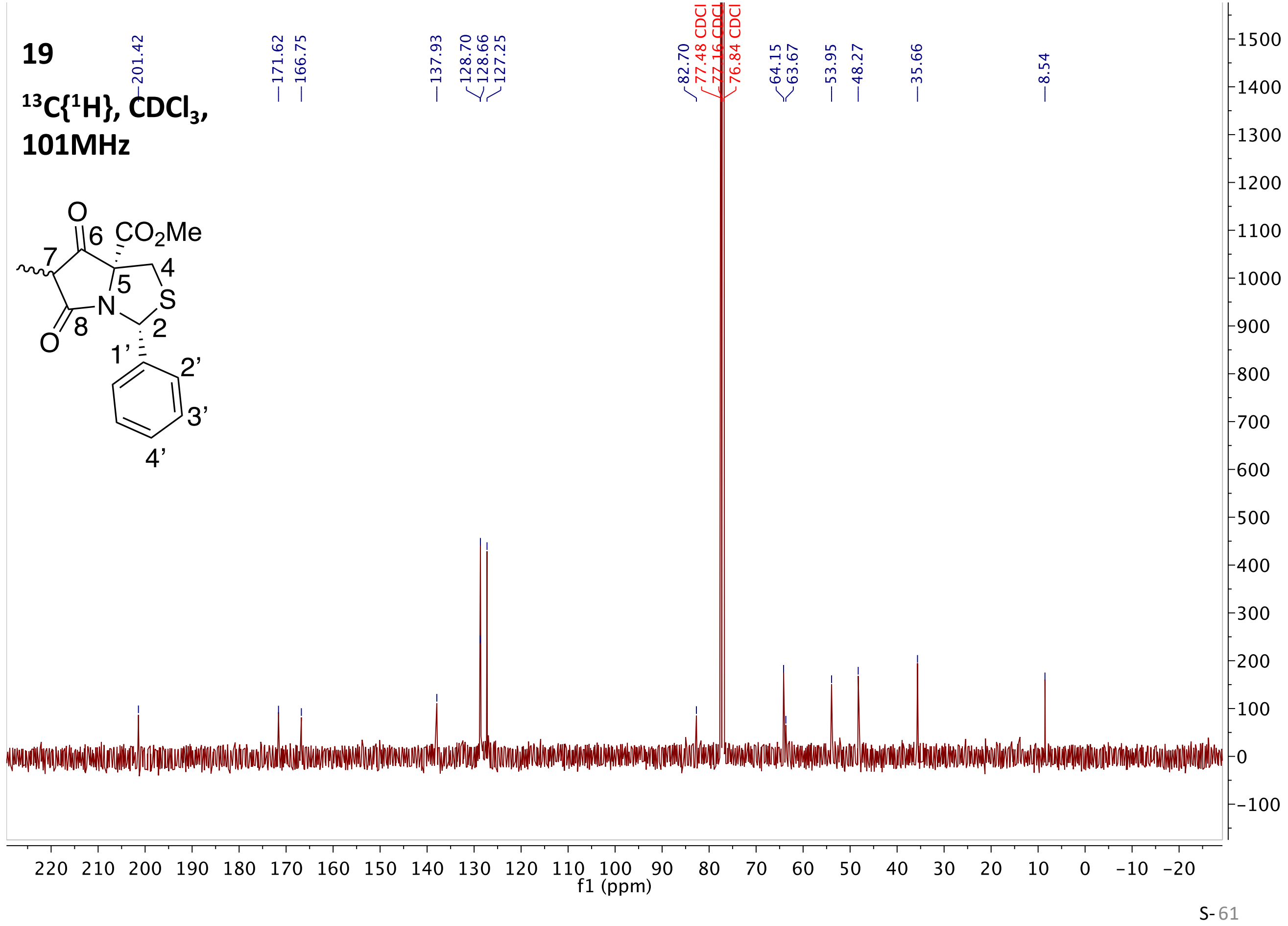




\section{0}

\section{$\mathrm{CDCl}_{3}, 400 \mathrm{MHz}$}

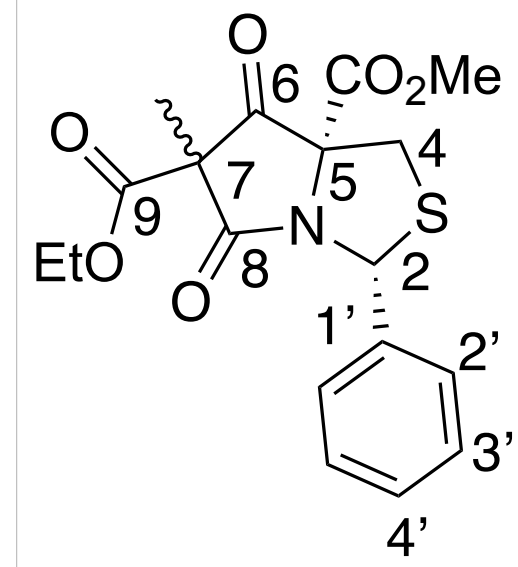

\section{絗}

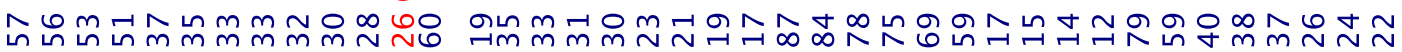

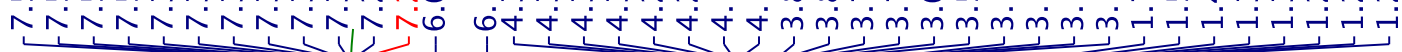

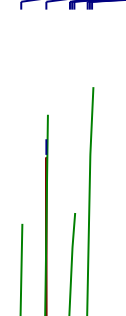

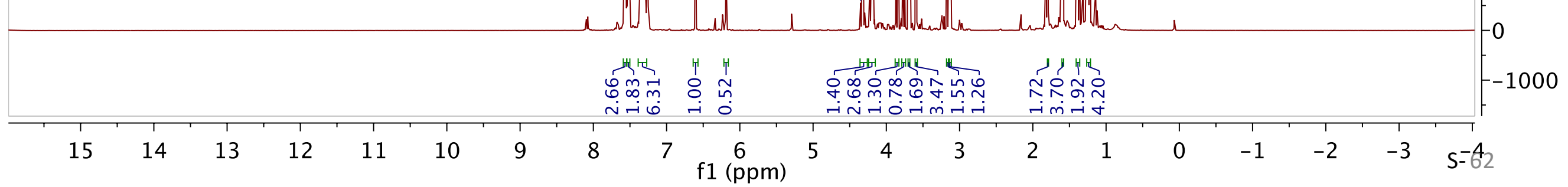


ก

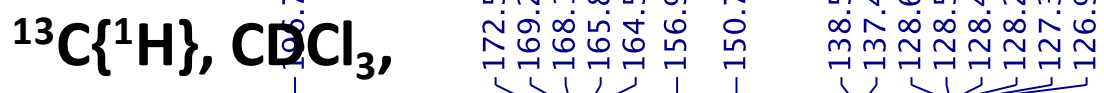
101MHz

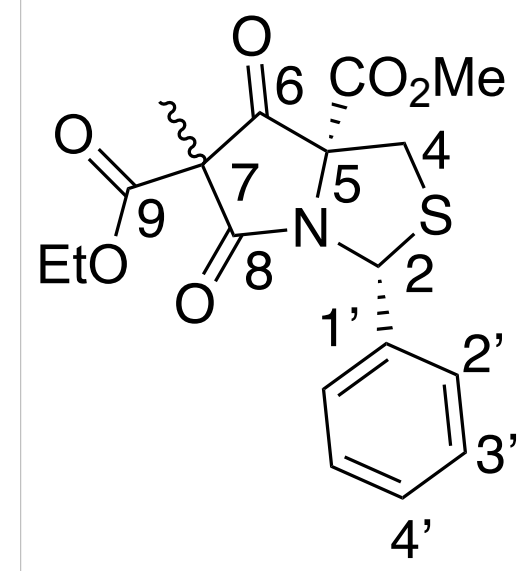

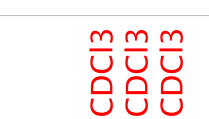

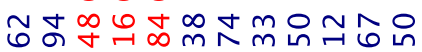

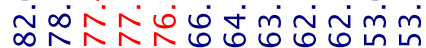
ㅅ․

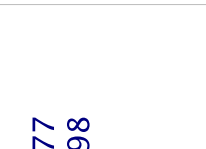

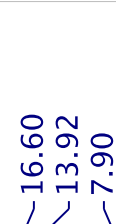

